\title{
A multi-year study of lower tropospheric aerosol variability and system- atic relationships from four North American regions
}

\author{
J. P. Sherman et al. \\ Correspondence to: J. P. Sherman (shermanjp@appstate.edu)
}

The copyright of individual parts of the supplement might differ from the CC-BY 3.0 licence. 


\section{Supplemental Materials}

\section{Overview}

The following materials supplement the manuscript "A multi-year study of lower tropospheric aerosol variability and systematic relationships from four North American regions". Section S1 contains a detailed analysis of aerosol optical property measurement uncertainties, including propagation of uncertainties. Section S2 includes a table (Table 3) showing the percentage of hours with PM1 scattering coefficient less than $1 \mathrm{Mm}^{-1}$ for each month at each site. These hours were not used for calculating the aerosol intensive properties. Section S3 contains a short justification for including aerosol light scattering measurements at EGB during months of elevated relative humidity. Section S4 contains boxplots of monthly-binned $\sigma_{\mathrm{sp}}$ and $\sigma_{\mathrm{ap}}$ for individual years during the 2010-2013 period. The boxplots (Fig(s).S1-S4) illustrate inter-annual $\sigma_{\mathrm{sp}}$ and $\sigma_{\mathrm{ap}}$ variability and illustrate that the geometric mean $\sigma_{\mathrm{sp}}$ and $\sigma_{\mathrm{ap}}$ presented in the paper are not heavily-biased by individual years. Section S5 illustrates the temperature-dependence of $\sigma_{\mathrm{sp}}$ at the sites, which is used in the paper to hypothesize the influence of biogenic SOA and ammonium nitrate partitioning on the annual $\sigma_{\mathrm{sp}}$ cycles. The temperature dependence of $\sigma_{\mathrm{sp}}$ is also used along with summer-autumn and summer-spring temperature differences to compare the observed seasonal $\sigma_{\mathrm{sp}}$ differences with those predicted based on temperature considerations. Section S6 contains a figure (Fig.S8) illustrating the annual cycles of PM10 AOPs. Section S7 contains figures illustrating the weekly and diurnal PM1 intensive AOP cycles (Fig(s).S9-S15). The weekly and diurnal PM1 $\sigma_{\mathrm{sp}}$ and $\sigma_{\mathrm{ap}}$ cycles are presented in the paper. Section $\mathrm{S} 8$ includes pollution-rose diagrams for $\mathrm{R}_{\mathrm{sp}}, \omega_{0}$, and $\mathrm{b}$ for each season at each site (Fig(s).S16S22). Pollution-rose diagrams for $\sigma_{\mathrm{sp}}$ and $\sigma_{\mathrm{ap}}$ are presented in the paper. Section S9 contains a table of annually-averaged PM10 and PM1 aerosol optical properties for the sites (Table S5). Annuallyaveraged PM1 aerosol optical properties are presented in graphical form in the paper (Fig.2). Section S10 contains monthly-binned boxplots of temperature and relative humidity at the sites (Fig.S23). Section S11 contains long-term time series plots of select AOPs at BND and SGP (Fig(s).S24-S25), along with trend lines. Time series plots of PM1 variables that demonstrate the most noticeable trends ( $\sigma_{\mathrm{sp}}$ and $b$, along with $\mathrm{R}_{\mathrm{sp}}$ ) are shown in Sect. 4.3 of the paper.

Note: All tables and figures are located together at the end of this document. Some sections of the document contain only figures/tables and others also include discussion. To avoid the impression of missing sections, we include section titles for all sections, even if they do not contain any discussion. 
We place figure and table captions in these sections to reference the reader to the appropriate figures and tables.

\section{S1 Measurement Uncertainties}

Measurement uncertainties for aerosol total scattering coefficient $\left(\sigma_{\mathrm{sp}}\right)$, hemispheric backscattering coefficient $\left(\sigma_{\mathrm{bsp}}\right)$, and absorption coefficient $\left(\sigma_{\mathrm{ap}}\right)$ are estimated in this section (Table S1). The uncertainties $\Delta \sigma_{\mathrm{sp}}, \Delta \sigma_{\mathrm{bsp}}$, and $\Delta \sigma_{\mathrm{ap}}$ are then propagated to yield uncertainties in the calculated aerosol optical properties reported in this paper (Table S2). Individual sources of uncertainty are calculated and propagated, based on values measured by the authors and tabulated values in the literature. Uncertainties are reported as 95\% confidence intervals. The same instruments and measurement protocols are used at all sites so the numerical results are applicable to APP, BND, EGB, and SGP. The uncertainties are expressed as percentages so as to facilitate their usage, along with equations used to calculate them.

\section{S1.1 Uncertainties in total scattering and hemispheric backscatter coefficients}

The major sources of uncertainty in $\sigma_{\mathrm{sp}}$ and $\sigma_{\mathrm{bsp}}$ measured by the TSI 3563 nephelometer are (1) instrumental noise; (2) uncertainty in the nephelometer calibration using filtered air and $\mathrm{CO}_{2}$ gases; (3) nephelometer calibration variability; (4) uncertainty in the correction for nephelometer angular non-idealities, which result in under-estimation (e.g., truncation) of light scattered in the near-forward direction; (5) uncertainty in correcting $\sigma_{\mathrm{sp}}$ and $\sigma_{\mathrm{bsp}}$ to standard temperature and pressure (STP) conditions; (6) uncertainties in correcting $\sigma_{\mathrm{sp}}$ and $\sigma_{\mathrm{bsp}}$ to $40 \%$ relative humidity during humid periods. Detailed accounts of most sources are given in Anderson and Ogren (1998) and Anderson et al. (1999). The total uncertainties $\Delta \sigma_{\mathrm{sp}}$, and $\Delta \sigma_{\mathrm{bsp}}$ are calculated by adding the major source contributions in quadrature (Anderson and Ogren, 1998). The uncertainty equations for $\sigma_{\mathrm{sp}}$ and $\sigma_{\mathrm{bsp}}$ are identical and (for brevity) only the total scattering uncertainty equations are shown, although numerical values are provided for both in Tables S1 and S2.

$\Delta \sigma_{\mathrm{sp}}^{2}=\Delta \sigma_{\text {sp,noise }}{ }^{2}\left(\tau_{\mathrm{avg}}\right)+\Delta \sigma_{\mathrm{sp}, \mathrm{cal}}{ }^{2}+\Delta \sigma_{\mathrm{sp}, \mathrm{var}}{ }^{2}+\Delta \sigma_{\mathrm{sp}, \text { trunc }}{ }^{2}+\Delta \sigma_{\mathrm{sp}, \mathrm{stp}}{ }^{2}+\Delta \sigma_{\mathrm{sp}, \mathrm{RH}}{ }^{2}$

All terms in Eq.S1 except the truncation uncertainty are the same for PM10 and PM1 size cuts and all terms except the noise term are independent of averaging time. The uncertainty due to noise is 


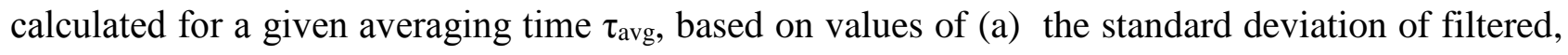
particle-free air scattering coefficient values $\sigma_{\text {meas,air }}\left(\tau_{0}\right)$ measured over an extended period at a rate $\tau_{0}=1$ min; (b) known Rayleigh scattering coefficient values $\sigma_{\text {air }}(\mathrm{T}, \mathrm{P})$ for filtered air at temperature $\mathrm{T}$ and pressure P; (c) $\sigma_{\mathrm{sp}}$; and (d) nephelometer background scattering coefficient W (Eq.6 of Anderson and Ogren, 1998)

$$
\Delta \sigma_{\mathrm{sp}, \text { noise }}\left(\tau_{\text {avg }}\right)=2^{*} \operatorname{stdev}\left(\sigma_{\text {meas, air }}\left(\tau_{0}\right)\right)^{*}\left(\tau_{0} / \tau_{\text {avg }}\right)^{1 / 2} *\left(\left(\sigma_{s p}+\sigma_{\text {air }}(T, P)+W_{s p}\right) /\left(\sigma_{\text {air }}+W\right)\right)^{1 / 2}
$$

The factor of 2 in Eq.S2 is to convert standard deviations to 95\% confidence intervals. The known Rayleigh total scattering coefficient $\sigma_{\text {air }}$ at STP is $27.89 \mathrm{Mm}^{-1}$ at $450 \mathrm{~nm}, 12.26 \mathrm{Mm}^{-1}$ at $550 \mathrm{~nm}$, and 4.605 $\mathrm{Mm}^{-1}$ at $700 \mathrm{~nm}$ (Penndorf, 1957); the hemispheric backscattering coefficients are half these values. Rayleigh scattering coefficients are corrected to ambient temperature and pressure using the relationship $\sigma_{\text {air }}(\mathrm{T}, \mathrm{P})=\sigma_{\text {air,stp }} *(\mathrm{P} / 1013.25 \mathrm{hPa})(273.15 \mathrm{~K} / \mathrm{T})$. Typical background total scattering (backscatter) coefficient W for the TSI 3563 at APP is $4 \mathrm{Mm}^{-1}\left(3 \mathrm{Mm}^{-1}\right)$ at $450 \mathrm{~nm}$ and $550 \mathrm{~nm}$ and $14 \mathrm{Mm}^{-1}\left(10 \mathrm{Mm}^{-1}\right)$ at $700 \mathrm{~nm}$. The standard deviation of 1-min values ( $\tau_{0}=1 \mathrm{~min}$ ) of filtered air

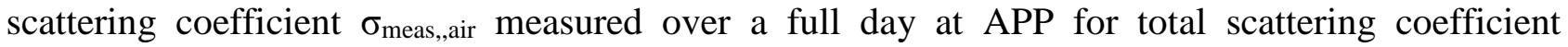
(hemispheric backscatter coefficient) is $0.32 \mathrm{Mm}^{-1}\left(0.19 \mathrm{Mm}^{-1}\right)$ at $450 \mathrm{~nm}, 0.15 \mathrm{Mm}^{-1}\left(0.09 \mathrm{Mm}^{-1}\right)$ at $550 \mathrm{~nm}$ and $0.22 \mathrm{Mm}^{-1}\left(0.19 \mathrm{Mm}^{-1}\right)$ at $700 \mathrm{~nm}$.

Calibration uncertainties for the total and backscatter coefficients are estimated as $7.0 \%$ for all wavelengths (Table 2 of Anderson et al., 1999), based on laboratory closure studies (Anderson et al., 1996). Variability in the nephelometer calibrations for total scattering (hemispheric backscatter) coefficient is estimated as $2.4 \%(2.3 \%)$ at $450 \mathrm{~nm}, 2.3 \%(2.5 \%)$ at $550 \mathrm{~nm}$, and $3.8 \%(5.2 \%)$ at 700 $\mathrm{nm}$, based on nephelometer span check errors over five years at APP. Sheridan et al. (2002) reported similar nephelometer calibration variability values of $\sim 3 \%$ at $550 \mathrm{~nm}$. The uncertainty associated with adjusting scattering and backscatter coefficients to STP conditions is estimated as $0.4 \%$ (Sheridan et al., 2002). Anderson and Ogren (1998) reported maximum and mean fractional values of nephelometer scattering truncation correction uncertainties (their Table 4) when scattering Ångström exponent is used to correct for truncation of near-forward scattered light $\Delta \sigma_{\text {sp,trunc. We use the mean }}$ fractional uncertainties and justify this choice by the relatively large scattering Ångström exponents (less forward scattering) at the four sites. The mean PM10 total scattering (hemispheric backscatter) coefficient uncertainty due to nephelometer truncation correction is 5.0\% (3.8\%) at $450 \mathrm{~nm}, 4.6 \%$ (3.8\%) at $550 \mathrm{~nm}$, and $4.2 \%(4.0 \%)$ at $700 \mathrm{~nm}$. The mean PM1 total scattering (hemispheric 
backscatter) coefficient uncertainty due to nephelometer truncation correction is $1.0 \%(0.9 \%)$ at 450 $\mathrm{nm}, 0.7 \%(0.9 \%)$ at $550 \mathrm{~nm}$, and $0.4 \%(1.0 \%)$ at $700 \mathrm{~nm}$.

An additional source of uncertainty in $\sigma_{\mathrm{sp}}$, and $\sigma_{\mathrm{bsp}}$ results from adjusting their values during periods of elevated relative humidity(RH) to 'dry' aerosol values at $\mathrm{RH}=40 \%$. The $\mathrm{RH}$ inside the nephelometer occasionally exceeds $40 \%$ during the humid summer months and on occasion during other months (reaching as high as $\sim 50 \%$ at some sites), which can result in a small enhancement of light scattering above 'dry' aerosol light scattering levels. We estimate $\Delta \sigma_{\mathrm{sp}, \mathrm{RH}} \sim 3 \%$., based on arguments presented in Sect. S3 of this document. Since the RH correction is only applied during periods of elevated nephelometer internal $\mathrm{RH}$, its inclusion in the total uncertainties reported in this section results in upper-bound estimates of $\Delta \sigma_{\mathrm{sp}}$, and $\Delta \sigma_{\mathrm{bsp}}$. The fractional PM10 and PM1 scattering and hemispheric backscatter uncertainties $\Delta \sigma_{\mathrm{sp}}$ and $\Delta \sigma_{\text {bsp }}$ at $550 \mathrm{~nm}$ are calculated in Table S1 or 1hour averaging time. They can be calculated for an arbitrary averaging time $\tau_{\text {avg }}$ by re-scaling the noise term in the Table S1 by sqrt ( $\tau_{\text {avg }} / 1$ hour) and then re-applying Eq.S1.

\section{S 1.2 Uncertainties in absorption coefficient}

The major sources of uncertainty in aerosol light absorption coefficient $\sigma_{\text {ap }}$ measured by the Radiance Research Particle Soot Absorption Photometer (PSAP) are (1) instrumental noise; (2) unitto-unit instrumental variability; and (3) uncertainty in the calibration of PSAP-measured absorption coefficient, using extinction minus scattering (Bond, 1999). Uncertainties in the PSAP spot size and flow rate corrections are often incorporated into the unit-to-unit variability term (Müller et al., 2011; Anderson et al., 1999). The measurement uncertainty in aerosol absorption coefficient $\Delta \sigma_{\mathrm{ap}}$ is calculated from the major sources of uncertainty

$\Delta \sigma_{\text {ap }}^{2}=\Delta \sigma_{\text {ap,noise }}{ }^{2}\left(\tau_{\text {avg }}\right)+\Delta \sigma_{\text {ap,var }}{ }^{2}+\Delta \sigma_{\text {ap,cal }}{ }^{2}$

The noise contribution $\Delta \sigma_{\text {ap,noise }}\left(\tau_{\text {avg }}\right)$ is typically calculated by multiplying the standard deviation of 1 -min values $\left(\tau_{0}=1 \mathrm{~min}\right)$ of filtered air absorption coefficient $\sigma_{\text {meas,air }}$ by $2^{*}\left(\tau_{\text {avg }} / \tau_{0}\right)^{-\mathrm{x}}$. The value of $x$ is chosen to represent the statistical properties of instrument noise, and theoretical values of 0.5, 1.0, and 1.5 have been shown to be possible for different averaging algorithms of PSAP data (Springston and Sedlacek, 2007). Laboratory tests (not shown here) have shown that a power-law relationship $(x=1)$ between PSAP noise and averaging time gives a reasonable representation of instrument 
behavior for averaging times of less than about $10 \mathrm{~min}$, but that the measured noise is greater than predicted for longer averaging times. For two PSAPs tested by the authors, the standard deviations of 1-min and 1-hour average absorption coefficients of filtered air, were 0.17 and $0.02 \mathrm{Mm}^{-1}$, respectively, at $550 \mathrm{~nm}$ wavelength.

PSAP unit-to-unit variability $\Delta \sigma_{\mathrm{ap}, \mathrm{var}}=16 \%$ is based on the standard deviation of $\sigma_{\mathrm{ap}}$ measured by six three-wavelength PSAP instruments over a range of $\sigma_{\text {ap }}$ values, which were all referenced to $\sigma_{\text {ap }}$ measured by a reference multi-angle absorption photometer (Müller et al., 2011). We multiply the reported standard deviation of $8 \%$ (Müller et al., 2011) by 2 to convert the uncertainty to a $95 \%$ confidence interval. The value of $\Delta \sigma_{\mathrm{ap}, \mathrm{var}}$ reported by Mueller et al (2011) is nearly three times as large as the unit-to-unit PSAP variability of 6\% (95\% confidence interval) reported for three singlewavelength PSAPs by Bond et al. (1999).

The Bond et al (1999) PSAP correction, as modified by Ogren (2010), is used correct the manufacturer's calibration for the sensitivity of the PSAP to absorbing and scattering particles. The PSAP-measured absorption coefficient $\sigma_{\text {ap,meas }}$ is related to the true scattering and absorption coefficients $\sigma_{\mathrm{ap}}$ and $\sigma_{\mathrm{sp}}$ via the following parameterization (Bond et al., 1999)

$\sigma_{\mathrm{ap}, \text { meas }}=\mathrm{K}_{1} * \sigma_{\mathrm{sp}}+\mathrm{K}_{2} * \sigma_{\mathrm{ap}}$

The values $K_{1}=0.02$ (Bond, et al., 1999) and $K_{2}=1.44$ (from Bond et al., 1999 with Ogren 2010 adjustment) are calibration constants. The uncertainty in the calibration $\Delta \sigma_{\mathrm{ap}, \mathrm{cal}}$ is calculated by first casting Eq.S4(a) in terms of the single-scattering albedo $\omega_{0}=\sigma_{\mathrm{sp}} /\left(\sigma_{\mathrm{sp}}+\sigma_{\mathrm{ap}}\right)$ and then defining

$$
\begin{aligned}
& \mathrm{a}=\omega_{0} /\left(1-\omega_{0}\right) \\
& \sigma_{\mathrm{ap}}=\frac{\sigma_{\mathrm{ap}, \text { meas }}}{a * K_{1}+K_{1}}
\end{aligned}
$$

The uncertainty in $\sigma_{\mathrm{ap}}$ resulting from uncertainties in the calibration constants is then given by

$$
\begin{aligned}
& \Delta \sigma_{\mathrm{ap}, \mathrm{cal}}=\left(\left(\frac{\partial \sigma_{\mathrm{ap}}}{\partial K_{1}} * \Delta K_{1}\right)^{2}+\left(\frac{\partial \sigma_{\mathrm{ap}}}{\partial K_{2}} * \Delta K_{2}\right)^{2}\right)^{1 / 2} \\
& \Delta \sigma_{\mathrm{ap}, \mathrm{cal}}=\frac{\sigma_{\mathrm{ap}, \text { meas }}}{\left(a * K_{1}+K_{2}\right)^{2}} *\left(\left(a * \Delta K_{1}\right)^{2}+\Delta K_{2}{ }^{2}\right)^{1 / 2}
\end{aligned}
$$


$\Delta \sigma_{\mathrm{ap}, \mathrm{cal}}=\frac{\sigma_{\mathrm{ap}, \text { meas }}}{\left(0.02 * \frac{\omega_{0}}{1-\omega_{0}}+1.44\right)^{2}} *\left(\left(0.02 * \frac{\omega_{0}}{1-\omega_{0}}\right)^{2}+(0.24)^{2}\right)^{\frac{1}{2}}$

Uncertainties in the calibration constants are $\Delta K_{1}=0.02$ (Bond, et al., 1999) and $\Delta K_{2}=0.24$ (from Bond et al., 1999 with Ogren 2010 adjustment). From this point forward, we drop the 'meas' subscript from $\sigma_{\mathrm{ap}}$ and all $\sigma_{\mathrm{ap}}$ values are assumed to be measured values. The fractional PSAP calibration uncertainty calculated from Eq.S4(c) is $13.6 \%$ for $\omega_{0}=0.95,11.4 \%$ for $\omega_{0}=0.90$, and $11.0 \%$ for $\omega_{0}=0.85$. The total uncertainties $\Delta \sigma_{\text {ap }}$ at $550 \mathrm{~nm}$ reported for 1-hour averaging time (Table S3) can be calculated for an arbitrary averaging time $\tau_{\text {avg }}$ by re-scaling the noise term in the Table S3 by $\operatorname{sqrt}\left(\tau_{\mathrm{avg}} / 1\right.$ hour $)$ and then re-applying Eq.S3.

Lack et al (2008) suggested caution in the interpretation of filter-based aerosol absorption measurements made under the following conditions: (1) air masses containing mono-disperse or large (>500 nm diameter) particles; (2) air masses with variable size distributions; or (3) air masses containing organic aerosol. Lack et al. (2008) reported a $\sigma_{\text {ap }}$ PSAP measurement bias due to coating of the PSAP filter by organic aerosol, which changes the filter scattering artifact and also enhances the absorption of absorbing material already present on the filter. Lack et al. (2008) also reported that the PSAP measurement bias depended on the ratio of organic aerosol to light-absorbing carbon Roc$\mathrm{LAC}=[\mathrm{OC}] /[\mathrm{LAC}]$ and to a lesser extent, organic aerosol concentration, in addition the degree to which the organic aerosol is oxygenated. A detailed analysis regarding the possibility that this applies to the $\sigma_{\mathrm{ap}}$ and $\alpha_{\mathrm{ap}}$ measurements presented in this paper is beyond the scope of the current paper. We use a quick calculation to hypothesize that coating of the filters with liquid-like organic aerosol likely does not influence the measurements in this study. APP is likely most influenced by secondary organic aerosol (relative to BND, EGB, and SGP) and this influence is largest in summer. Link et al. (2015) reported organic aerosol mass concentrations [OC] $=1.63 \pm 1.05 \mu \mathrm{g} \mathrm{m}^{-3}$ for summer 2013 at APP. The [OC] reported by Link et al. (2015) is typical of a 'rural/remote' aerosol environment (Lack et al, 2008), for which Lack et al. (2008) determined the PSAP measurement bias to be lower than for more polluted environments. An upper-bound estimate of the ratio Roc-LAC can be obtained by (1) using an upper-bound of [OC] $\sim \mu \mathrm{g} \mathrm{m}^{-3}$; and (2) using a lower bound estimate for the concentration of light-absorbing carbon [LAC], based on measured a low summer value of $\sigma_{\mathrm{ap}} \sim 2 \mathrm{Mm}^{-1}$ and the same assumed BC mass absorption coefficient MAC $=7.75 \mathrm{~m}^{2} \mathrm{~g}^{-1}$ used by Lack et al. (2008). This gives an estimate of ROC-LAC $\sim 3 \mu \mathrm{g} \mathrm{m}^{-3} / 0.3 \mu \mathrm{g} \mathrm{m}^{-3} \sim 10$. Inspection of Fig.4 of Lack et al. (2008) 
reveals that the PSAP measurement bias is small for this relatively low ROC-LAC, given that nearly all of the summer SOA measured at APP is highly-oxygenated. In a separate study, Lack et al. (2009) applied Mie theory and laboratory-based, size-resolvedmeasurements at $532 \mathrm{~nm}$ of absorbing polystyrene spheres both uncoated and coated with oleic acid (made simultaneously using a PSAP and photo-acoustic spectrometer) to demonstrate a size-dependent PSAP measurement bias (PSAP measured low), possibly due to the same mechanisms discussed above. Given the measurements available for our study, it is impossible to speculate if/how much this effect would have on the $\sigma_{\mathrm{sp}}$ measurements or the wavelength-dependence (e.g., $\alpha_{\mathrm{ap}}$ ).

\section{S 1.3 Uncertainties in calculated aerosol optical properties}

Uncertainty in derived aerosol properties (aerosol intensive variables) can be calculated using the uncertainties $\Delta \sigma_{\mathrm{sp}}, \sigma_{\mathrm{ap}}$, and $\sigma_{\mathrm{bsp}}$. We apply standard techniques for combining uncertainties (p.21 of http://www.bipm.org/en/publications/guides/gum.html) to the equations for aerosol optical properties listed in Table 2 of our paper, leading to the following equations

\section{Aerosol light extinction coefficient:}

$$
\Delta \sigma_{\mathrm{ep}}=\left(\Delta \sigma_{\mathrm{sp}}^{2}+\Delta \sigma_{\mathrm{ap}}^{2}+2 * \operatorname{corr}\left(\sigma_{s p}, \sigma_{a p}\right) * \Delta \sigma_{s p} * \Delta \sigma_{a p}\right)^{1 / 2}
$$

\section{PM1 scattering fraction}

$$
\begin{aligned}
& \Delta R_{s p}=\left(\left(\frac{\partial R_{s p}}{\partial \sigma_{\mathrm{sp}, \mathrm{PM} 10}}\right)^{2} \Delta{\sigma_{\mathrm{sp}, \mathrm{PM} 10}}^{2}+\left(\frac{\partial R_{s p}}{\partial \sigma_{\mathrm{sp}, \mathrm{PM} 1}}\right)^{2} \Delta \sigma_{\mathrm{sp}, \mathrm{PM} 1}{ }^{2}+2 * \operatorname{corr}\left(\sigma_{s p, P M 10}, \sigma_{s p, P M 1}\right) *\right. \\
& \left.\left(\frac{\partial R_{s p}}{\partial \sigma_{\mathrm{sp}, \mathrm{PM} 10}}\right)\left(\frac{\partial R_{s p}}{\partial \sigma_{\mathrm{sp}, \mathrm{PM} 1}}\right) * \Delta \sigma_{\mathrm{sp}, \mathrm{PM} 10} * \Delta \sigma_{\mathrm{sp}, \mathrm{PM} 1}\right)^{1 / 2} \\
& \Delta R_{s p}=\left(\left(\frac{\sigma_{\mathrm{sp}, \mathrm{PM} 1}^{2}}{\sigma_{\mathrm{sp}, \mathrm{PM} 10^{4}}{ }^{2}} \Delta{\sigma_{\mathrm{sp}, \mathrm{PM} 10}}^{2}+\left(\frac{1}{\sigma_{\mathrm{sp}, \mathrm{PM} 10^{2}}}\right) \Delta{\sigma_{\mathrm{sp}, \mathrm{PM} 1}}^{2}-2 * \operatorname{corr}\left(\sigma_{s p, P M 10}, \sigma_{s p, P M 1}\right) *\right.\right. \\
& \left.\left(\frac{\sigma_{\mathrm{sp}, \mathrm{PM} 1}}{\sigma_{\mathrm{sp}, \mathrm{PM} 10^{3}}}\right) * \Delta \sigma_{\mathrm{sp}, \mathrm{PM} 10} * \Delta \sigma_{\mathrm{sp}, \mathrm{PM} 1}\right)^{\frac{1}{2}}
\end{aligned}
$$


PM1 absorption fraction

$$
\begin{aligned}
& \Delta R_{a p}=\left(\left(\frac{\partial R_{a p}}{\partial \sigma_{\mathrm{ap}, \mathrm{PM} 10}}\right)^{2} \Delta \sigma_{\mathrm{ap}, \mathrm{PM} 10}^{2}+\left(\frac{\partial R_{a p}}{\partial \sigma_{\mathrm{ap}, \mathrm{PM} 1}}\right)^{2} \Delta \sigma_{\mathrm{ap}, \mathrm{PM} 1}^{2}+2\right. \\
& * \operatorname{corr}\left(\sigma_{a p, P M 10}, \sigma_{a p, P M 1}\right) * *\left(\frac{\partial R_{a p}}{\partial \sigma_{\mathrm{ap}, \mathrm{PM} 10}}\right)\left(\frac{\partial R_{a p}}{\partial \sigma_{\mathrm{ap}, \mathrm{PM} 1}}\right) * \Delta \sigma_{\mathrm{ap}, \mathrm{PM} 10} \\
& \left.* \Delta \sigma_{\mathrm{ap}, \mathrm{PM} 1}\right)^{\frac{1}{2}} \\
& \Delta R_{s p}=\left(\left(\frac{\sigma_{\mathrm{ap}, \mathrm{PM} 1}^{2}}{\sigma_{\mathrm{ap}, \mathrm{PM} 10}{ }^{4}}\right) \Delta \sigma_{\mathrm{ap}, \mathrm{PM} 10}{ }^{2}+\left(\frac{1}{\sigma_{\mathrm{ap}, \mathrm{PM} 10^{2}}}\right) \Delta \sigma_{\mathrm{ap}, \mathrm{PM} 1}{ }^{2}-2 * \operatorname{corr}\left(\sigma_{a p, P M 10}, \sigma_{a p, P M 1}\right) *\right. \\
& \left.\left(\frac{\sigma_{\mathrm{ap}, \mathrm{PM} 1}}{\sigma_{\mathrm{ap}, \mathrm{PM} 10^{3}}}\right) * \Delta \sigma_{\mathrm{ap}, \mathrm{PM} 10} * \Delta \sigma_{\mathrm{ap}, \mathrm{PM} 1}\right)^{\frac{1}{2}}
\end{aligned}
$$

\section{Hemispheric back-scatter fraction:}

$$
\begin{aligned}
& \Delta \mathrm{b}=\left(\left(\frac{\partial \mathrm{b}}{\partial \sigma_{\mathrm{sp}}}\right)^{2} \Delta{\sigma_{\mathrm{sp}}}^{2}+\left(\frac{\partial \mathrm{b}}{\partial \sigma_{\mathrm{bsp}}}\right)^{2} \Delta{\sigma_{\mathrm{bsp}}}^{2}+2 * \operatorname{corr}\left(\sigma_{s p}, \sigma_{b s p}\right) *\left(\frac{\partial \mathrm{b}}{\partial \sigma_{\mathrm{sp}}}\right) *\left(\frac{\partial \mathrm{b}}{\partial \sigma_{\mathrm{bsp}}}\right) * \Delta \sigma_{\mathrm{sp}}\right. \\
& \left.* \Delta \sigma_{\mathrm{bsp}}\right)^{1 / 2} \\
& \Delta \mathrm{b}=\left(\left(\frac{\sigma_{\mathrm{bsp}}{ }^{2}}{\sigma_{\mathrm{sp}}{ }^{2}}\right) \Delta{\sigma_{\mathrm{sp}}}^{2}+\left(\frac{1}{\sigma_{\mathrm{sp}^{2}}}\right) \Delta{\sigma_{\mathrm{bsp}}}^{2}-2 * \operatorname{corr}\left(\sigma_{s p}, \sigma_{b s p}\right) *\left(\frac{\sigma_{\mathrm{bsp}}}{\sigma_{\mathrm{sp}}{ }^{3}}\right) * \Delta \sigma_{\mathrm{sp}} *\right. \\
& \left.\Delta \sigma_{\mathrm{bsp}}\right)^{1 / 2}
\end{aligned}
$$


Single-scattering albedo:

$$
\begin{aligned}
& \Delta \omega_{0}=\left(\left(\frac{\partial \omega_{0}}{\partial \sigma_{\mathrm{sp}}}\right)^{2} \Delta{\sigma_{\mathrm{sp}}}^{2}+\left(\frac{\partial \omega_{0}}{\partial \sigma_{\mathrm{ap}}}\right)^{2} \Delta{\sigma_{\mathrm{ap}}}^{2}+2 * \operatorname{corr}\left(\sigma_{\mathrm{sp}}, \sigma_{\mathrm{ap}}\right) *\left(\frac{\partial \omega_{0}}{\partial \sigma_{\mathrm{sp}}}\right) *\left(\frac{\partial \omega_{0}}{\partial \sigma_{\mathrm{ap}}}\right) * \Delta \sigma_{\mathrm{sp}}\right. \\
& \left.* \Delta \sigma_{\mathrm{ap}}\right)^{1 / 2} \\
& \Delta \omega_{0}=\left(\frac{1}{\sigma_{\mathrm{sp}}+\sigma_{\mathrm{ap}}}\right)^{2}\left({\sigma_{\mathrm{ap}}}^{2} * \Delta{\sigma_{\mathrm{sp}}}^{2}+{\sigma_{\mathrm{sp}}}^{2} * \Delta{\sigma_{\mathrm{ap}}}^{2}-2 * \operatorname{corr}\left(\sigma_{s p}, \sigma_{a p}\right) * \sigma_{\mathrm{sp}} * \sigma_{\mathrm{ap}} * \Delta \sigma_{\mathrm{sp}} *\right. \\
& \left.\Delta \sigma_{\mathrm{ap}}\right)^{\frac{1}{2}}
\end{aligned}
$$

\section{Scattering Ångström exponent:}

$$
\begin{aligned}
& \Delta \alpha_{s p}(450 / 700 \mathrm{~nm})=\left(\left(\frac{\partial \alpha_{s p}}{\partial \sigma_{\mathrm{sp}, 450}}\right)^{2} \Delta{\sigma_{\mathrm{sp}, 450}}^{2}+\left(\frac{\partial \alpha_{s p}}{\partial \sigma_{\mathrm{sp}, 700}}\right)^{2} \Delta \sigma_{\mathrm{sp}, 700}{ }^{2}+2 *\right. \\
& \left.\operatorname{corr}\left(\sigma_{s p, 450}, \sigma_{s p, 700}\right) *\left(\frac{\partial \alpha_{s p}}{\partial \sigma_{\mathrm{sp}, 450}}\right) *\left(\frac{\partial \alpha_{s p}}{\partial \sigma_{\mathrm{sp}, 700}}\right) * \Delta \sigma_{\mathrm{sp}, 450} * \Delta \sigma_{\mathrm{sp}, 700}\right)^{1 / 2}
\end{aligned}
$$

Where

$$
\begin{gathered}
\frac{\partial \alpha_{s p}}{\partial \sigma_{\mathrm{sp}, 450}}=\frac{-1}{\ln (10) * \log _{10}\left(\frac{450}{700}\right)} * \frac{1}{\sigma_{s p, 450}}=\frac{2.26}{\sigma_{s p, 450}} \\
\frac{\partial \alpha_{s p}}{\partial \sigma_{\mathrm{sp}, 700}}=\frac{1}{\ln (10) * \log _{10}\left(\frac{450}{700}\right)} * \frac{1}{\sigma_{s p, 700}}=\frac{-2.26}{\sigma_{s p, 700}}
\end{gathered}
$$

\section{Absorption Ångström exponent:}

$$
\begin{aligned}
& \Delta \alpha_{a p}(450 / 700 \mathrm{~nm})=\left(\left(\frac{\partial \alpha_{a p}}{\partial \sigma_{\mathrm{ap}, 450}}\right)^{2} \Delta{\sigma_{\mathrm{ap}, 450}}^{2}+\left(\frac{\partial \alpha_{a p}}{\partial \sigma_{\mathrm{ap}, 700}}\right)^{2} \Delta{\sigma_{\mathrm{ap}, 700}}^{2}+2 *\right. \\
& \left.\operatorname{corr}\left(\sigma_{a p, 450}, \sigma_{a p, 700}\right) *\left(\frac{\partial \alpha_{a p}}{\partial \sigma_{\mathrm{ap}, 450}}\right) *\left(\frac{\partial \alpha_{a p}}{\partial \sigma_{\mathrm{ap}, 700}}\right) * \Delta \sigma_{\mathrm{ap}, 450} * \Delta \sigma_{\mathrm{ap}, 700}\right)^{1 / 2}
\end{aligned}
$$


Where

$$
\begin{gathered}
\frac{\partial \alpha_{a p}}{\partial \sigma_{\mathrm{ap}, 450}}=\frac{-1}{\ln (10) * \log _{10}\left(\frac{450}{700}\right)} * \frac{1}{\sigma_{a p, 450}}=\frac{2.26}{\sigma_{a p, 450}} \\
\frac{\partial \alpha_{a p}}{\partial \sigma_{\mathrm{ap}, 700}}=\frac{1}{\ln (10) * \log _{10}\left(\frac{450}{700}\right)} * \frac{1}{\sigma_{a p, 700}}=\frac{-2.26}{\sigma_{a p, 700}}
\end{gathered}
$$

\section{Direct radiative forcing efficiency}

$\Delta \mathrm{DRFE}=\left(\left(\frac{\partial \mathrm{DRFE}}{\partial \omega_{0}}\right)^{2} \Delta \omega_{0}{ }^{2}+\left(\frac{\partial \mathrm{DRFE}}{\partial \beta}\right)^{2} \Delta \beta^{2}+2 * \operatorname{corr}\left(\omega_{0}, \beta\right) *\left(\frac{\partial \mathrm{DRFE}}{\partial \omega_{0}}\right) *\left(\frac{\partial \mathrm{DRFE}}{\partial \beta}\right) * \Delta \omega_{0} * \Delta \beta\right)^{1 / 2}$

Where

$$
\begin{aligned}
& \frac{\partial(\mathrm{DRFE})}{\partial \omega_{0}}=\mathrm{K} \beta\left(1-\mathrm{R}_{\mathrm{s}}\right)^{2}+2 \mathrm{KR}_{\mathrm{s}} \\
& \frac{\partial(\mathrm{DRFE})}{\partial \beta}=\mathrm{K} \omega_{0}\left(1-\mathrm{R}_{\mathrm{s}}\right)^{2} \\
& \mathrm{~K}=-\mathrm{DS}_{0} \mathrm{~T}_{\mathrm{atm}}^{2}\left(1-\mathrm{A}_{\mathrm{C}}\right)
\end{aligned}
$$

Table S2 contains fractional uncertainties in calculated PM10 and PM1 aerosol optical properties. The uncertainties are nonlinear in the measured AOPs (Eq(s).S5-S12) so percentages must be calculated for a set of prescribed aerosol conditions. Uncertainties reported in the table are calculated using near annual-average AOP values at APP, BND, EGB, and SGP. Hourly averages are shown due to the negligible change in the uncertainties for averaging times longer than 1 hour, as can be seen by the small contributions from the noise terms. The uncertainties in calculated AOPs (Table S2) are significantly reduced by strong correlation among most aerosol optical properties (Eq(s).S5S12). 


\section{S1.4 Comparing measurements made at different locations and times}

Identical nephelometers, PSAPs, calibration and correction methods are used at the four sites reported in this paper, with the exception of the replacement of PSAP with the nearly-identical CLAP at BND (discussed in Sect. 2.2 of manuscript). The uncertainties when comparing measurements separated in space and time are thus likely smaller than the total fractional measurement uncertainties listed in cołumn 2 of Table S2, as discussed in detail by Anderson and Ogren (1998) and by Anderson et al. (1999). Some contributions to the measurement uncertainties are nearly the same for different sites and times and approximately cancel when comparing AOPs between different sites and times, as noted by Anderson et al. (1999). Examples include the nephelometer calibration and STP correction uncertainties. The nephelometer truncation correction uncertainties are also nearly the same, due to the fact that the scattering Ångström exponent used to correct for nephelometer truncation of forward-scattered light (Anderson and Ogren, 1998) exhibits little temporal variability at each of the four sites and is of similar magnitude for each site (Fig.2g). The PSAP unit-to-unit variability term can be neglected when comparing measurements made at the same site but cannot be neglected when comparing measurements made at different sites. The other uncertainty sources described above must be considered both for intra-site and inter-site AOP comparisons. We follow a similar methodology to that employed by Anderson et al. (1999). We consider the combined effect of all uncertainty sources that would not be expected to cancel or nearly-cancel when comparing AOPs measured at different sites and times. We refer to their combined effect as measurement precision uncertainty, using the same notation as Anderson et al. (1999). We note that Anderson et al. (1999) did not include the nephelometer RH correction uncertainty nor the PSAP calibration uncertainty in their measurement precision uncertainties so our reported measurement precision uncertainties may represent upper bounds. We calculate measurement precision uncertainties calculated from near annually-averaged aerosol optical properties at the four sites (Table S2). We use the same precision uncertainty magnitudes for all sites. Differences between sites/seasons can be assessed by comparison with the measurement precision uncertainty ranges. 


\section{S2 Statistics related to data quality assurance claims made in the paper}

Table S4. Percentage of hours with PM 1 aerosol scattering coefficient less than $1 \mathbf{M m}^{-1}$ for each month of year over the 2010-2013 period at APP, BND, EGB, and SGP. Blank fields indicate that there were no hours with PM1 $\sigma_{\mathrm{sp}}(550 \mathrm{~nm})<1 \mathrm{Mm}^{-1}$. We do not include hours with PM1 $\sigma_{\mathrm{sp}}(550$ $\mathrm{nm})<1 \mathrm{Mm}^{-1}$ when calculating statistics for intensive AOPs.

\section{S3 Justification for inclusion of aerosol light scattering measurements at EGB}

Unlike APP, BND, and SGP, the sampled air RH is not actively-controlled at EGB. Naturally this will lead to questions as to whether the scattering and back-scattering measured at EGB is also representative of 'dried aerosols'. The temperature inside the nephelometer is several degrees higher than the ambient air temperature for all seasons so the instrument RH is much less than the sampled RH. However, small enhancements in scattering coefficient above 'dried aerosol levels' are still likely during summer at EGB. We make the argument that the lack of RH control at EGB results in negligible effect during non-summer months and a small effect on geometric mean scattering coefficients during summer, but not near enough to explain the seasonal scattering variability demonstrated at EGB. To estimate the magnitude of the scattering enhancement, we applied scattering hygroscopic growth gamma fit parameters (Quinn et al., 2005) based on humidified light scattering and hemispheric backscattering measurements at APP and SGP (not included here) to the hourly-averaged light scattering and hemispheric backscattering values for hours when the nephelometer internal RH exceeded $40 \%$. For gamma values encompassing the $5^{\text {th }}$ through $95^{\text {th }}$ percentiles (i.e., basically the entire range of possible growth factors), the correction of light scattering and hemispheric backscattering from modestly-elevated $\mathrm{RH}$ values (RH 45-50\%) to values at $\mathrm{RH}=40 \%$ was $\sim 3-4 \%$ and the uncertainty in applying static correction factors for sites with no humidified scattering measurements (BND, EGB) was similarly small. The number of hours for which nephelometer RH exceeded 40\%, 50\%, 60\%, and 70\% are shown in Table S3. Based on these relatively small adjustments, hours with elevated nephelometer RH at EGB are retained and no RH corrections are applied to the EGB scattering measurements for these hours. Application of typical summer hygroscopic growth factors measured at APP ( $\mathrm{f}(\mathrm{RH}) \sim 1.5-1.6)$ can be applied to show that scattering enhancements of $\sim 50-60 \%$ are possible for $\mathrm{RH}=85 \%$ and that the enhancements are $\sim 20 \%$ or less for $\mathrm{RH}=70 \%$. Even during July and August, the internal nephelometer RH at EGB only 
exceeds $\mathrm{RH}>50 \%$ for $60 \%$ of the hours and $\mathrm{RH}>70 \%$ for $8-18 \%$ of the hours (Table S3). Scattering enhancements of $20-50 \%$ during $8-18 \%$ of the hours will produce a small enhancement in geometric mean scattering coefficient during these months but this enhancement is nowhere close to the seasonal differences in scattering observed at EGB (Fig. 2a of paper) and reported in this paper.

\section{S4 Boxplots of PM1 $\sigma_{\mathrm{sp}}$ and $\sigma_{\mathrm{ap}}$ annual cycles for entire period and for individual years}

Fig S1. Boxplots of monthly-binned PM1 $\sigma_{\mathrm{sp}}$ and $\sigma_{\mathrm{ap}}$ for APP over the entire 2010-2013 period and over individual years. The top The 'ALL' box provides the statistics for all hours of the given year(s). The mean is denoted by the dot for while the horizontal bar represents the median. The top and bottom of the box represent $75^{\text {th }}$ and $25^{\text {th }}$ percentiles while the top and bottom whisker extend to the $95^{\text {th }}$ and $5^{\text {th }}$ percentiles, respectively. The horizontal line drawn through all boxes of each plot represents the median value over all hours for the given year(s).

Fig S2. Boxplots of monthly-binned PM1 $\sigma_{\mathrm{sp}}$ and $\sigma_{\mathrm{ap}}$ for BND over the entire 2010-2013 period and over individual years.

Fig S3. Boxplots of monthly-binned PM1 $\sigma_{\mathrm{sp}}$ and $\sigma_{\mathrm{ap}}$ for EGB over the entire 2010-2013 period and over individual years.

Fig S4. Boxplots of monthly-binned PM1 $\sigma_{\mathrm{sp}}$ and $\sigma_{\mathrm{ap}}$ for SGP over the entire 2010-2013 period and over individual years.

\section{S5 Temperature-dependence of scattering coefficient and single-scattering albedo}

The temperature dependence of $\sigma_{\mathrm{sp}}$ (Fig.S5) and single-scattering albedo (Fig.S6) can provide some information regarding aerosol sources and can also be used as a consistency check on the seasonality of observed AOPs. Gas-to-particle portioning of $\mathrm{NH}_{3}$ and $\mathrm{NO}_{\mathrm{x}}$ to form ammonium nitrate is more favorable at low temperature and is consistent with aerosol chemistry reported for BND (BuzcuGuvan et al., 2007), EGB (Rupakheti,et al., 2005 ), and SGP (Parworth et al., 2015) APP and EGB are located in regions with high forest densities and high summer concentration of temperaturedependent biogenic SOA(Goldstein et al., 2008; Link et al., 2015; Slowik et al, 2010). The summer $\sigma_{\text {sp }}$ peak at BND (and to a lesser extent-SGP) also coincide with peak temperatures and biogenic 
emissions but there are lower forest densities in these regions. Guenther et al. (1993) reported that a simple exponential model provides a good approximation for temperature dependence of monoterpene emissions, $E=E_{s} * \exp [\beta *(T-303 \mathrm{~K})]$, where $T$ is the leaf temperature and $\beta \sim 0.09 \mathrm{~K}^{-1}$ for all plants and monoterpenes. Goldstein et al. (2008) reported that this exponential dependence also well-described the temperature dependence of aerosol optical depth in the isoprene-dominated SE US. with very similar $\beta \sim 0.11 \mathrm{~K}^{-1}$ to that reported by Guenther et al. (1993) for monoterpene emissions. We apply a similar equation to determine the relationship between hourly-averaged $\sigma_{\mathrm{sp}}$ and surface temperatures at the four sites (Fig.S7) over the months April-October, coinciding with higher photosynthetically-active radiation and temperatures. The strong correlations between $\sigma_{\mathrm{sp}}$ and $\mathrm{T}$ (Fig.S7) exist at EGB ( $\mathrm{r}=0.62)$ and $\mathrm{APP}(\mathrm{r}=0.61)$, along with $\beta$ values similar to those reported by Guenther et al.(1993) and Goldstein et al.(2008). The correlation was nearly as high at BND ( $r=0.47)$, although $\beta$ is lower $(\sim 0.05)$. The relationship at SGP is weaker $(r=0.38, \beta=0.03)$.

\section{S6 Annual cycles of PM10 aerosol optical properties at APP, BND, and SGP}

Figure S8. Annual cycle of PM10 AOPs for APP, BND, and SGP over the 2010-2013 period: (a) geometric mean $\sigma_{\mathrm{sp}}$; (b) geometric mean $\sigma_{\mathrm{ap}}$; (c) mean $\mathrm{R}_{\mathrm{ap}}$; (d) mean b; (e) mean $\omega_{0}$; (f) mean DRFE; (g) mean $\left.\alpha_{\text {sp }} ; \mathrm{h}\right)$ mean $\alpha_{\mathrm{ap}}(450 / 700 \mathrm{~nm})$. The values corresponding to 'ALL' are geometric mean or mean values for the entire 2010-2013 period (all months). Error bars represent 95\% confidence intervals of mean values.

\section{S7 Weekly and diurnal cycles of PM1 scattering and absorption fractions and PM1 aerosol intensive optical properties}

Figure S9. Weekly and diurnal cycles of mean $\mathrm{R}_{\mathrm{sp}}$ over full years (ANN traces) and for winter (DJF), spring (MAM), summer (JJA), and fall (SON) at APP, BND, and SGP over the 2010-2013 period. The value corresponding to the 'ALL' data point of each trace is the mean value over all days of week or over all hours of day. Error bars represent $95 \%$ confidence intervals of mean $\mathrm{R}_{s p}$ values.

Figure S10. Weekly and diurnal cycles of mean $\mathrm{R}_{\text {ap }}$ over full years (ANN traces) and for winter (DJF), spring (MAM), summer (JJA), and fall (SON) at APP, BND, and SGP over the 2010-2013 period. 
The value corresponding to the 'ALL' data point of each trace is the mean value over all days of week or over all hours of day. Error bars represent 95\% confidence intervals of mean $\mathrm{R}_{\mathrm{ap}}$ values.

Figure S11. Weekly and diurnal cycles of mean PM 1 b for APP, BND, EGB, and SGP for winter (DJF), spring (MAM), summer (JJA), and fall (SON). Figure S12. Weekly and diurnal cycles of mean PM $1 \omega_{0}$ during winter (DJF), spring (MAM), summer (JJA), and fall (SON) months. The 'ANN' trace reports mean PM $1 \omega_{0}$ over all of that day of week or hour for the full annual cycle (all seasons) The values corresponding to 'ALL' on each trace are mean values for the corresponding season over entire 2010-2013 period (all months). Error bars represent 95\% confidence intervals of mean values.

Figure S12. Weekly and diurnal cycles of mean PM1 $\omega_{0}$ over full years (ANN traces) and for winter (DJF), spring (MAM), summer (JJA), and fall (SON) at APP, BND, EGB, and SGP over the 20102013 period. The value corresponding to the 'ALL' data point of each trace is the mean value over all days of week or over all hours of day. Error bars represent $95 \%$ confidence intervals of mean $\omega_{0}$ values.

Figure S13. Weekly and diurnal cycles of mean PM1 DRFE over full years (ANN traces) and for winter (DJF), spring (MAM), summer (JJA), and fall (SON) at APP, BND, EGB, and SGP over the 2010-2013 period. The value corresponding to the 'ALL' data point of each trace is the mean value over all days of week or over all hours of day. Error bars represent 95\% confidence intervals of mean DRFE values.

Figure S14. Weekly and diurnal cycles of mean PM10 $\alpha_{\mathrm{sp}}$ over full years (ANN traces) and for winter (DJF), spring (MAM), summer (JJA), and fall (SON) at APP, BND, and SGP over the 2010-2013 period. The value corresponding to the 'ALL' data point of each trace is the mean value over all days of week or over all hours of day. Error bars represent 95\% confidence intervals of mean $\alpha_{\mathrm{sp}}$ values.

Figure S15. Weekly and diurnal cycles of mean PM1 $\alpha_{\text {ap }}$ over full years (ANN traces) and for winter (DJF), spring (MAM), summer (JJA), and fall (SON) at APP, BND, and SGP over the 2010-2013 period. The value corresponding to the 'ALL' data point of each trace is the mean value over all days of week or over all hours of day. Error bars represent 95\% confidence intervals of mean $\alpha_{\mathrm{ap}}$ values. 


\section{S8 Pollution-rose diagrams for PM1 Rsp, $\omega_{0}$, and $b$ at APP, BND, EGB, and SGP}

Figure S16 Pollution-rose diagram of $\mathrm{R}_{\mathrm{sp}}$ at APP. The percentages at a given radius represent the percentage of hourly profiles for a given wind sector.

Figure S17 Pollution-rose diagram of PM1 (a) $\omega_{0}$ and (b) b at APP.

Figure S18 Pollution-rose diagram of $\mathrm{R}_{\mathrm{sp}}$ at BND.

Figure S19 Pollution-rose diagram of PM1 (a) $\omega_{0}$ and (b) b at APP.

Figure S20 Pollution-rose diagram of PM1 (a) $\omega_{0}$ and (b) b at EGB.

Figure S21 Pollution-rose diagram of $\mathrm{R}_{\mathrm{sp}}$ at SGP.

Figure S22 Pollution-rose diagram of PM1 (a) $\omega_{0}$ and (b) b at SGP.

\section{S9 Table of annually-averaged PM10 and PM1 aerosol optical properties}

Table S5: Mean \pm standard error of mean PM10 and PM1 aerosol optical properties, based on hourlyaveraged data over the years 2010-2013 (N=25K-34K hours). Geometric means */ standard deviations are reported for $\sigma_{\mathrm{sp}}$ and $\sigma_{\mathrm{ap}}$, based on the near log-normal distribution of these variables. The sites are ordered from west to east for easy identification of any potential longitudinal gradients in aerosol optical properties.

\section{S10 Annual cycles of temperature and relative humidity at APP, BND, EGB, and SGP}

Figure S23. Boxplots of monthly-binned temperature and relative humidity over the entire 2010-2013 period.

\section{S11 Long-term time series plots of select AOPs for BND and SGP}

Figure S24. Time series of monthly-averaged PM10 $\sigma_{\mathrm{sp}}$ for BND (1996-2013) and SGP (1997-2013), along with PM10 and PM1 $\sigma_{\mathrm{ap}}$ for BND. Trend lines, representing least-squared fits of the data, are also shown. Broken lines on the curves represent data gaps.

Figure S25. Time series of monthly-averaged PM10 $b$ and PM10 $\alpha_{\mathrm{sp}}$ for BND (1996-2013) and SGP (1997-2013), along with PM10 and PM1 $\omega_{0}$ for BND. Trend lines, representing least-squared fits of the data, are also shown. Broken lines on the curves represent data gaps. 
Table S1. Total fractional uncertainties (\%) of PM1 (PM10) aerosol light scattering coefficient $\sigma_{\mathrm{sp}}$, hemispheric back-scattering coefficient $\sigma_{\text {bsp }}$, and absorption coefficient $\sigma_{\mathrm{ap}}$ at $550 \mathrm{~nm}$, along with the individual contributions. Uncertainties are calculated for 1-hour averaging time and expressed as 95\% confidence intervals. The nephelometer noise term depends weakly on $\sigma_{\mathrm{sp}}$ and is calculated using $\sigma_{\mathrm{sp}}=30 \mathrm{Mm}^{-1}$ (Eq. S2).

\begin{tabular}{|c|c|c|c|c|c|c|c|c|c|c|}
\hline & $\begin{array}{l}\text { Total } \\
\text { uncert } \\
(\%)\end{array}$ & $\begin{array}{l}\text { Neph } \\
\text { noise } \\
(\%)\end{array}$ & $\begin{array}{l}\text { Neph } \\
\text { cal } \\
(\%)\end{array}$ & $\begin{array}{l}\text { Neph } \\
\text { cal var } \\
(\%)\end{array}$ & $\begin{array}{l}\text { Neph } \\
\text { trunc } \\
\text { cor } \\
(\%)\end{array}$ & $\begin{array}{l}\text { Neph } \\
\text { STP } \\
\text { cor } \\
(\%)\end{array}$ & $\begin{array}{l}\text { Neph } \\
\text { RH cor } \\
(\%)\end{array}$ & $\begin{array}{l}\text { PSAP } \\
\text { noise } \\
(\%)\end{array}$ & $\begin{array}{l}\text { PSAP } \\
\mathrm{cal}^{1} \\
(\%)\end{array}$ & $\begin{array}{l}\text { PSAP } \\
\text { unit-to- } \\
\text { unit var. } \\
(\%)\end{array}$ \\
\hline$\Delta \sigma_{\mathrm{sp}}$ & $\begin{array}{l}8.0 \\
(9.2)\end{array}$ & $\begin{array}{l}0.27 \\
(0.23)\end{array}$ & $\begin{array}{l}7.0 \\
(7.0)\end{array}$ & $\begin{array}{l}2.3 \\
(2.3)\end{array}$ & $\begin{array}{l}0.070 \\
(4.6)\end{array}$ & $\begin{array}{l}0.40 \\
(0.40)\end{array}$ & $\begin{array}{l}3.0 \\
(3.0)\end{array}$ & - & - & - \\
\hline$\Delta \sigma_{\text {bsp }}$ & $\begin{array}{l}8.1 \\
(8.9)\end{array}$ & $\begin{array}{l}0.83 \\
(0.69)\end{array}$ & $\begin{array}{l}7.0 \\
(7.0)\end{array}$ & $\begin{array}{l}2.5 \\
(2.5)\end{array}$ & $\begin{array}{l}0.9 \\
(3.8)\end{array}$ & $\begin{array}{l}0.40 \\
(0.40)\end{array}$ & $\begin{array}{l}3.0 \\
(3.0)\end{array}$ & - & - & - \\
\hline$\Delta \sigma_{\mathrm{ap}}$ & $\begin{array}{l}20 \\
(20)\end{array}$ & & & & & & & $\begin{array}{l}1.7 \\
(1.5)\end{array}$ & $\begin{array}{l}11 \\
(12)\end{array}$ & $\begin{array}{l}16 \\
(16)\end{array}$ \\
\hline
\end{tabular}


Table S2. Total and precision fractional uncertainties (\%) of measured PM1 and PM10 aerosol optical properties (AOPs) $\sigma_{\mathrm{sp}}$, $\sigma_{\mathrm{bsp}}$, and $\sigma_{\mathrm{ap}}$ and calculated AOPs (e.g., the intensive AOPs) for 1hour averaging time. Uncertainties are expressed as 95\% confidence intervals. All uncertainties are for $\lambda=550 \mathrm{~nm}$ except for $\alpha_{\mathrm{sp}}$ and $\alpha_{\mathrm{ap}}$, which are calculated for the $450 / 700 \mathrm{~nm}$ wavelength pair. The uncertainties in columns 3 and 4 differ only by inclusion of the PSAP unit-to-unit variability term (Eq. S3) in column 3. All uncertainties except $\Delta \sigma_{\mathrm{sp}}, \Delta \sigma_{\mathrm{bsp}}$, and $\Delta \sigma_{\mathrm{ap}}$ depend nonlinearly on the measured value, and cannot rigorously be represented as a percentage ${ }^{1}$. For these intensive AOP uncertainties, we use approximate annual-mean values $\sigma_{\mathrm{sp}, 10}=30 \mathrm{Mm}^{-1}$, $\sigma_{\mathrm{ap}, 10}=3.0 \mathrm{Mm}^{-1}, \mathrm{R}_{\mathrm{sp}}=0.80, \mathrm{R}_{\mathrm{ap}}=0.88, \mathrm{~b}=0.14, \omega_{0}=0.91, \alpha_{\mathrm{sp}}=2.0$, and $\alpha_{\mathrm{ap}}=1.0$ to calculate fractional uncertainties. The calculations also use the following correlation coefficients in $\mathrm{Eq}(\mathrm{s})$ S5-S12 for PM1 (PM10) aerosol optical properties: $\operatorname{corr}\left(\sigma_{\mathrm{sp}, 550 \mathrm{~nm},} \sigma_{\mathrm{ap}, 550 \mathrm{~nm}}\right)=0.67(0.65)$; $\operatorname{corr}\left(\sigma_{\mathrm{sp}, 550 \mathrm{~nm}}, \sigma_{\mathrm{bsp}, 550 \mathrm{~nm}}\right)=0.96(0.96) ; \operatorname{corr}\left(\sigma_{\mathrm{sp}, 450 \mathrm{~nm},} \sigma_{\mathrm{ap}, 700 \mathrm{~nm}}\right)=0.99(0.99), \operatorname{corr}\left(\sigma_{\mathrm{ap}, 450 \mathrm{~nm}}\right.$, $\left.\sigma_{\mathrm{ap}, 700 \mathrm{~nm}}\right)=0.93(0.93)$; and $\operatorname{corr}\left(\omega_{0,550 \mathrm{~nm},} \beta_{700 \mathrm{~nm}}\right)=0.087(0.087)$. The intensive AOP fractional uncertainties apply for the average conditions listed above, and the equations presented in this section should be used to calculate uncertainties at different sites or for different conditions.

\begin{tabular}{llll}
\hline & $\begin{array}{l}\text { Total \% } \\
\text { uncertainty for } \\
\text { PM1 (PM10) }\end{array}$ & $\begin{array}{l}\text { PM1 (PM10) \% } \\
\text { precision uncertainty } \\
\text { for comparisons } \\
\text { among sites }\end{array}$ & $\begin{array}{l}\text { PM1 (PM10) \% } \\
\text { precision uncertainty } \\
\text { for comparisons at } \\
\text { single site }\end{array}$ \\
\hline$\Delta \sigma_{\mathrm{sp}}$ & $8.0(9.2)$ & $3.8(3.8)$ & $3.8(3.8)$ \\
$\Delta \sigma_{\mathrm{bsp}}$ & $8.1(8.9)$ & $4.0(3.9)$ & $4.0(3.9)$ \\
$\Delta \sigma_{\mathrm{ap}}$ & $20(20)$ & $20(20)$ & $12(12)$ \\
$\Delta \mathrm{R}_{\mathrm{sp}}$ & 2.7 & 1.1 & 1.1 \\
$\Delta \mathrm{R}_{\mathrm{ap}}$ & 4.2 & 4.2 & 2.5 \\
$\Delta \mathrm{b}$ & $2.3(2.6)$ & $1.1(1.1)$ & $1.1(1.1)$ \\
$\Delta \omega_{0}$ & $1.5(1.4)$ & $1.7(1.4)$ & $0.9(0.8)$ \\
$\Delta \alpha_{\mathrm{sp}}$ & $1.7(1.8)$ & $1.4(1.4)$ & $1.4(1.4)$ \\
$\Delta \alpha_{\mathrm{ap}}$ & $17(17)$ & $17(17)$ & $10(10)$ \\
$\Delta \mathrm{DRFE}$ & $4.8(4.4)$ & $5.2(4.7)$ & $4.8(4.4)$ \\
\hline 1
\end{tabular}

1 The uncertainties $\Delta \sigma_{\mathrm{sp}}, \Delta \sigma_{\mathrm{bsp}}$, and $\Delta \sigma_{\mathrm{ap}}$ depend very weakly on measured values, through the noise term. This term represents a negligible contribution to the uncertainties for averaging times of one hour or more. 
Table S3. Percentage of hours with PM 1 aerosol scattering coefficient less than $1 \mathrm{Mm}^{-1}$ for each month of year over the 2010-2013 period at APP, BND, EGB, and SGP. Blank fields indicate that there were no hours with PM1 $\sigma_{\text {sp }}(550 \mathrm{~nm})<1 \mathrm{Mm}^{-1}$. We do not include hours with PM1 $\sigma_{\mathrm{sp}}(550 \mathrm{~nm})<1 \mathrm{Mm}^{-1}$ when calculating statistics for intensive AOPs.

\begin{tabular}{lllll}
\hline Month / station & APP & BND & EGB & SGP \\
\hline JAN & $1.7 \%$ & & $0.4 \%$ & \\
FEB & $0.9 \%$ & $3.1 \%$ & $0.3 \%$ \\
MAR & $2.1 \%$ & $0.4 \%$ & \\
APR & $1.0 \%$ & $0.1 \%$ & $1.2 \%$ & $0.3 \%$ \\
MAY & $0.9 \%$ & & $0.8 \%$ & $0.5 \%$ \\
JUN & $0.7 \%$ & $0.5 \%$ & \\
JUL & $0.5 \%$ & & $0.4 \%$ & $0.1 \%$ \\
AUG & $2.3 \%$ & & & \\
SEP & $1.2 \%$ & & $3.9 \%$ & $1.1 \%$ \\
OCT & $1.3 \%$ & $0.1 \%$ & $2.7 \%$ & $0.5 \%$ \\
NOV & $1.1 \%$ & & $1.9 \%$ & $1.2 \%$ \\
DEC & $2.7 \%$ & $0.1 \%$ & $1.8 \%$ & $0.3 \%$ \\
All months & $1.4 \%$ & & & $0.5 \%$ \\
\hline
\end{tabular}


Table S4. Percentage of hours with elevated nephelometer RH at EGB for each month of year over the 2010-2013 period. Blank fields indicate months when the percentage of hours with nephelometer RH>40\% was zero.

\begin{tabular}{lllll}
\hline Month & RH $>40 \%$ & RH $>50 \%$ & RH $>60 \%$ & RH $>70 \%$ \\
\hline JAN & & & & \\
FEB & & & & \\
MAR & $11 \%$ & $1 \%$ & & \\
APR & $5 \%$ & $15 \%$ & $6 \%$ & \\
MAY & $29 \%$ & $27 \%$ & $12 \%$ & $18 \%$ \\
JUN & $47 \%$ & $60 \%$ & $36 \%$ & $8 \%$ \\
JUL & $88 \%$ & $62 \%$ & $30 \%$ & $5 \%$ \\
AUG & $90 \%$ & $32 \%$ & $14 \%$ & \\
SEP & $55 \%$ & $5 \%$ & & \\
OCT & $19 \%$ & & & \\
\hline
\end{tabular}


Table S5: Mean \pm standard error of mean PM10 and PM1 aerosol optical properties, based on hourly-averaged data over the years 2010-2013 ( $\mathrm{N}=25 \mathrm{~K}-34 \mathrm{~K}$ hours). Geometric means $* /$ standard deviations are reported for $\sigma_{\mathrm{sp}}$ and $\sigma_{\mathrm{ap}}$, based on the near log-normal distribution of these variables. The sites are ordered from west to east for easy identification of any potential longitudinal gradients in aerosol optical properties.

\begin{tabular}{|c|c|c|c|c|c|}
\hline & & SGP & BND & EGB & APP \\
\hline \multirow[t]{2}{*}{$\sigma_{\mathrm{sp}}\left(\mathrm{Mm}^{-1}\right)$} & $\mathrm{D}_{\mathrm{p}}<10 \mu \mathrm{m}$ & $25.1 * / 2.17$ & $32.9 * / 2.14$ & & $22.9 * / 2.5$ \\
\hline & $\mathrm{D}_{\mathrm{p}}<1 \mu \mathrm{m}$ & $18 * / 2.19$ & $24 * / 2.1$ & $14.3 * / 3.03$ & $19 * / 2.51$ \\
\hline \multirow[t]{2}{*}{$\sigma_{\mathrm{ap}}\left(\mathrm{Mm}^{-1}\right)$} & $\mathrm{D}_{\mathrm{p}}<10 \mu \mathrm{m}$ & $1.95 * / 2.17$ & $2.51 * / 2.06$ & & $2.28 * / 2$ \\
\hline & $\mathrm{D}_{\mathrm{p}}<1 \mu \mathrm{m}$ & $1.61 * / 2.24$ & $2.11 * / 2.1$ & $1.46 * / 3.1$ & $2.08 * / 2.0$ \\
\hline \multirow[t]{2}{*}{$\omega_{0}$} & $\mathrm{D}_{\mathrm{p}}<10 \mu \mathrm{m}$ & $0.913 \pm 0.000286$ & $0.917 \pm 0.000275$ & & $0.901 \pm 0.000283$ \\
\hline & $\mathrm{D}_{\mathrm{p}}<1 \mu \mathrm{m}$ & $0.90 \pm 0.000348$ & $0.905 \pm 0.000322$ & $0.879 \pm 0.000657$ & $0.892 \pm 0.000306$ \\
\hline \multirow[t]{2}{*}{$b$} & $\mathrm{D}_{\mathrm{p}}<10 \mu \mathrm{m}$ & $0.141 \pm 0.00016$ & $0.141 \pm 0.000151$ & & $0.151 \pm 0.000158$ \\
\hline & $\mathrm{D}_{\mathrm{p}}<1 \mu \mathrm{m}$ & $0.146 \pm 0.000202$ & $0.145 \pm 0.00015$ & $0.137 \pm 0.000163$ & $0.15 \pm 0.000155$ \\
\hline \multirow[t]{2}{*}{$\alpha_{\mathrm{sp}}(450 / 700)$} & $\mathrm{D}_{\mathrm{p}}<10 \mu \mathrm{m}$ & $1.67 \pm 0.00278$ & $1.96 \pm 0.00169$ & & $2.06 \pm 0.00159$ \\
\hline & $\mathrm{D}_{\mathrm{p}}<1 \mu \mathrm{m}$ & $2.13 \pm 0.00246$ & $2.35 \pm 0.00147$ & $2.32 \pm 0.00157$ & $2.39 \pm 0.00137$ \\
\hline \multirow[t]{2}{*}{$\alpha_{\text {ap }}(450 / 700)$} & $\mathrm{D}_{\mathrm{p}}<10 \mu \mathrm{m}$ & $1.09 \pm 0.00243$ & $1.01 \pm 0.00212$ & & $0.95 \pm 0.0023$ \\
\hline & $\mathrm{D}_{\mathrm{p}}<1 \mu \mathrm{m}$ & $1.05 \pm 0.00246$ & $1.01 \pm 0.00234$ & & $0.949 \pm 0.0024$ \\
\hline \multirow[t]{2}{*}{ DRFE $\left(\mathrm{Wm}^{-2} \mathrm{AOD}^{-1}\right)$} & $\mathrm{D}_{\mathrm{p}}<10 \mu \mathrm{m}$ & $-25.2 \pm 0.0235$ & $-25.4 \pm 0.0176$ & & $-25.1 \pm 0.0183$ \\
\hline & $\mathrm{D}_{\mathrm{p}}<1 \mu \mathrm{m}$ & $-24.7 \pm 0.0273$ & $-24.8 \pm 0.0208$ & $-22.2 \pm 0.0496$ & $-24.4 \pm 0.0202$ \\
\hline $\mathrm{R}_{\mathrm{sp}}$ & & $0.736 \pm 0.00241$ & $0.739 \pm 0.000597$ & & $0.838 \pm 0.000625$ \\
\hline $\mathrm{R}_{\mathrm{ap}}$ & & $0.848 \pm 0.00373$ & $0.847 \pm 0.00137$ & & $0.915 \pm 0.000582$ \\
\hline
\end{tabular}



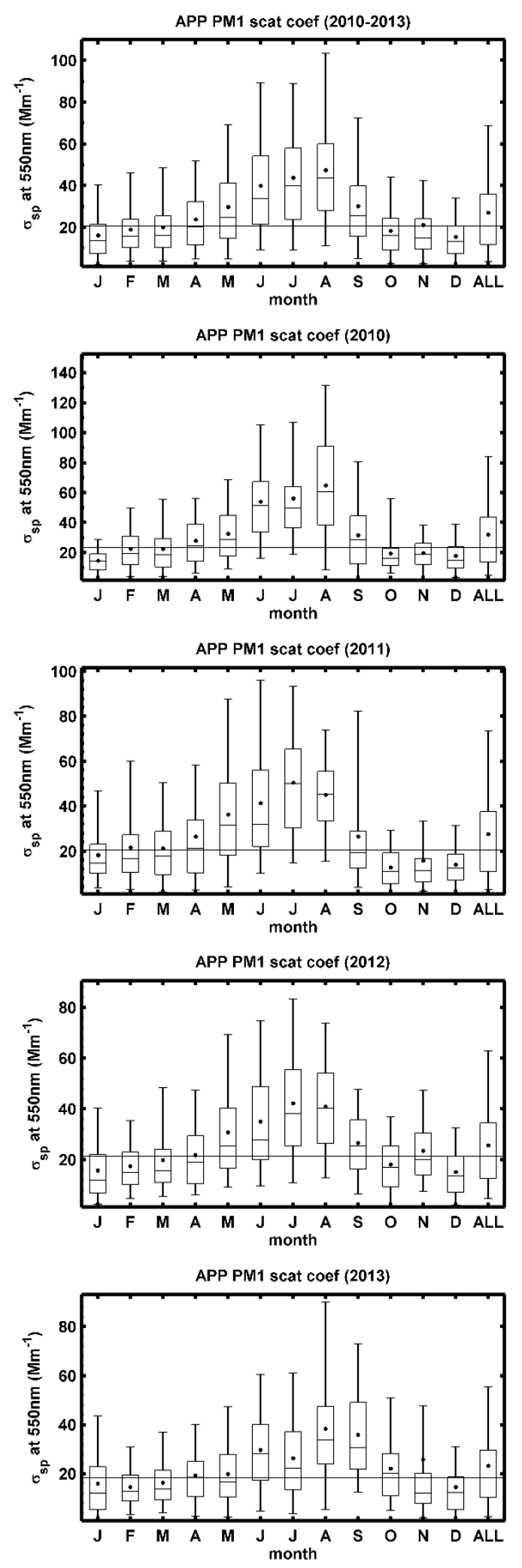
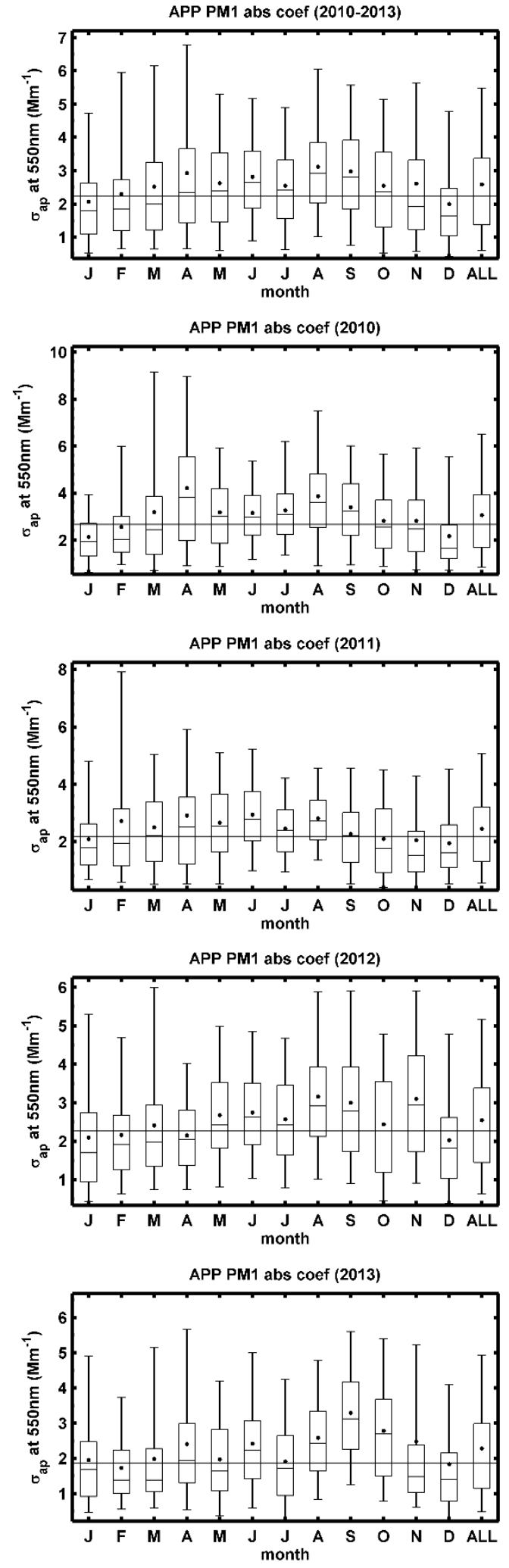

Figure S1. Boxplots of monthly-binned PM1 $\sigma_{\mathrm{sp}}$ and $\sigma_{\mathrm{ap}}$ for APP over the entire 2010-2013 period and over individual years. The top The 'ALL' box provides the statistics for all hours of the given year(s). The mean is denoted by the dot for while the horizontal bar represents the median. The top and bottom of the box represent $75^{\text {th }}$ and $25^{\text {th }}$ percentiles while the top and bottom whisker extend to the $95^{\text {th }}$ and $5^{\text {th }}$ percentiles, respectively. The horizontal line drawn through all boxes of each plot represents the median value over all hours for the given year(s). 

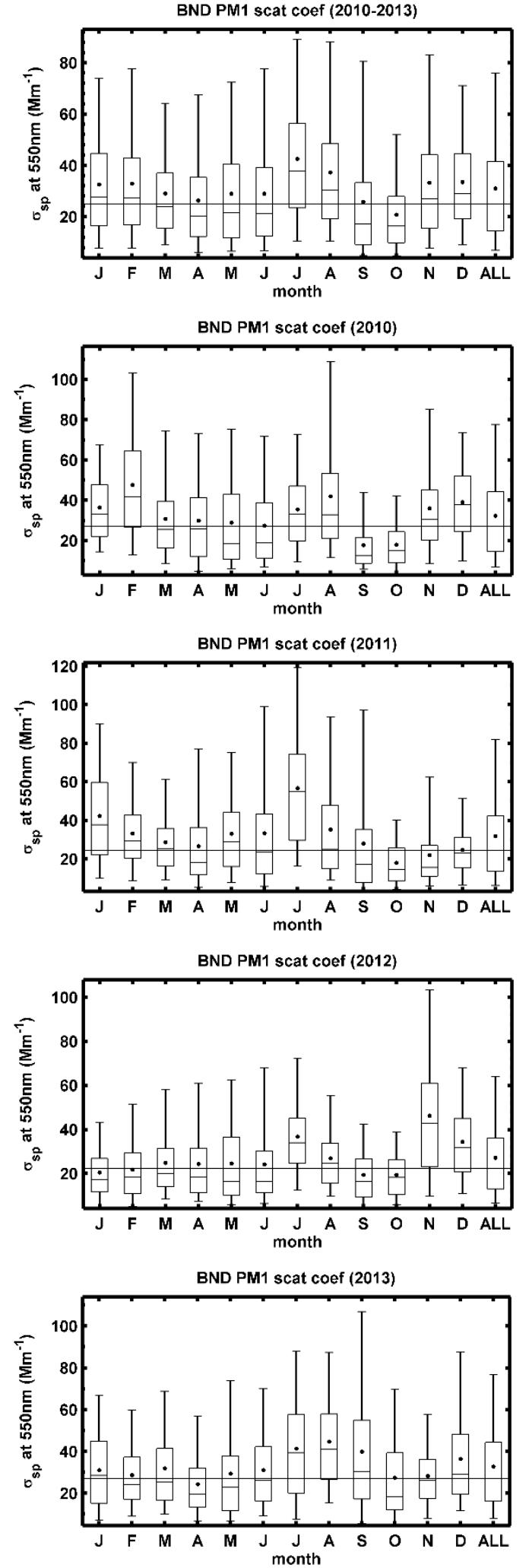
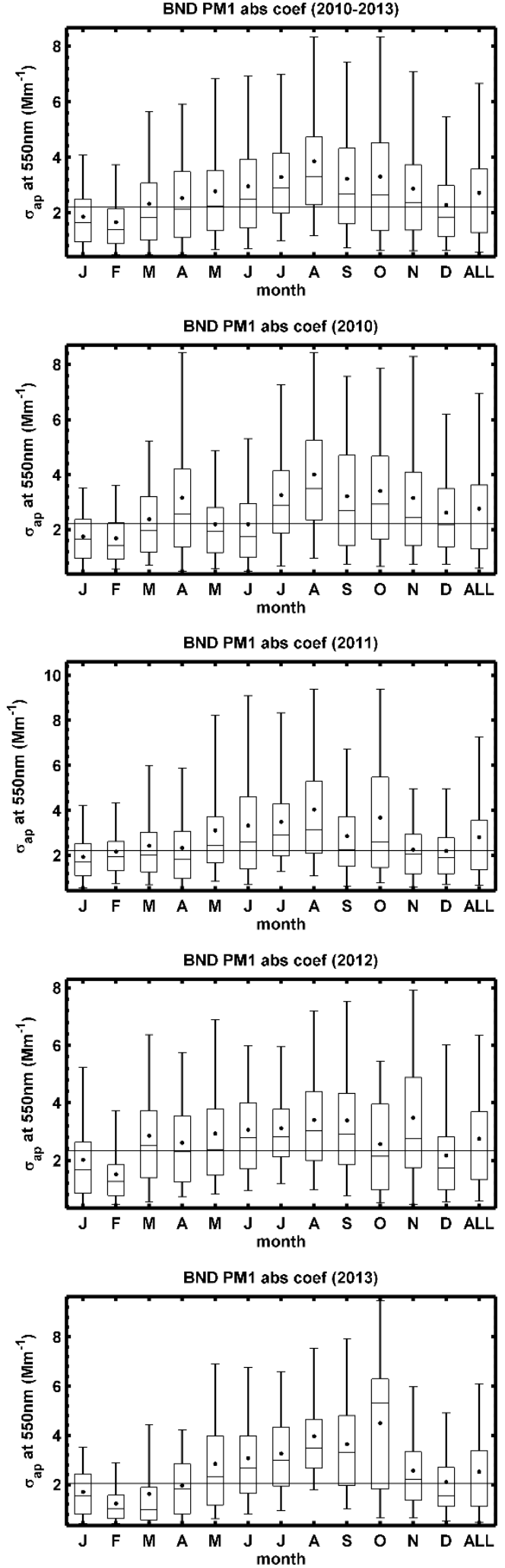

Figure S2. Boxplots of monthly-binned PM1 $\sigma_{\mathrm{sp}}$ and $\sigma_{\mathrm{ap}}$ for BND over the entire 2010-2013 period and over individual years. 

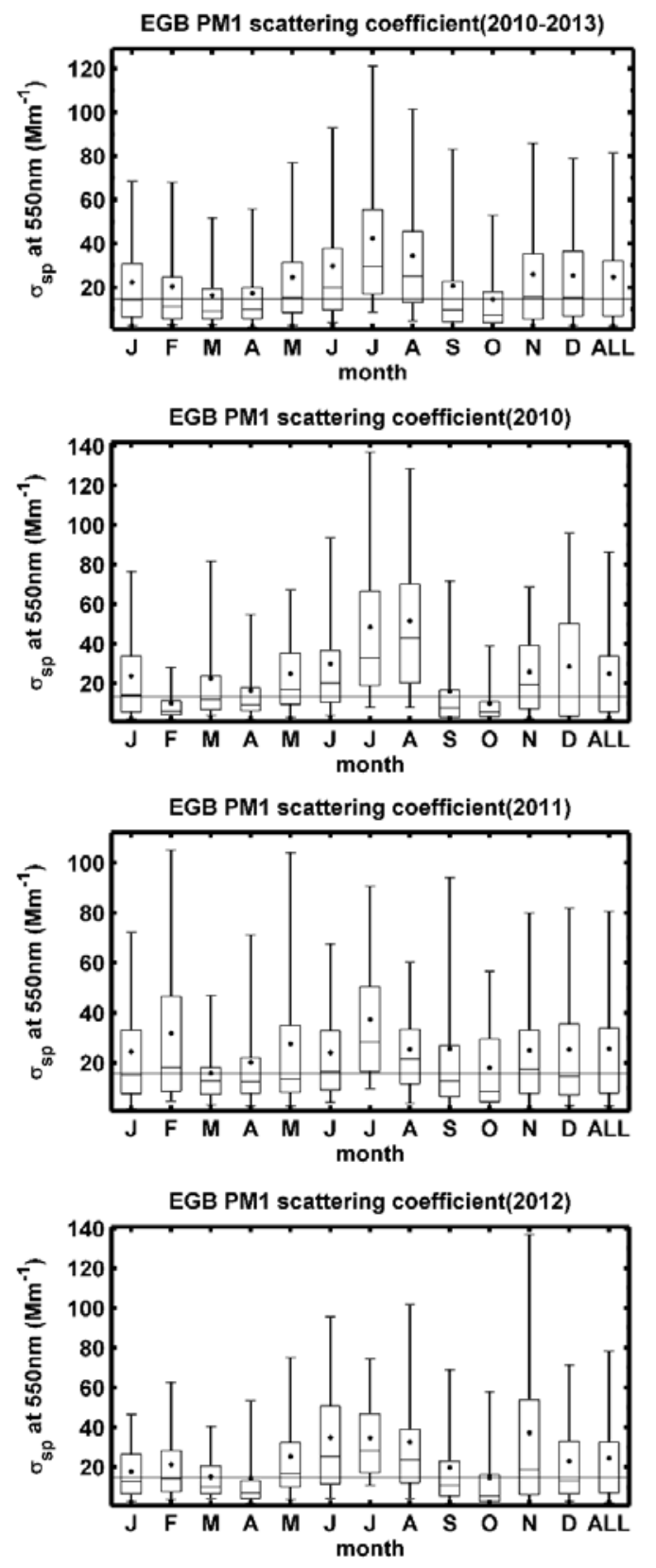

EGB PM1 scattering coefficient(2013)

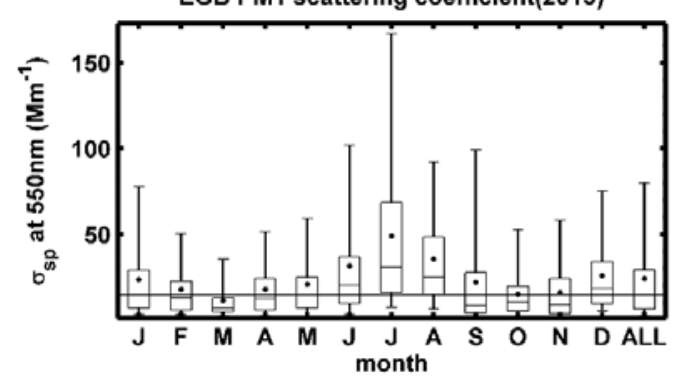

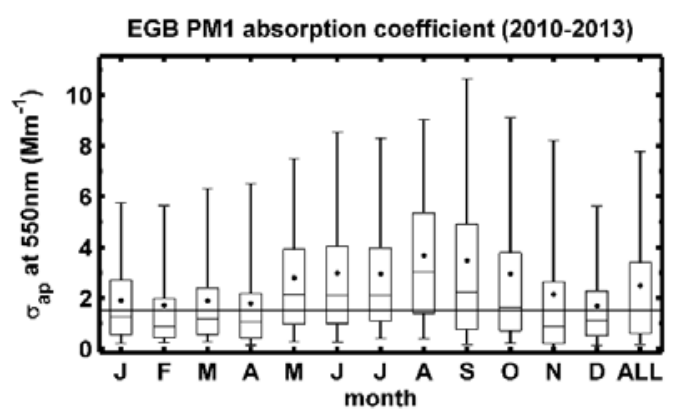
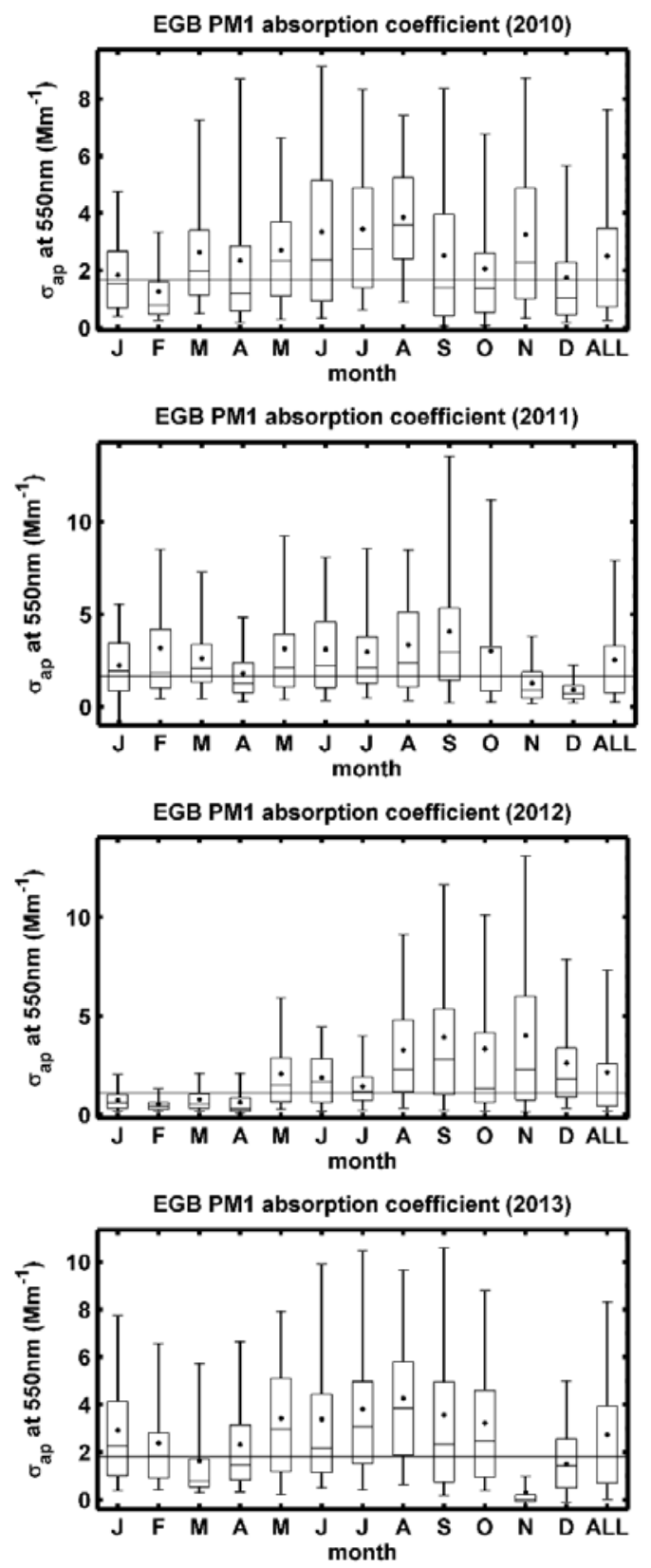

Figure S3. Boxplots of monthly-binned PM1 $\sigma_{\mathrm{sp}}$ and $\sigma_{\mathrm{ap}}$ for EGB over the entire 2010-2013 period and over individual years. 

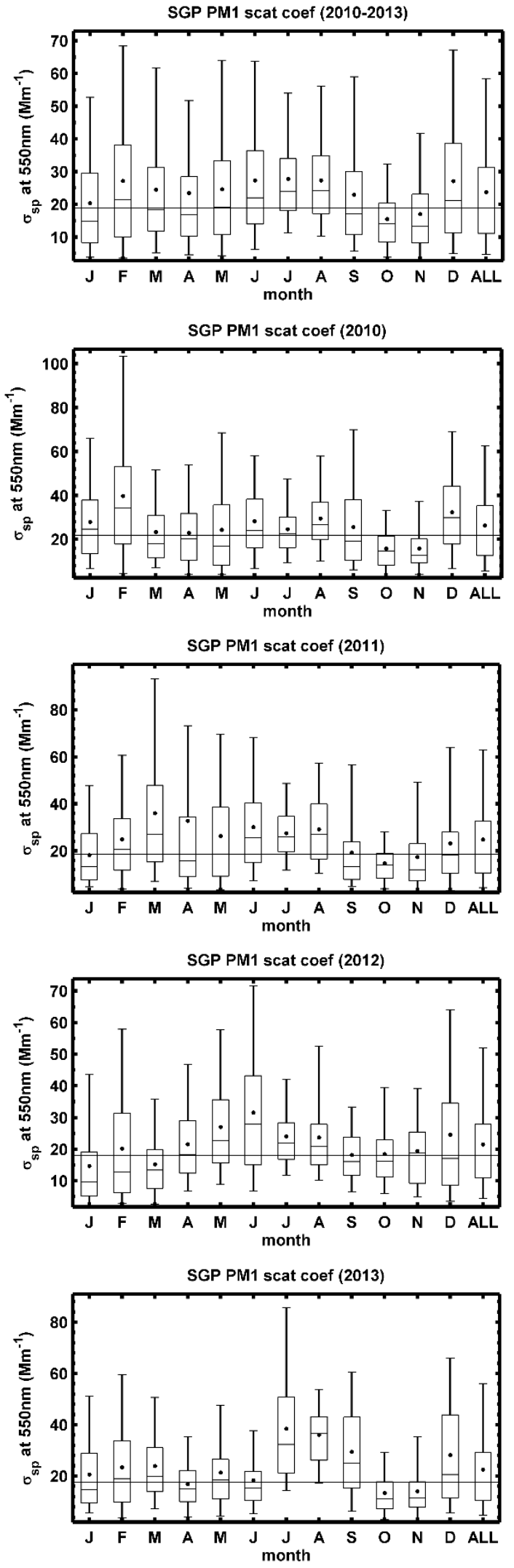
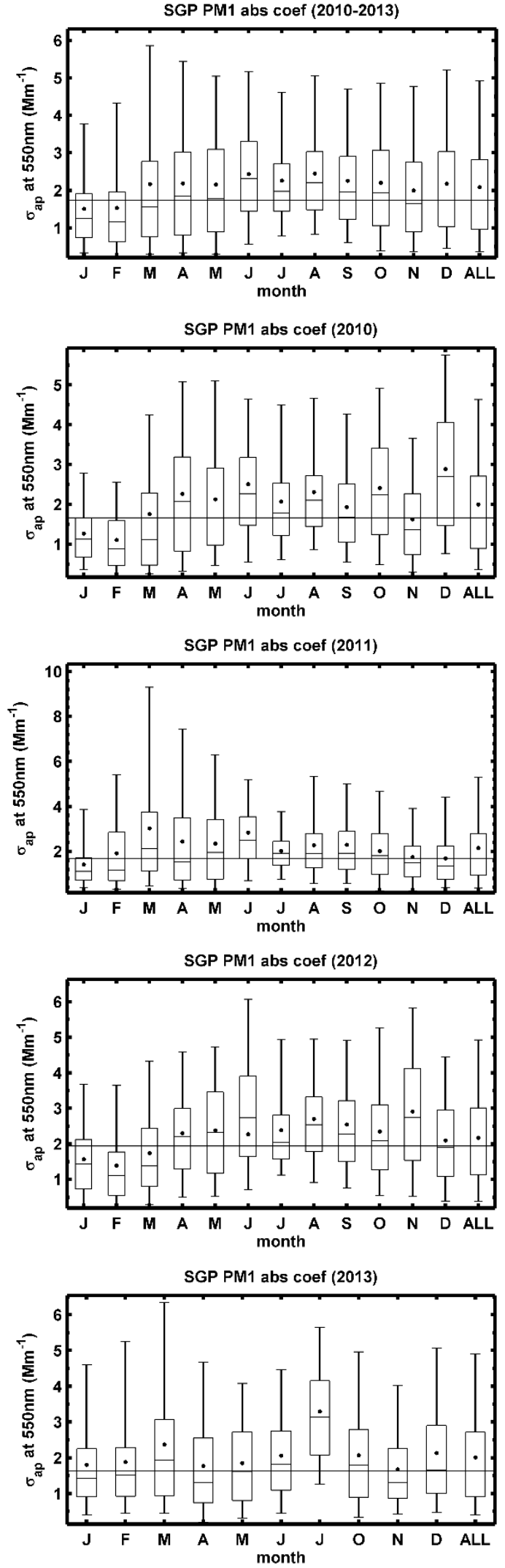

Figure S4. Boxplots of monthly-binned PM1 $\sigma_{\mathrm{sp}}$ and $\sigma_{\mathrm{ap}}$ for SGP over the entire 2010-2013 period and over individual years. 

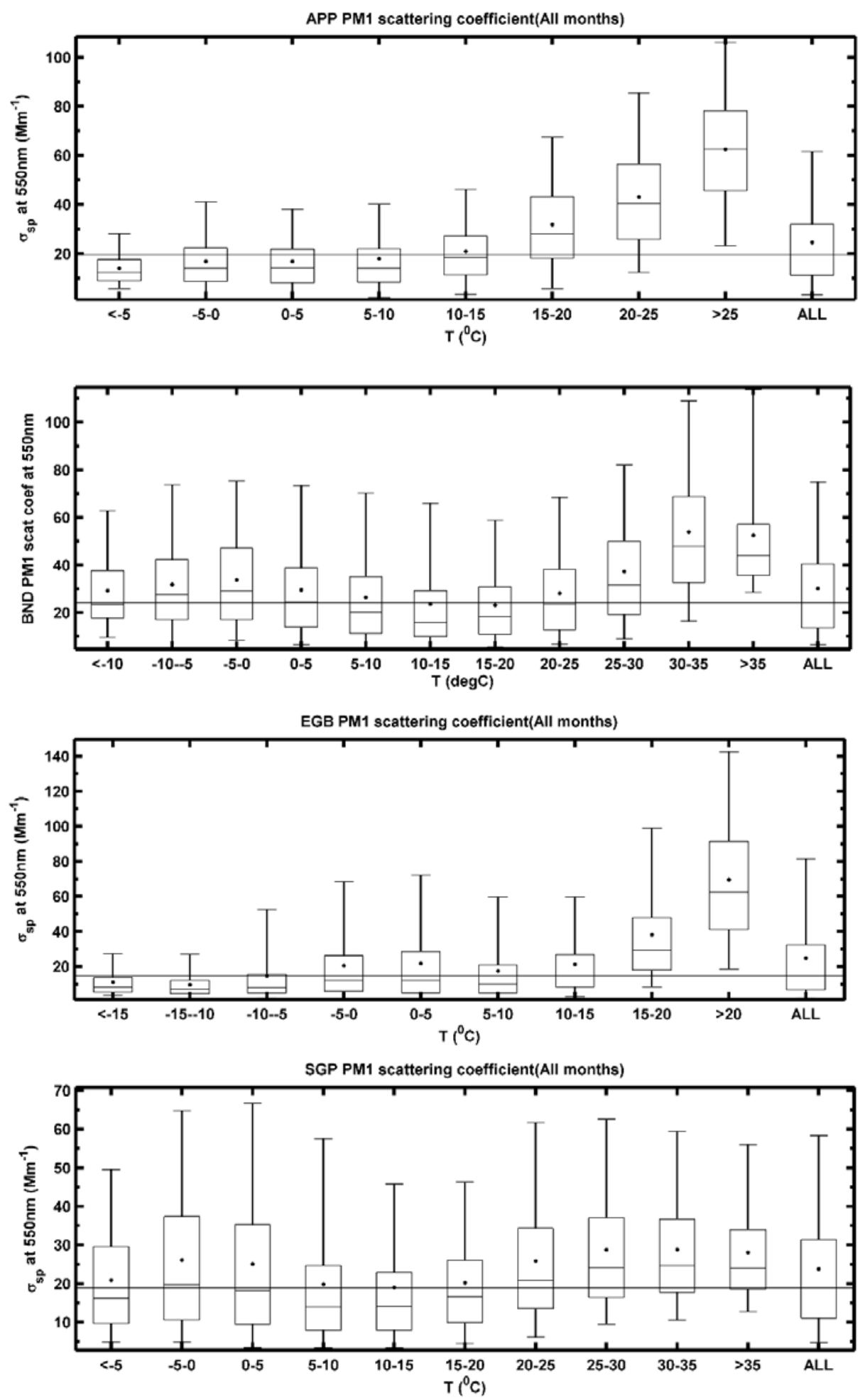

Figure S5. Boxplots of PM1 $\sigma_{\mathrm{sp}}$ at $550 \mathrm{~nm}$ versus temperature for 2010-2013 time period at APP, BND, EGB, and SGP. 

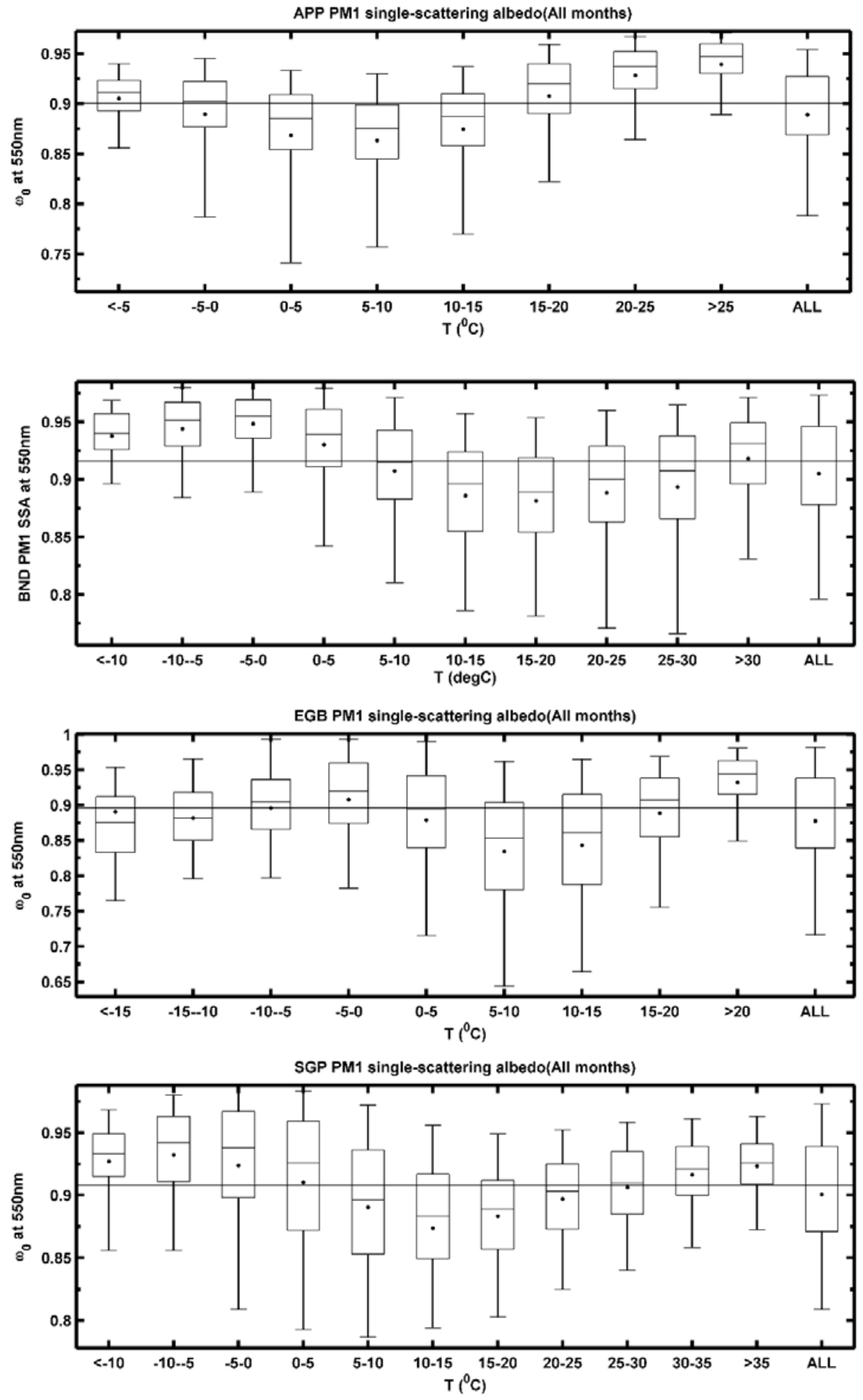

Figure S6. Boxplots of PM1 $\omega_{0}$ at $550 \mathrm{~nm}$ versus temperature for 2010-2013 time period at APP, BND, EGB, and SGP. 

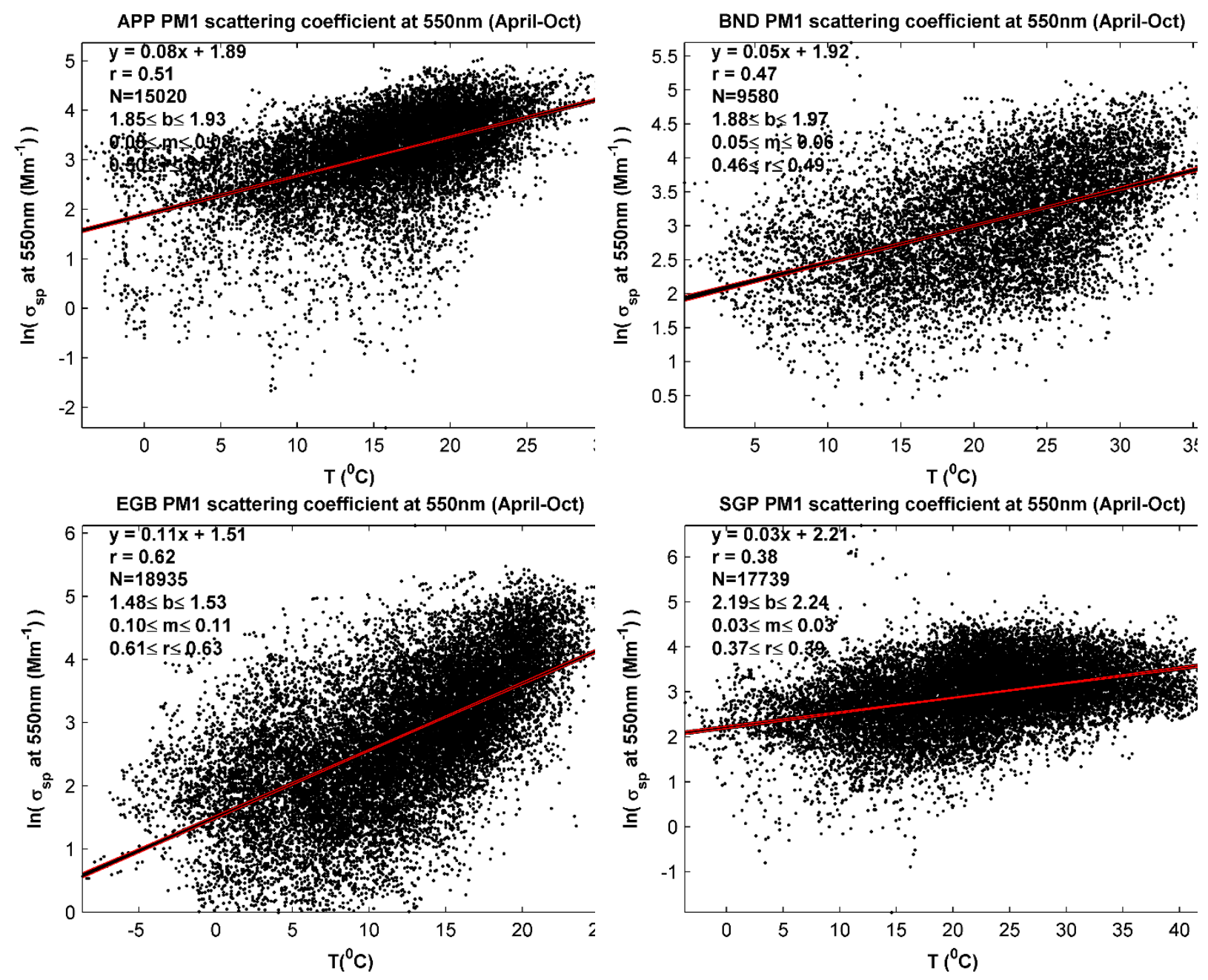

Figure. S7. Correlation of $\ln \left(\sigma_{\mathrm{sp}}\right)$ versus T for PM1 aerosol at APP, BND, EGB, and SGP over the months April-October. 
(a)

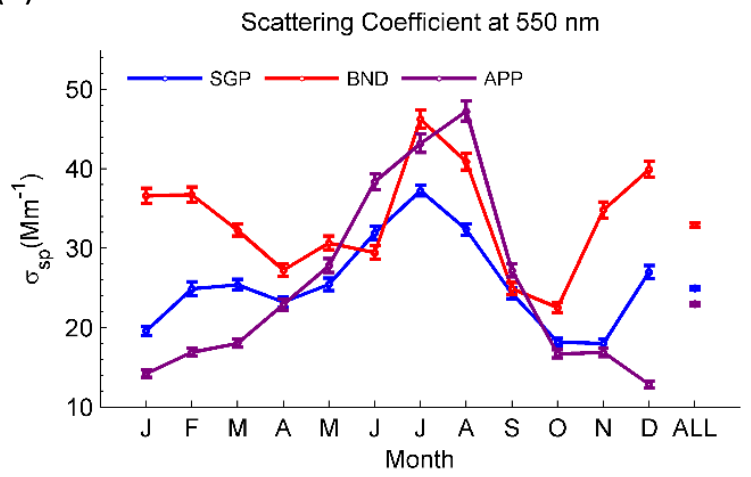

(c)

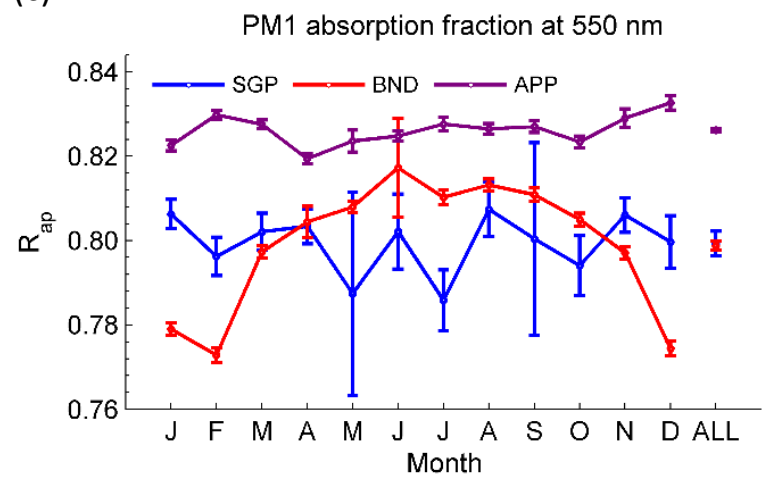

(e)

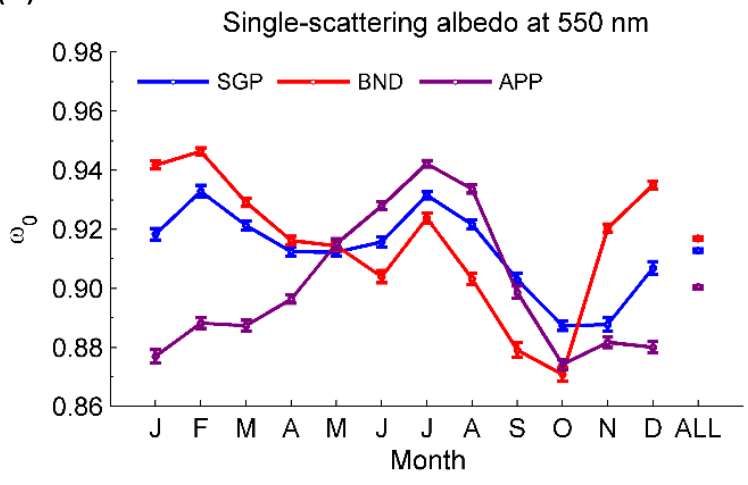

(g)

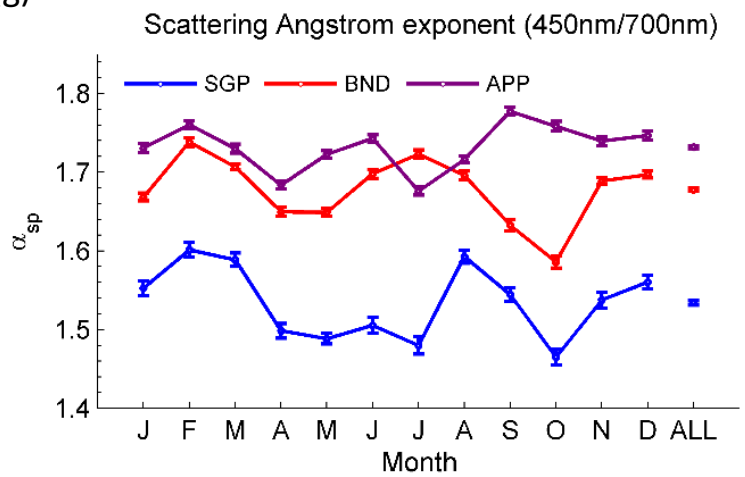

(b)

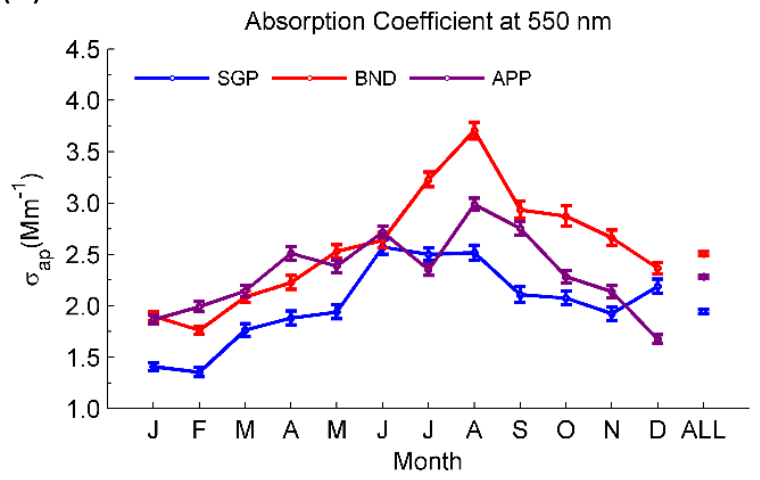

(d)

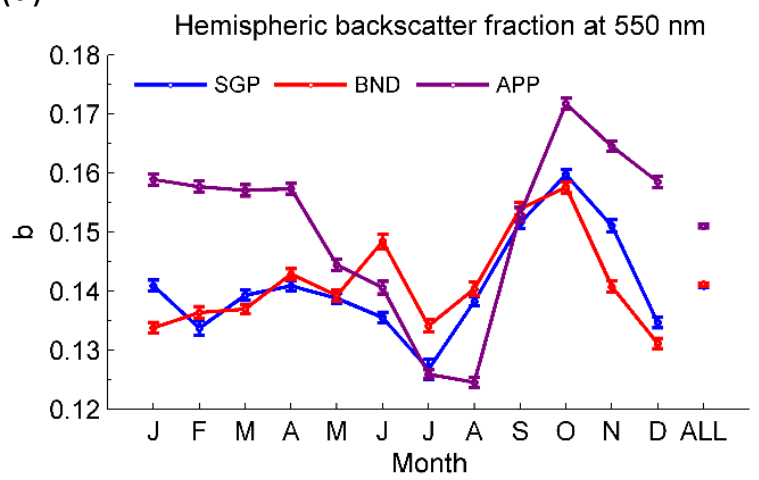

(f)

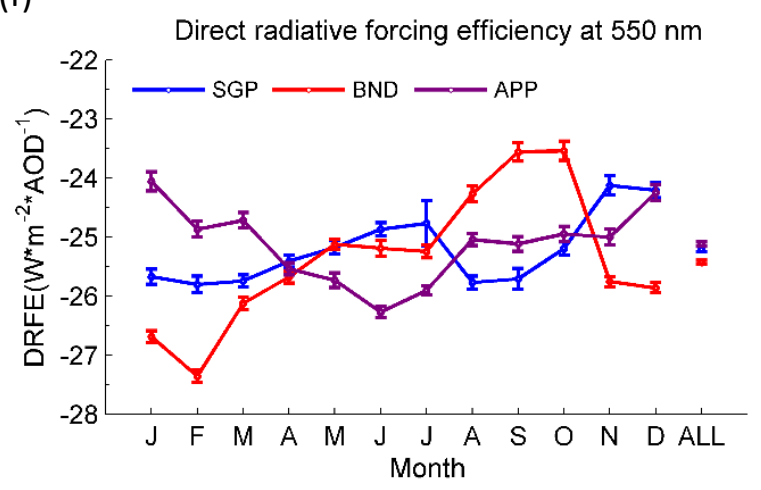

(h)

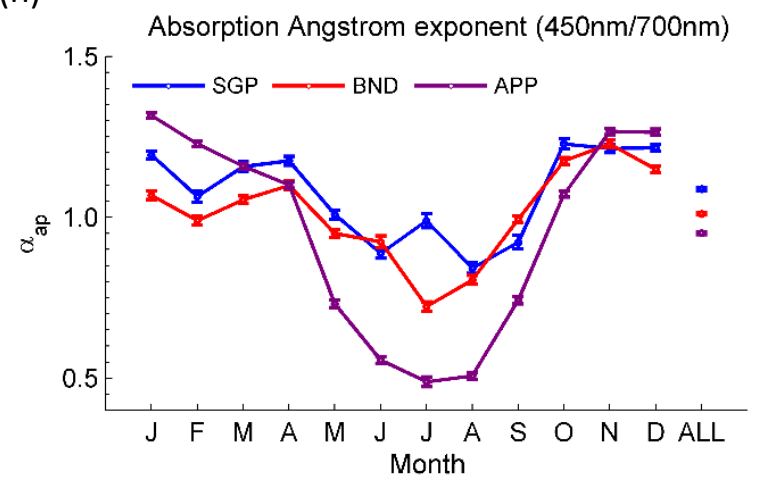

Figure S8. Annual cycle of PM10 AOPs for APP, BND, and SGP over the 2010-2013 period: (a) geometric mean $\sigma_{\mathrm{sp}}$; (b) geometric mean $\sigma_{\mathrm{ap}}$; (c) mean $\mathrm{R}_{\mathrm{ap}}$; (d) mean b; (e) mean $\omega_{0}$; (f) mean DRFE; (g) mean $\alpha_{\mathrm{sp}}$; h) mean $\alpha_{\mathrm{ap}}(450 / 700 \mathrm{~nm})$. The values corresponding to 'ALL' are geometric mean or mean values for the entire 2010-2013 period (all months). Error bars represent 95\% confidence intervals of mean values. 
(a)

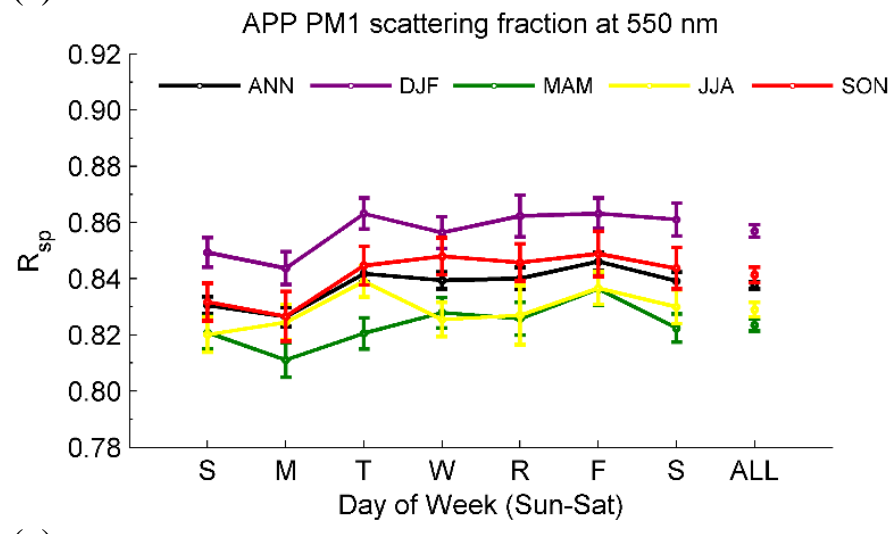

(c)

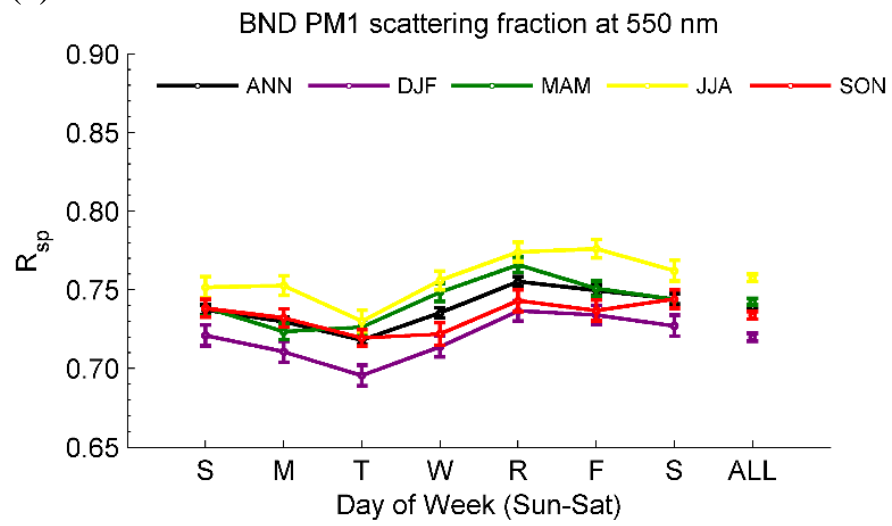

(e)

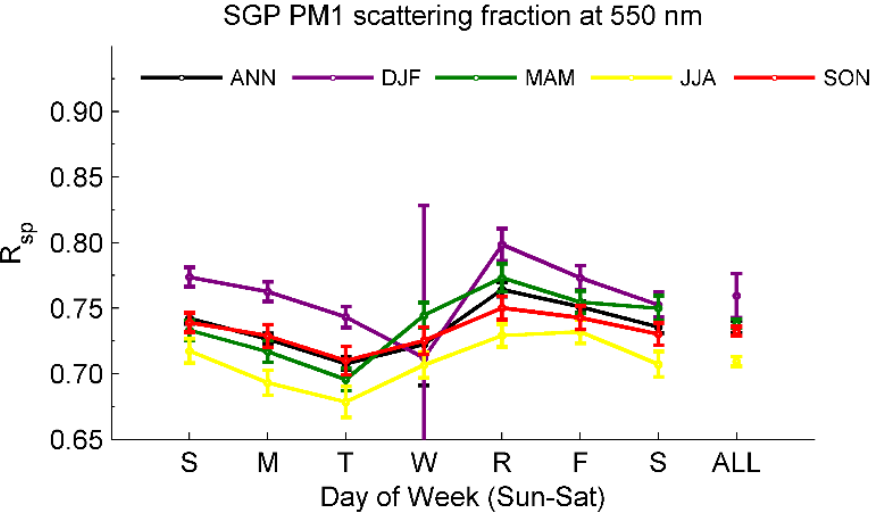

(b)

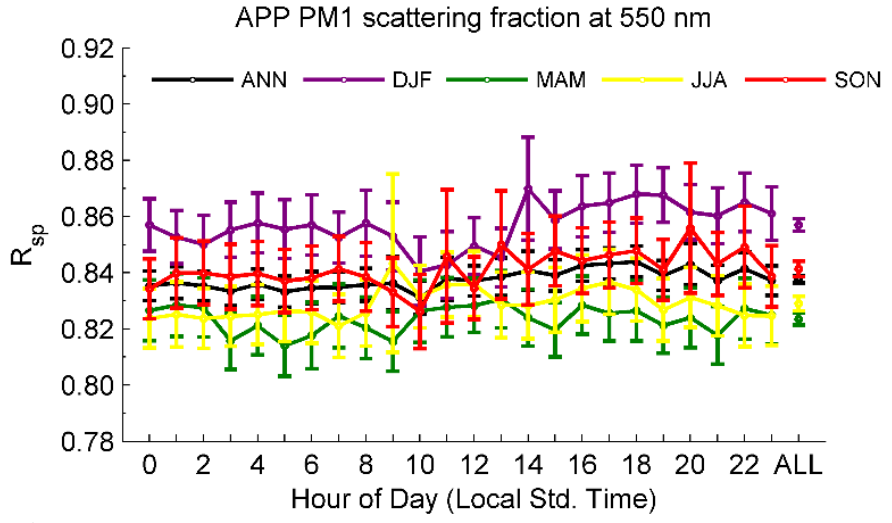

(d)

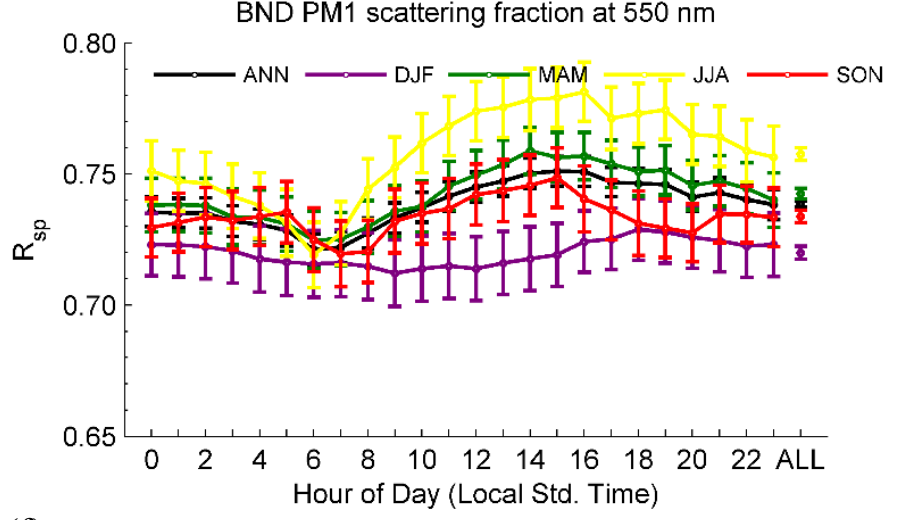

(f)

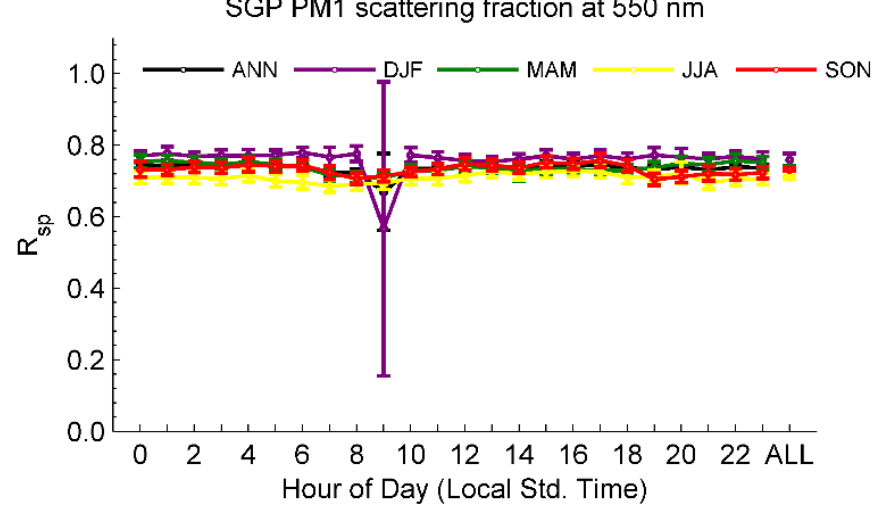

Figure S9. Weekly and diurnal cycles of mean $\mathrm{R}_{\mathrm{sp}}$ over full years (ANN traces) and for winter (DJF), spring (MAM), summer (JJA), and fall (SON) at APP, BND, and SGP over the 2010-2013 period. The value corresponding to the 'ALL' data point of each trace is the mean value over all days of week or over all hours of day. Error bars represent $95 \%$ confidence intervals of mean $\mathrm{R}_{\mathrm{sp}}$ values. 
(a)

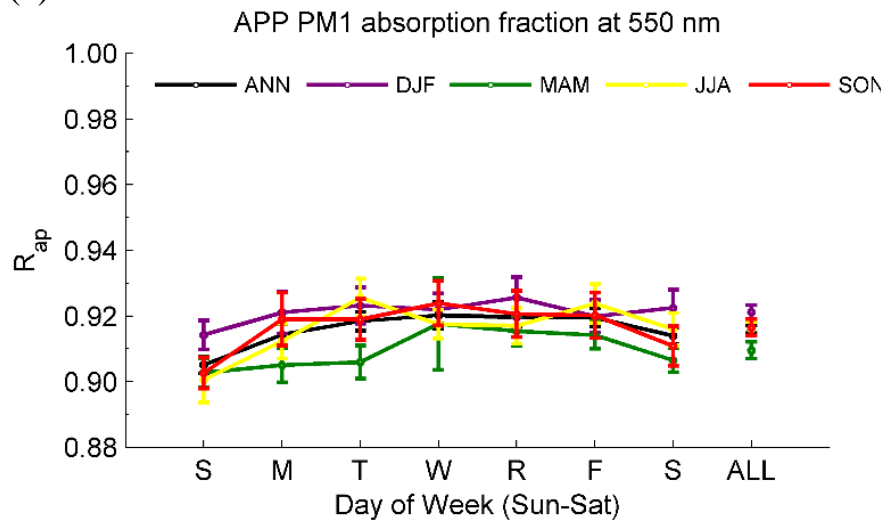

(c)

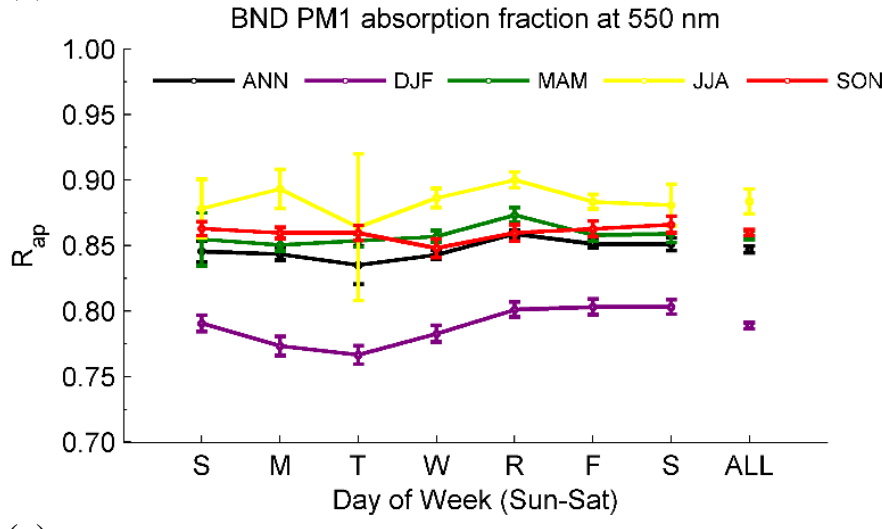

(e)

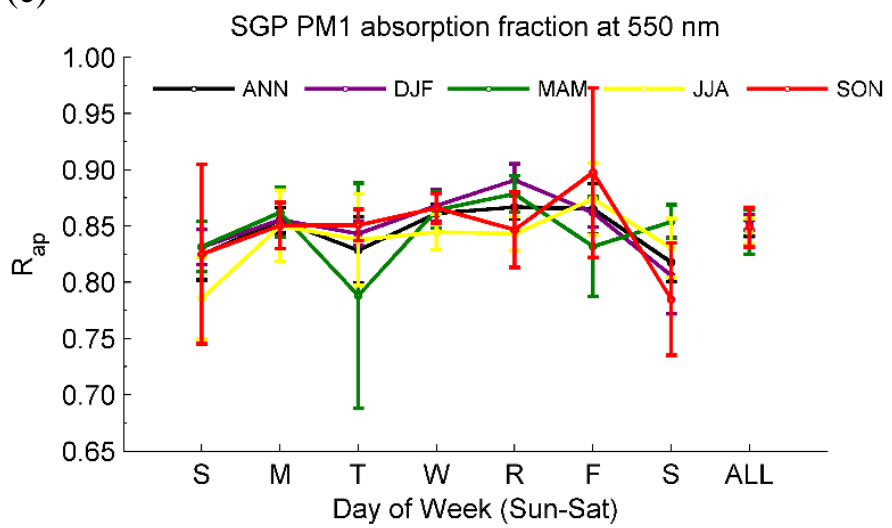

(b)

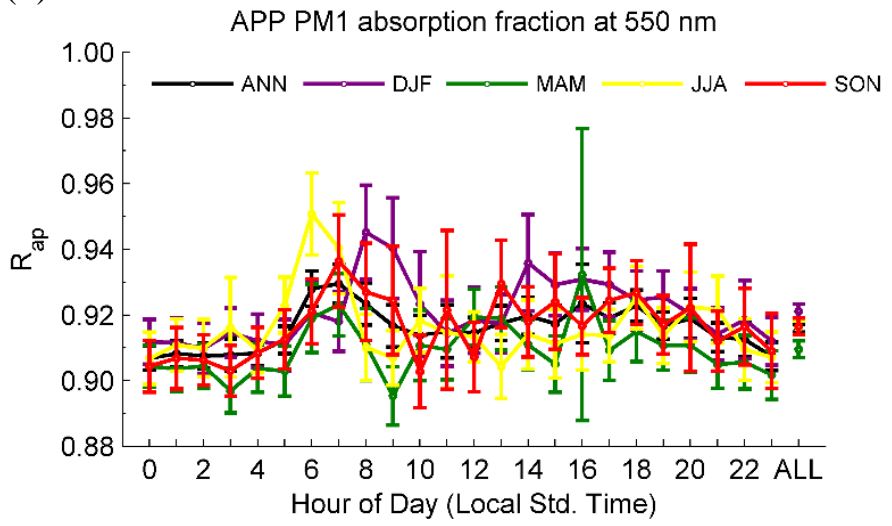

(d)

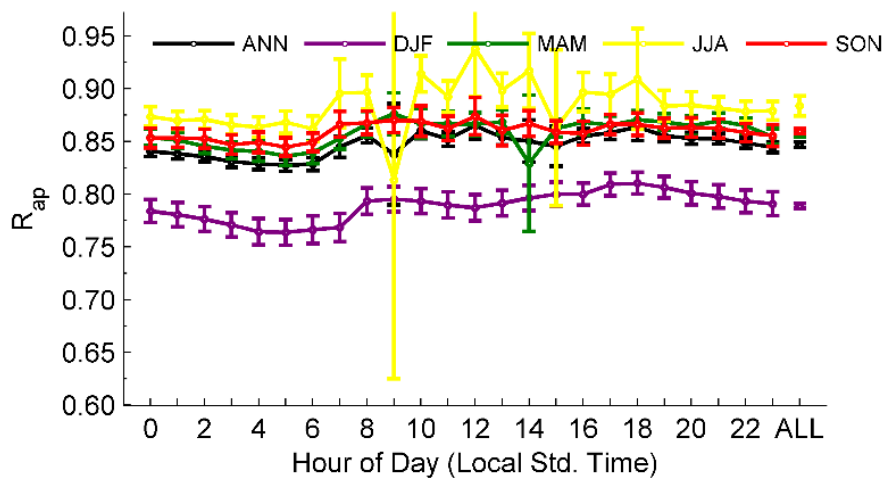

(f)

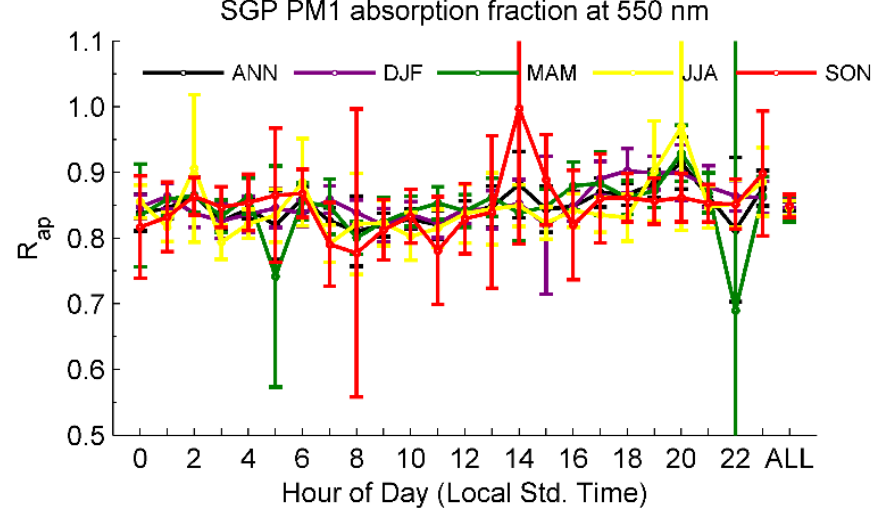

Figure S10. Weekly and diurnal cycles of mean $R_{a p}$ over full years (ANN traces) and for winter (DJF), spring (MAM), summer (JJA), and fall (SON) at APP, BND, and SGP over the 2010-2013 period. The value corresponding to the 'ALL' data point of each trace is the mean value over all days of week or over all hours of day. Error bars represent $95 \%$ confidence intervals of mean $\mathrm{R}_{\mathrm{ap}}$ values. 
(a)

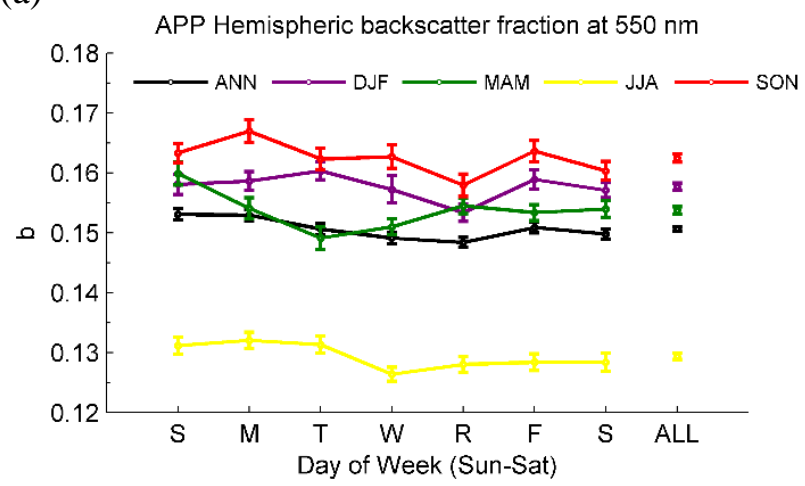

(c)

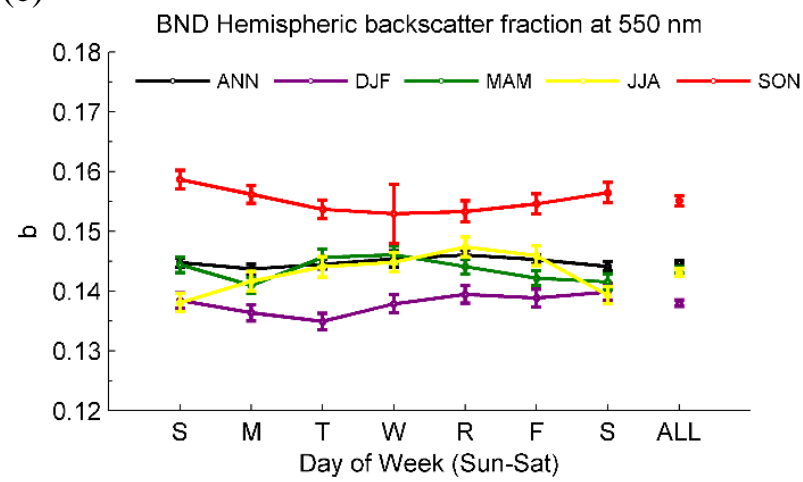

(e)

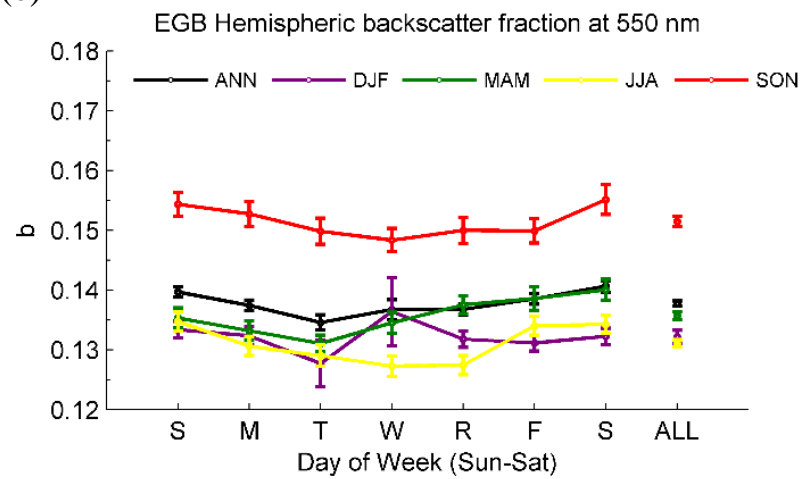

(g)

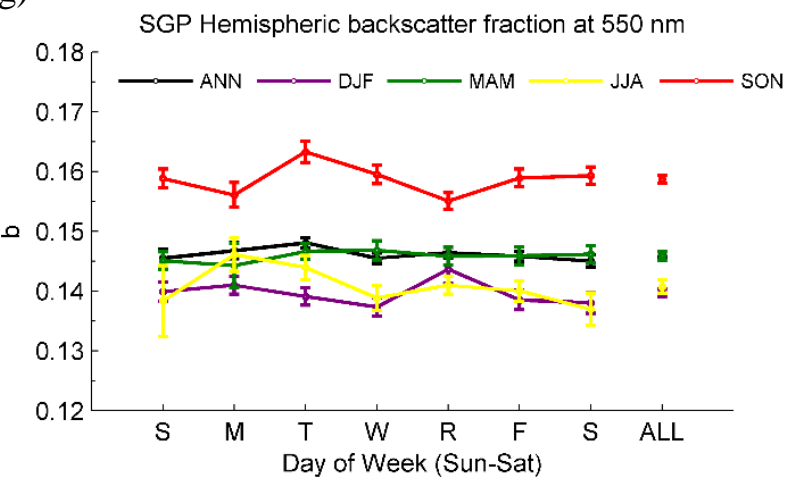

(b)

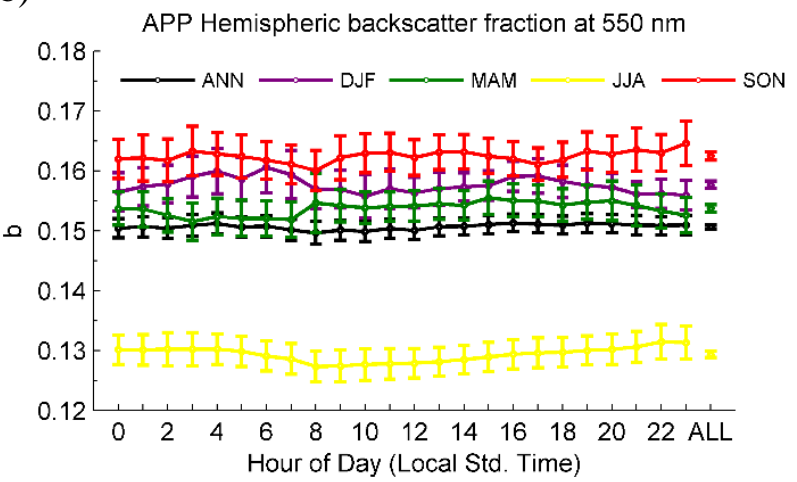

(d)

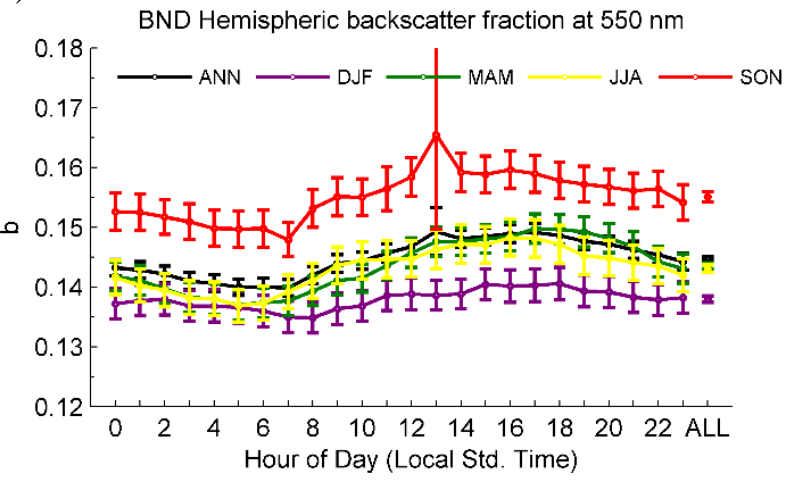

(f)

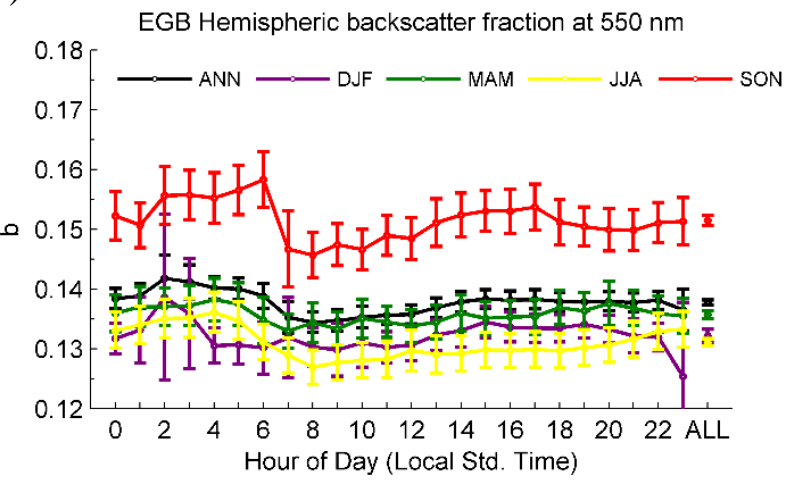

(h)

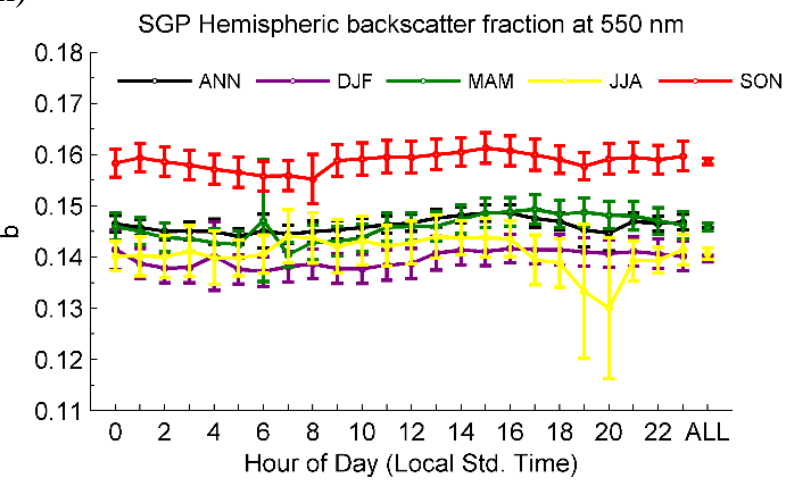

Figure S11. Weekly and diurnal cycles of mean PM1 b over full years (ANN traces) and for winter (DJF), spring (MAM), summer (JJA), and fall (SON) at APP, BND, EGB, and SGP over the 2010-2013 period. The value corresponding to the 'ALL' data point of each trace is the mean value over all days of week or over all hours of day. Error bars represent 95\% confidence intervals of mean b values. 
(a)

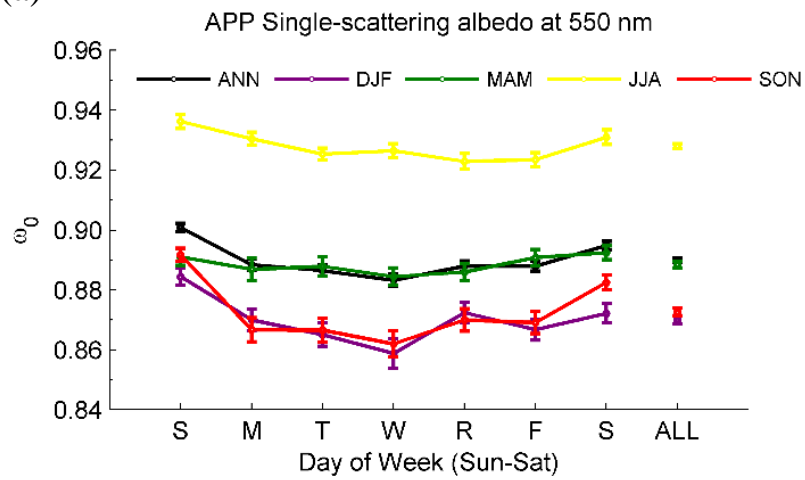

(c)

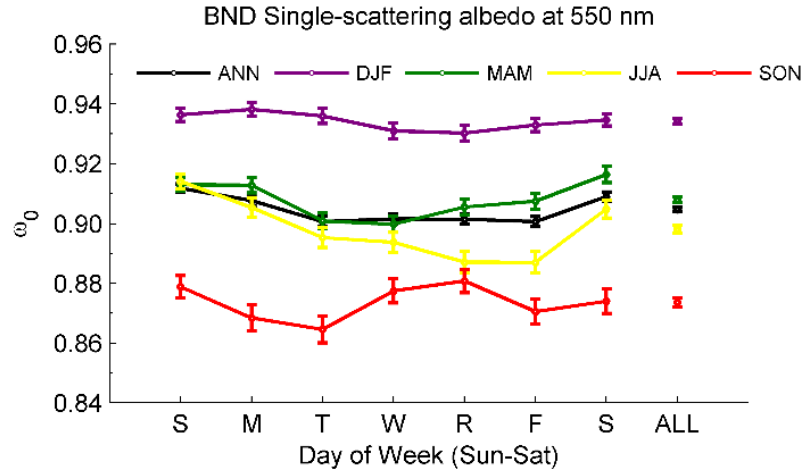

(e)

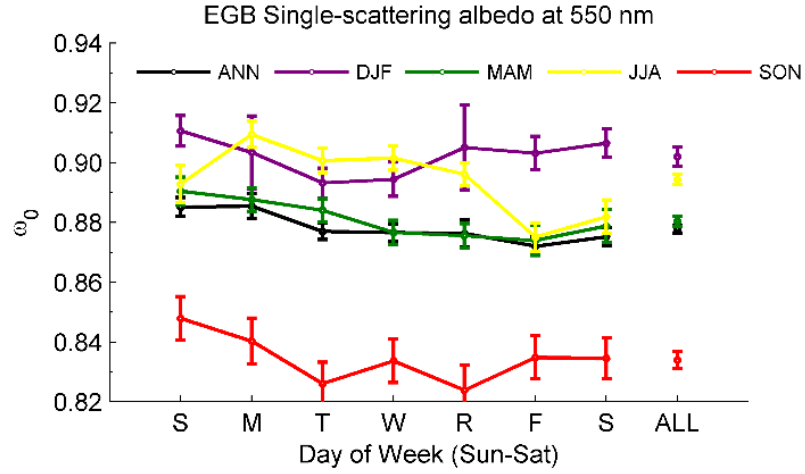

(g)

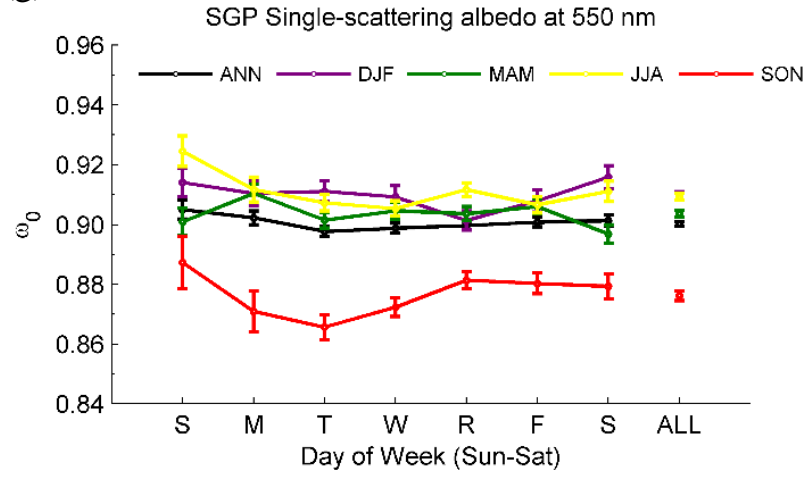

(b)

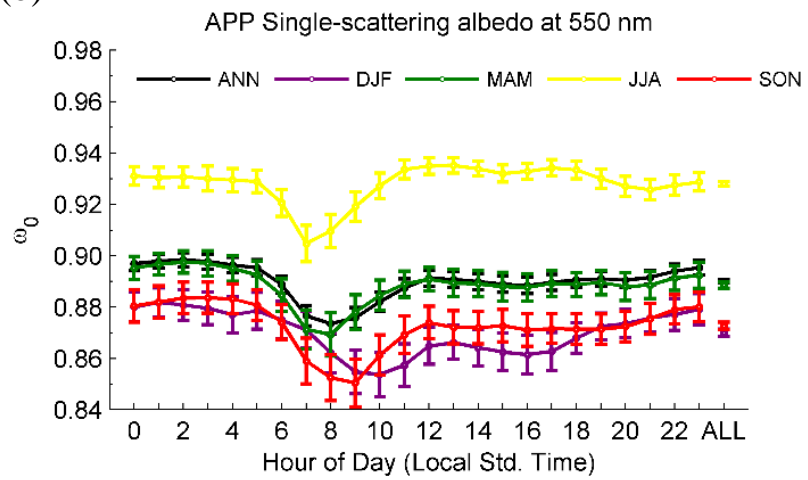

(d)

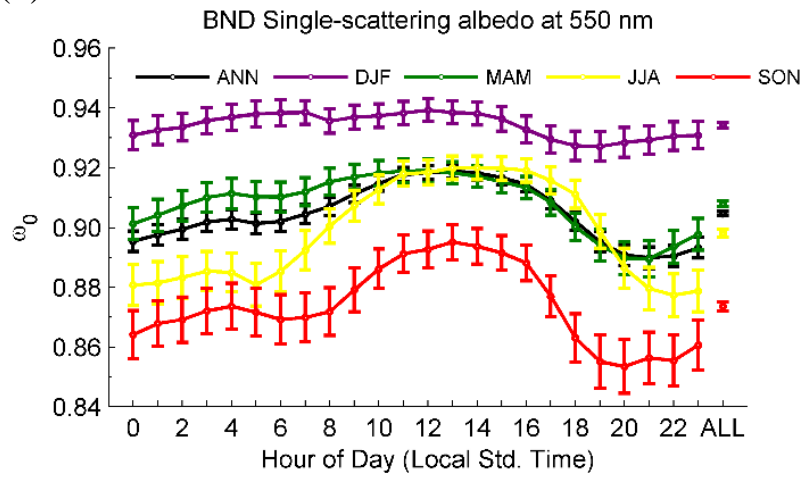

(f)

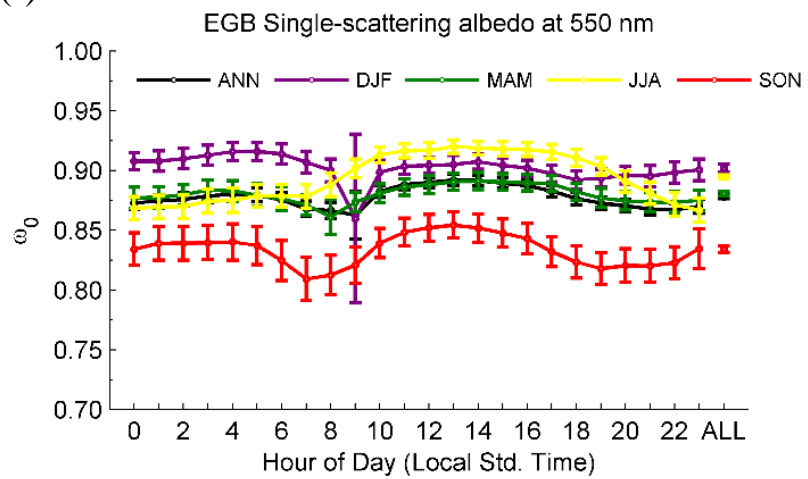

(h)

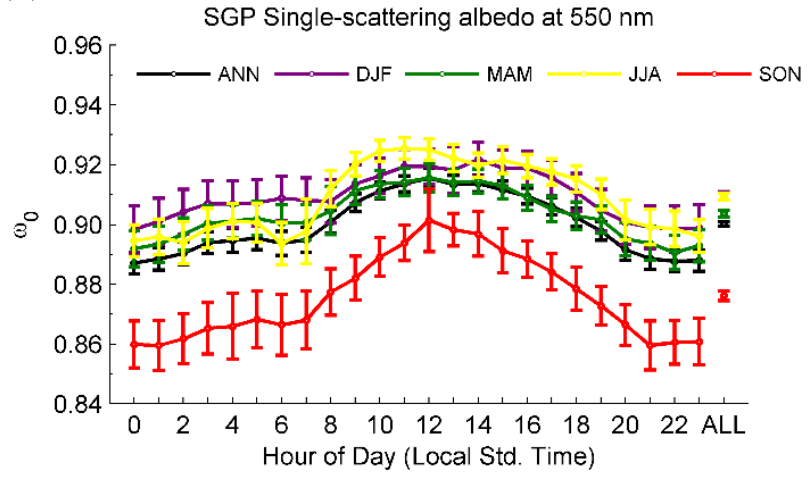

Figure S12. Weekly and diurnal cycles of mean PM1 $\omega_{0}$ over full years (ANN traces) and for winter (DJF), spring (MAM), summer (JJA), and fall (SON) at APP, BND, EGB, and SGP over the 2010-2013 period. The value corresponding to the 'ALL' data point of each trace is the mean value over all days of week or over all hours of day. Error bars represent 95\% confidence intervals of mean $\omega_{0}$ values. 
(a)

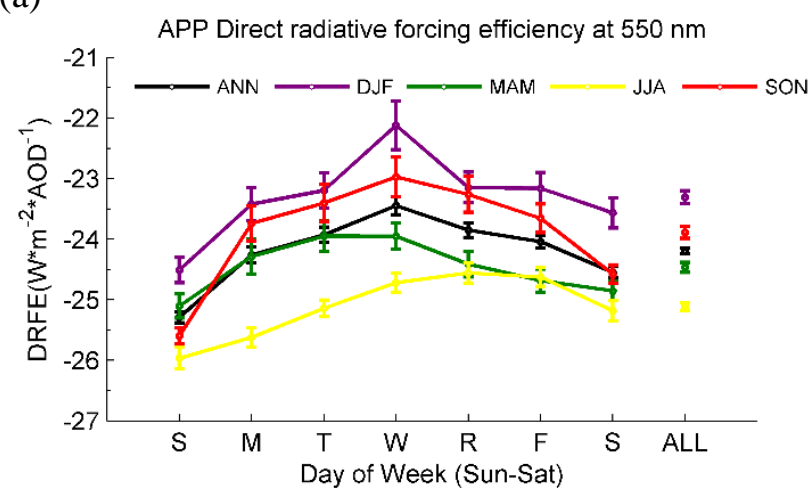

(c)

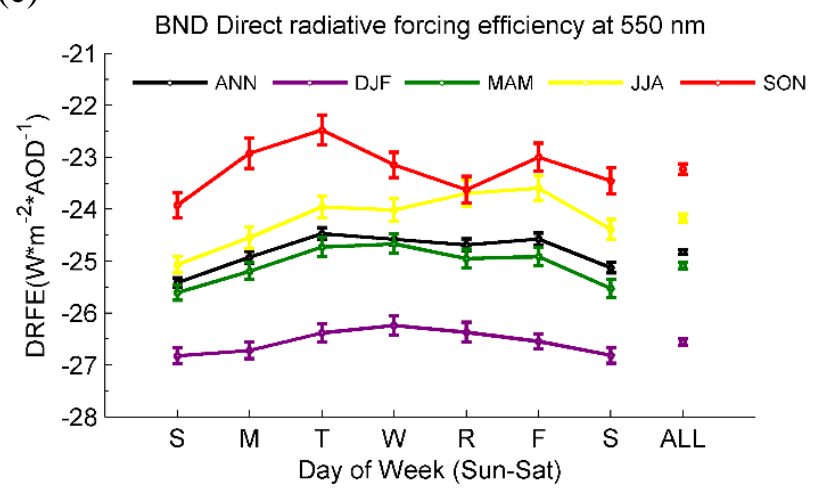

(e)

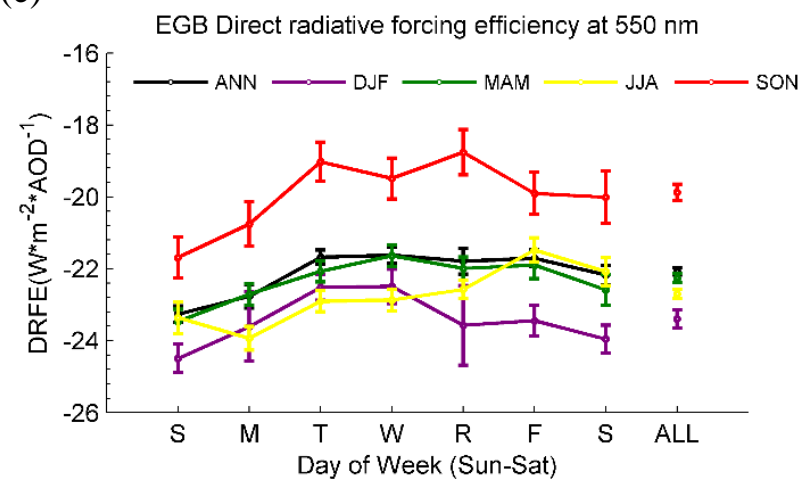

(g)

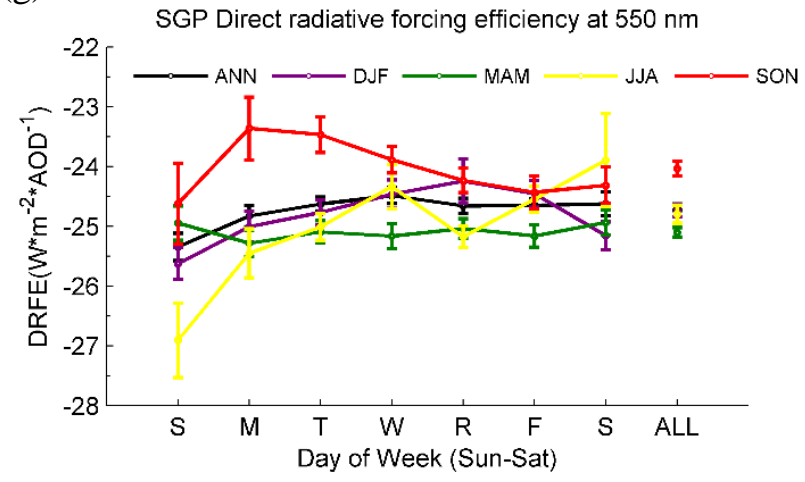

(b)

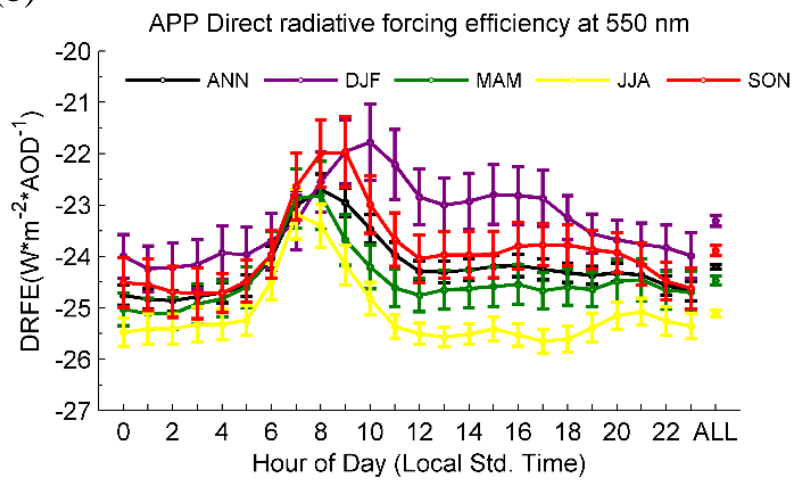

(d)

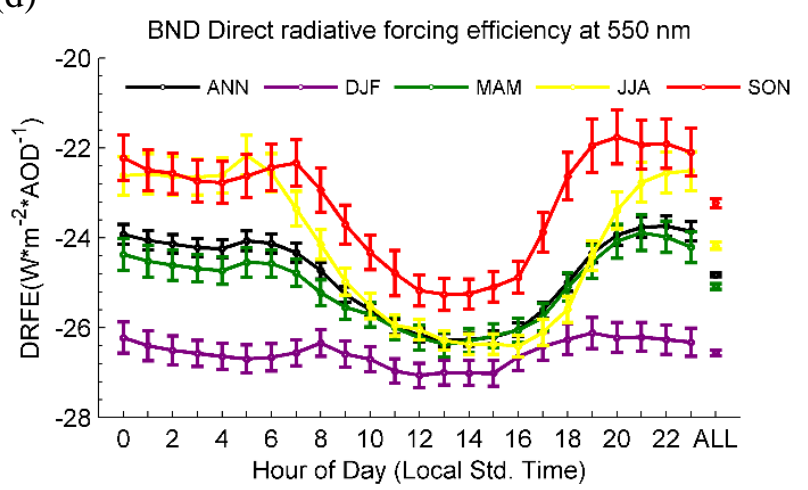

(f)

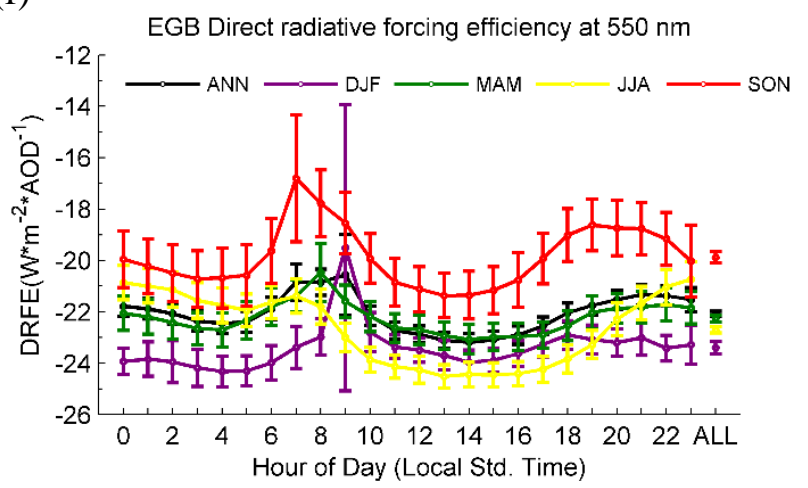

(h)

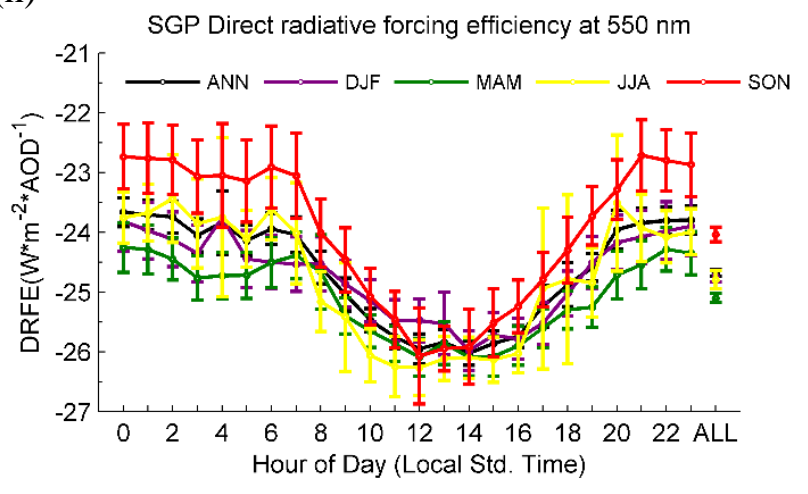

Figure S13. Weekly and diurnal cycles of mean PM1 DRFE over full years (ANN traces) and for winter (DJF), spring (MAM), summer (JJA), and fall (SON) at APP, BND, EGB, and SGP over the 2010-2013 period. The value corresponding to the 'ALL' data point of each trace is the mean value over all days of week or over all hours of day. Error bars represent 95\% confidence intervals of mean DRFE values. 
(a)

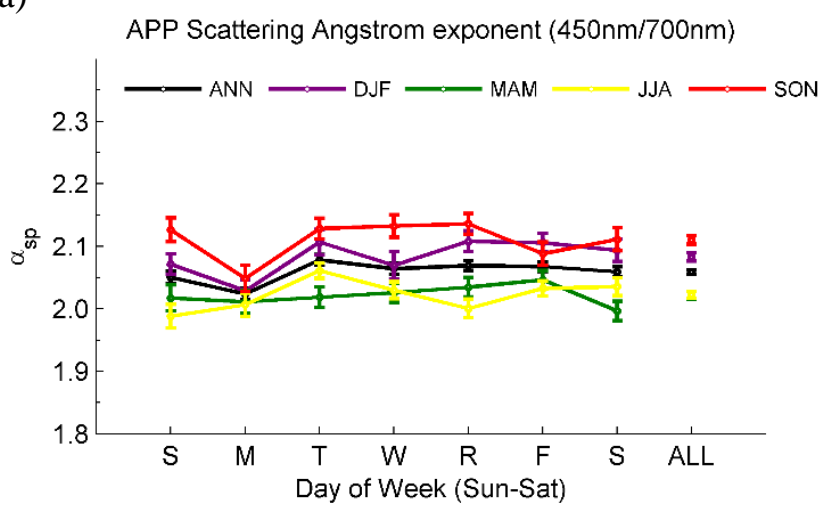

(c)

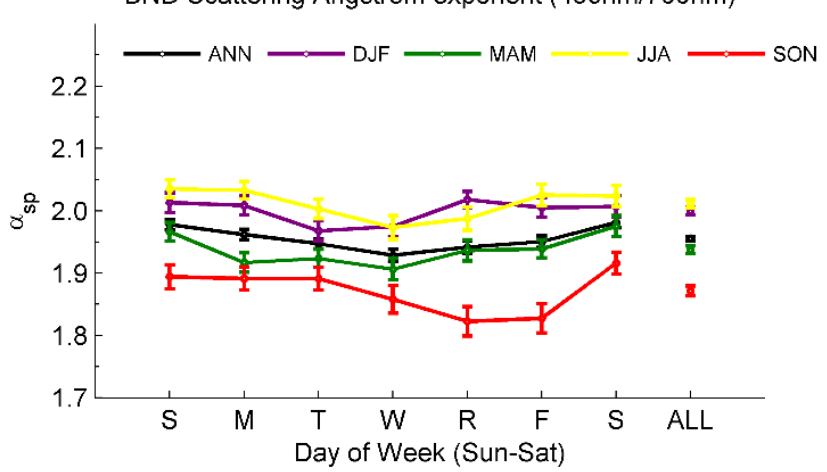

(e)

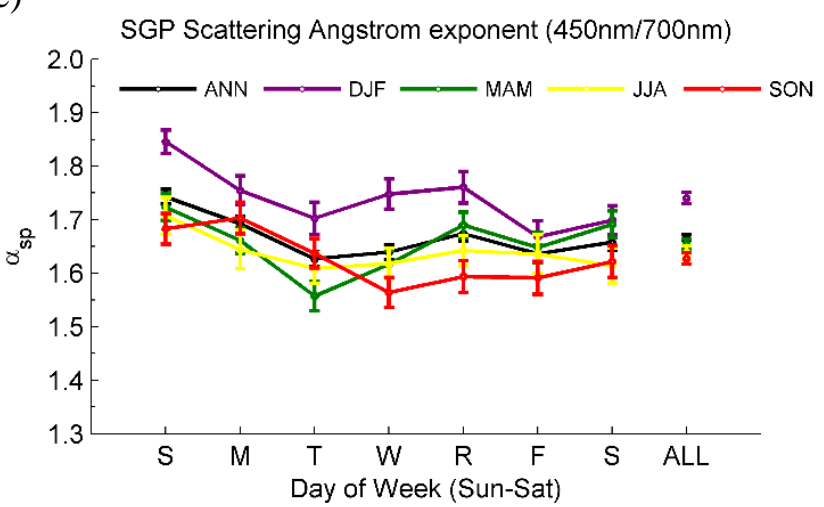

(b)

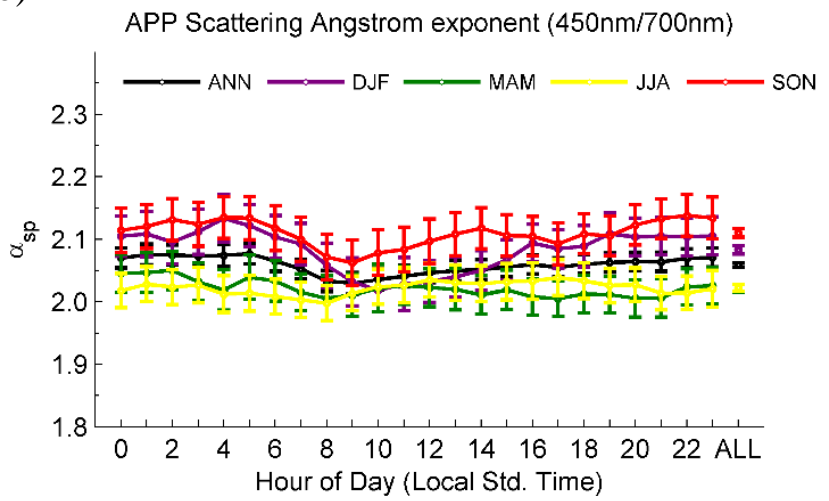

(d)

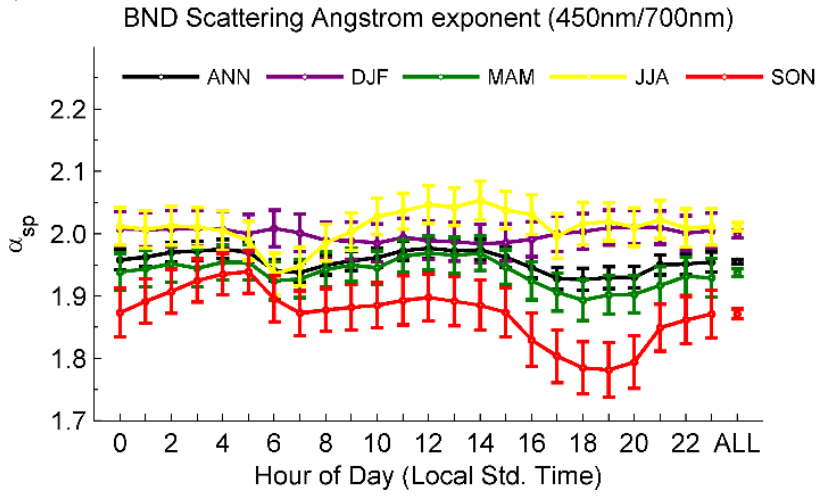

(f)

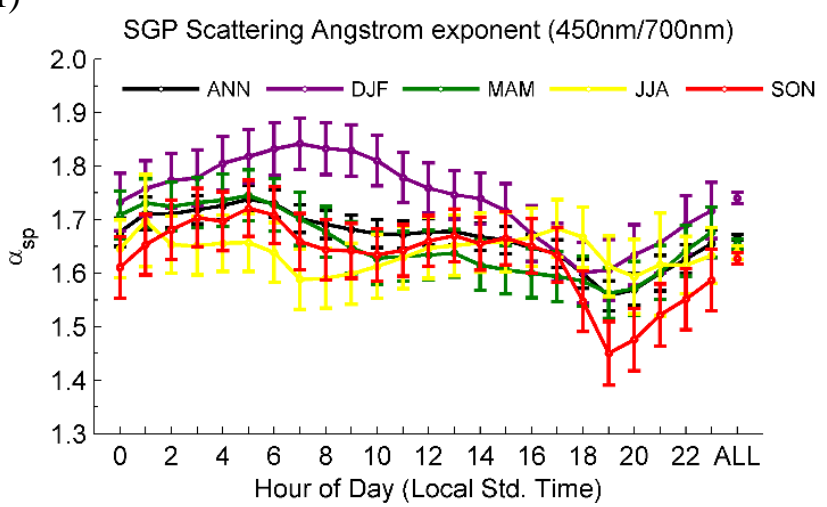

Figure S14. Weekly and diurnal cycles of mean PM10 $\alpha_{\text {sp }}$ over full years (ANN traces) and for winter (DJF), spring (MAM), summer (JJA), and fall (SON) at APP, BND, and SGP over the 2010-2013 period. The value corresponding to the 'ALL' data point of each trace is the mean value over all days of week or over all hours of day. Error bars represent $95 \%$ confidence intervals of mean $\alpha_{\text {sp }}$ values. 
(a)

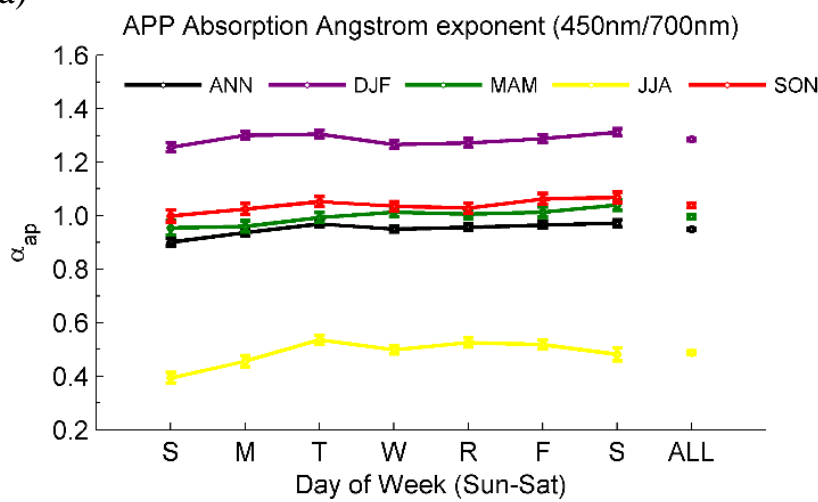

(c)

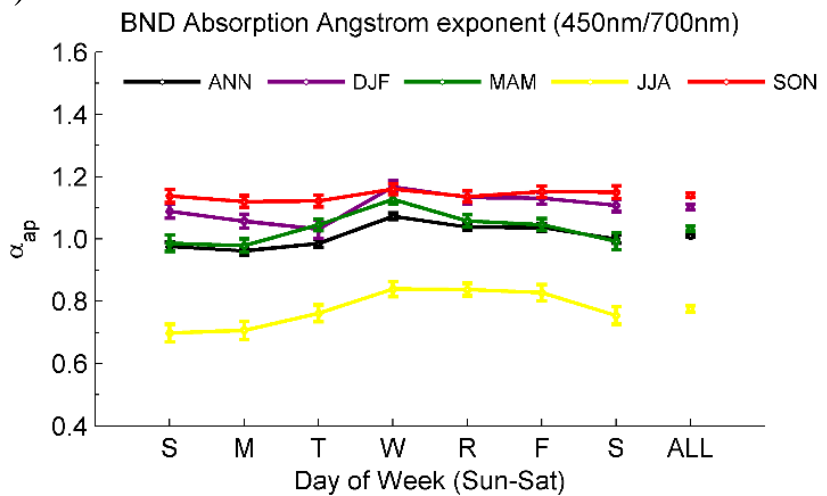

(e)

SGP Absorption Angstrom exponent (450nm/700nm)

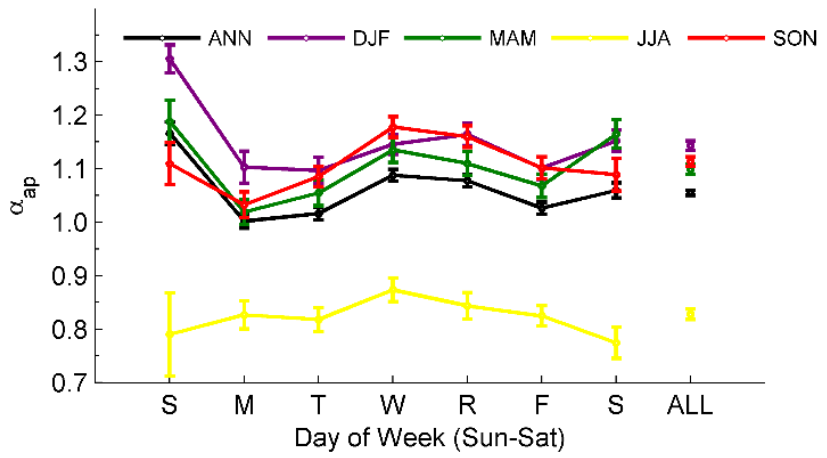

(b)

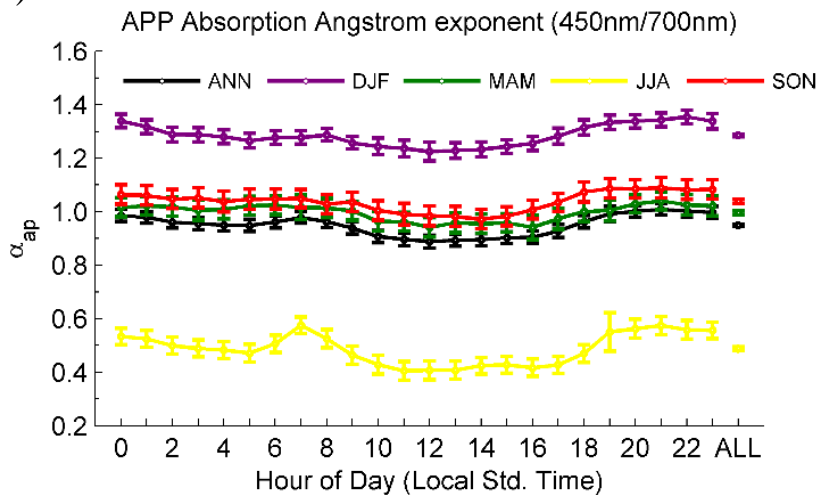

(d)

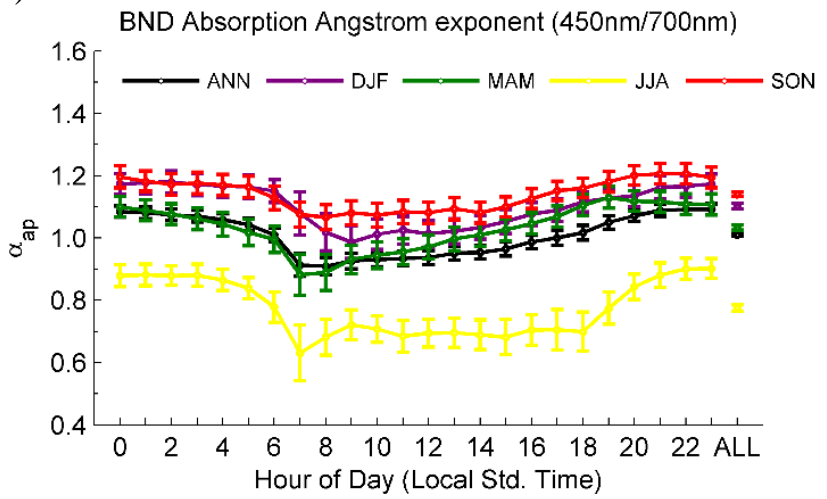

(f)

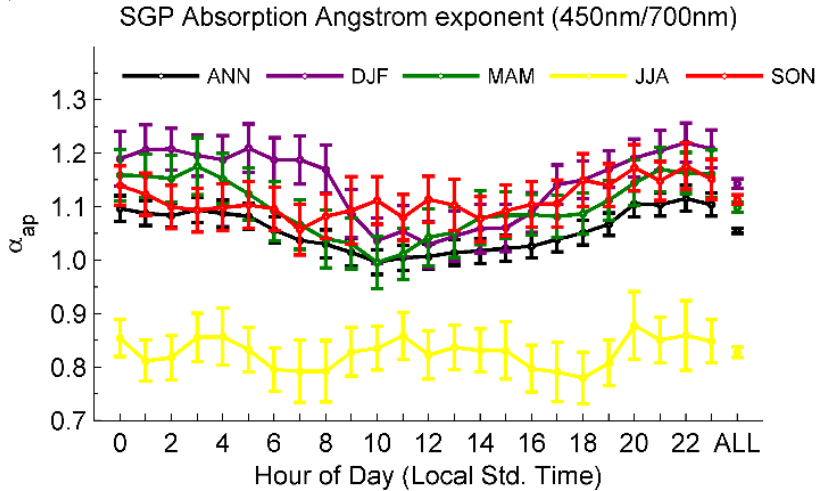

Figure S15. Weekly and diurnal cycles of mean PM1 $\alpha_{\text {ap }}$ over full years (ANN traces) and for winter (DJF), spring (MAM), summer (JJA), and fall (SON) at APP, BND, and SGP over the 2010-2013 period. The value corresponding to the 'ALL' data point of each trace is the mean value over all days of week or over all hours of day. Error bars represent 95\% confidence intervals of mean $\alpha_{a p}$ values. 


\section{APP}

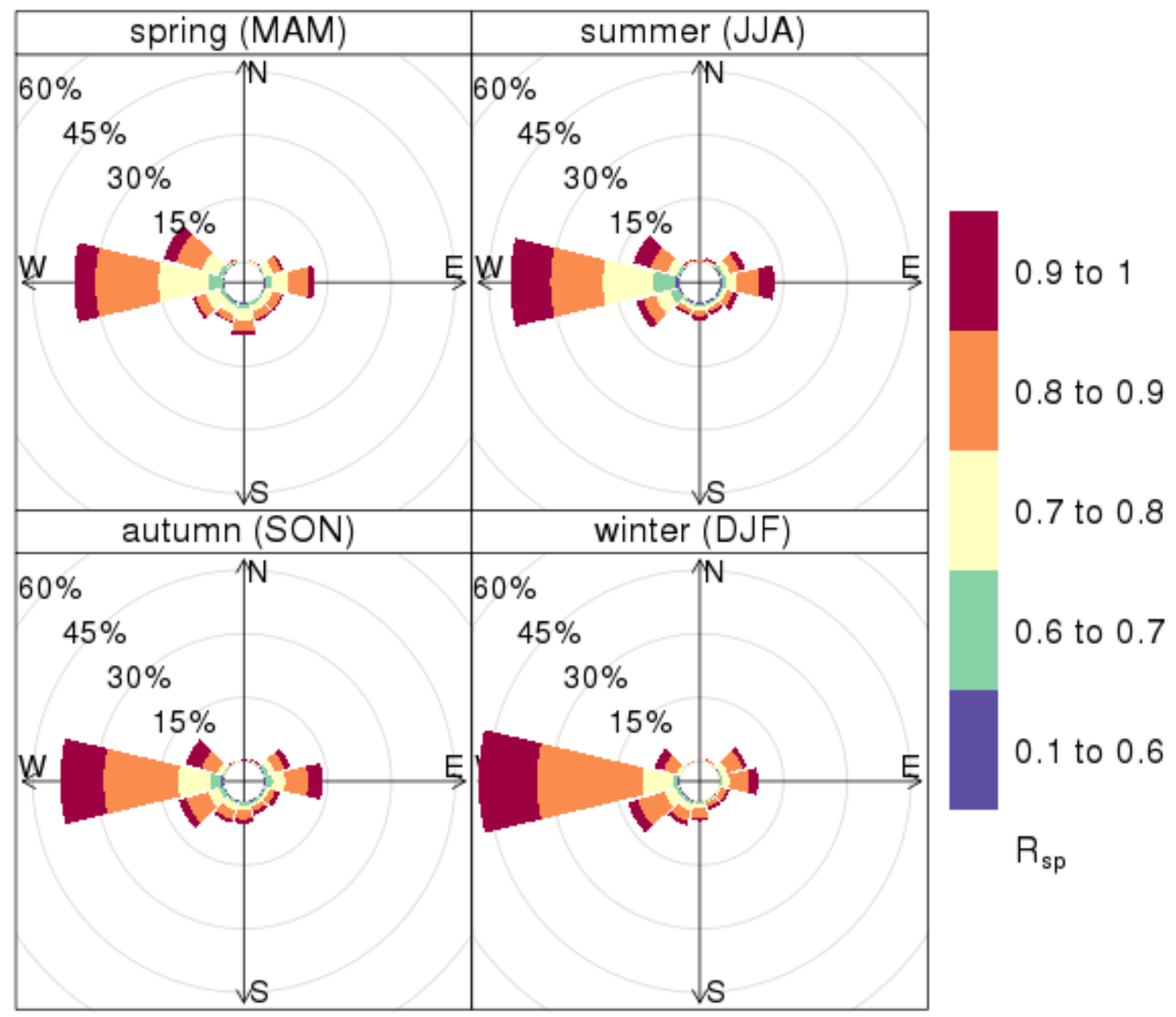

Figure S16 Pollution-rose diagram of $\mathrm{R}_{\mathrm{sp}}$ at APP. The percentages at a given radius represent the percentage of hourly profiles for a given wind sector. 
(a)

\section{APP}

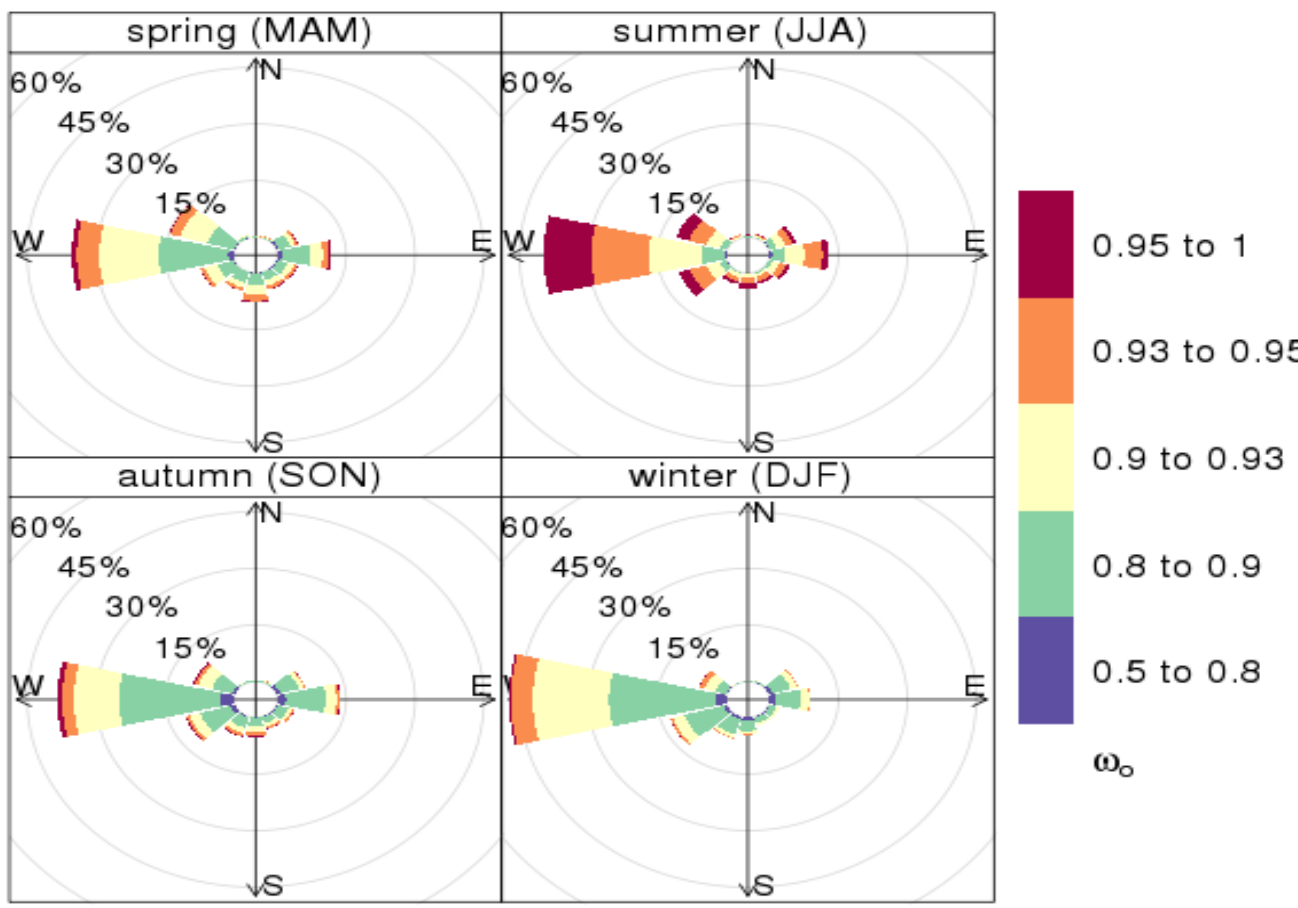

(b)

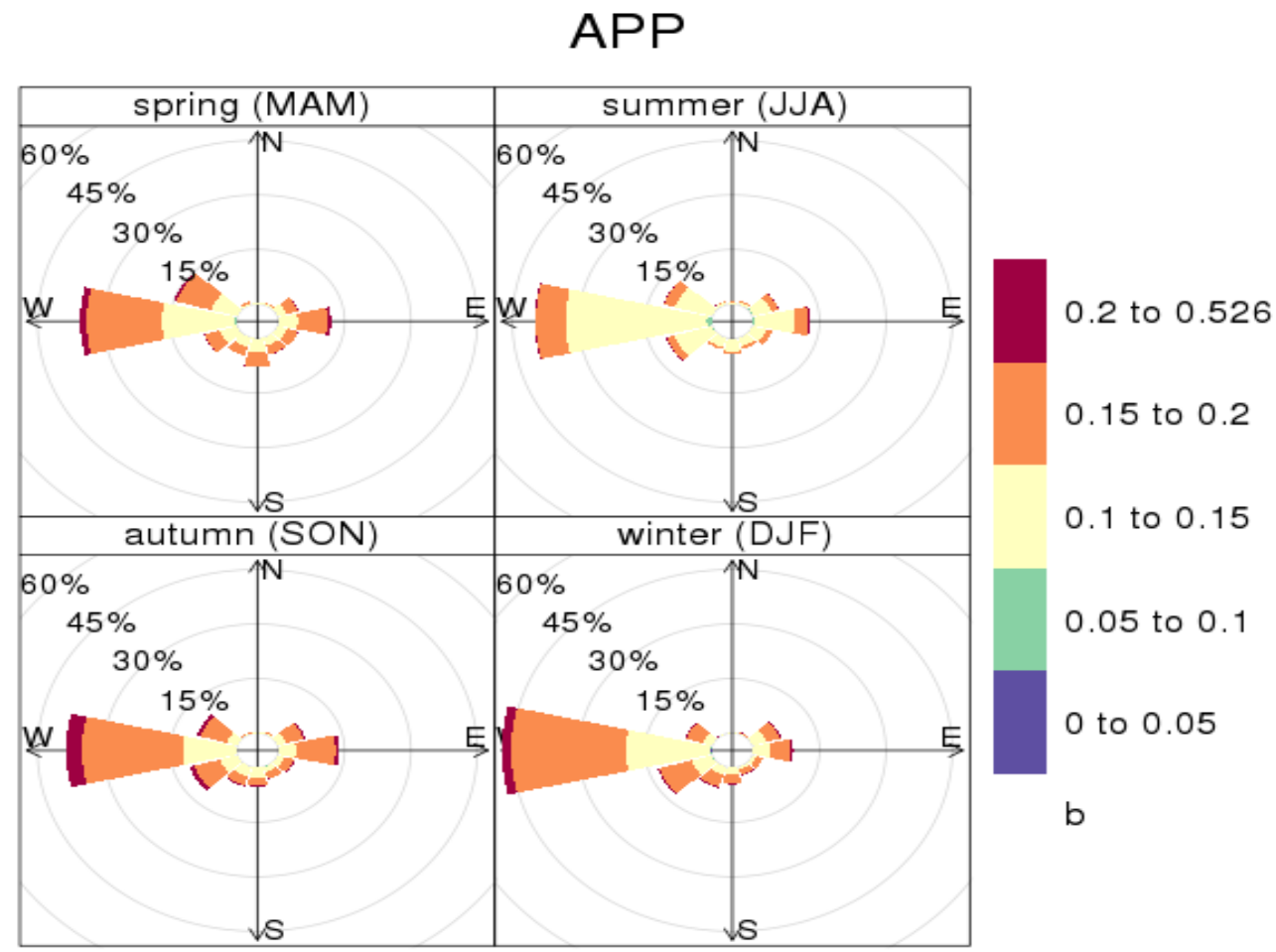

Figure S17 Pollution-rose diagram of PM1 (a) $\omega_{0}$ and (b) b at APP. The percentages at a given radius represent the percentage of hourly profiles for a given wind sector. 


\section{BND}

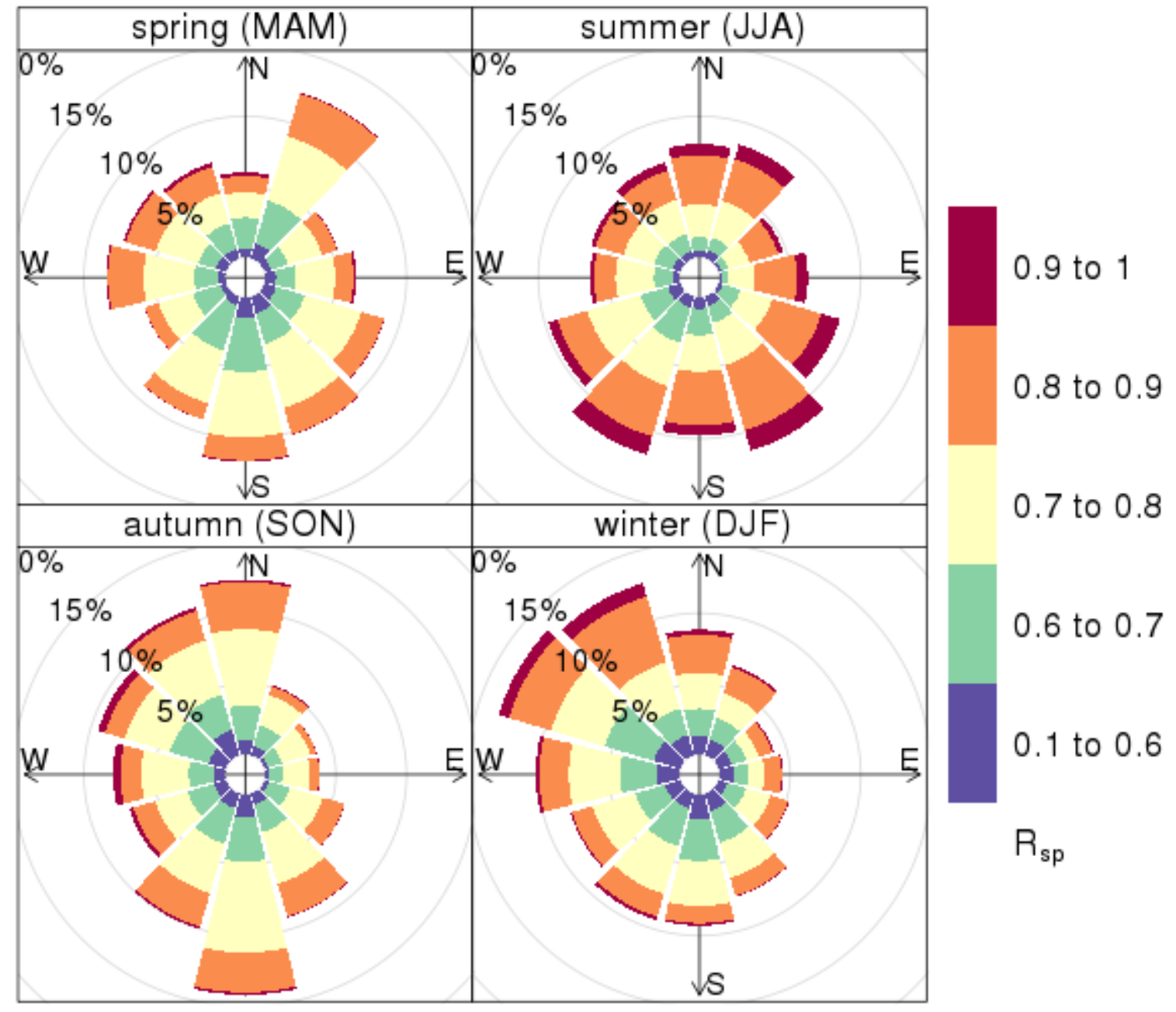

Figure S18 Pollution-rose diagram of $\mathrm{R}_{\mathrm{sp}}$ at BND. The percentages at a given radius represent the percentage of hourly profiles for a given wind sector. 
(a)

\section{BND}

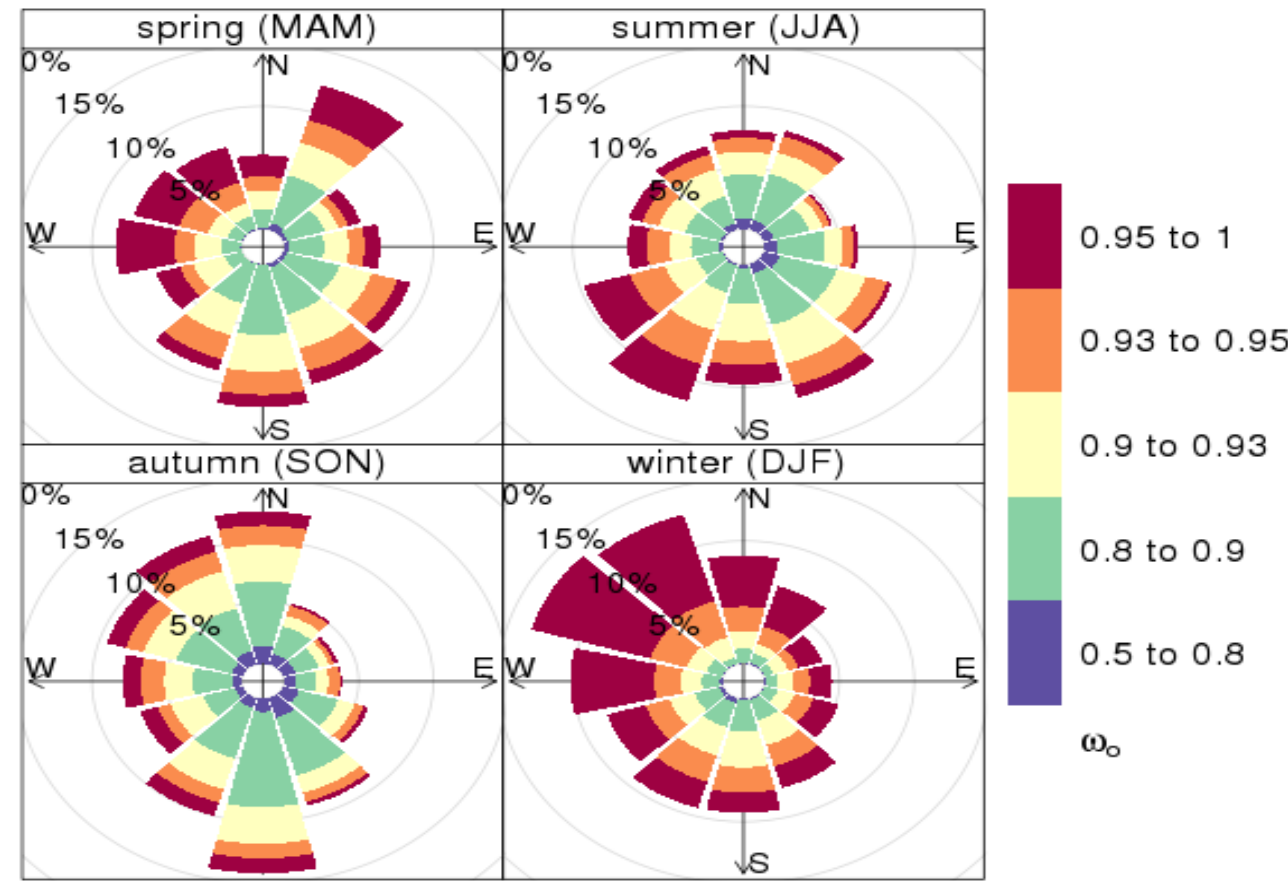

(b)

\section{BND}

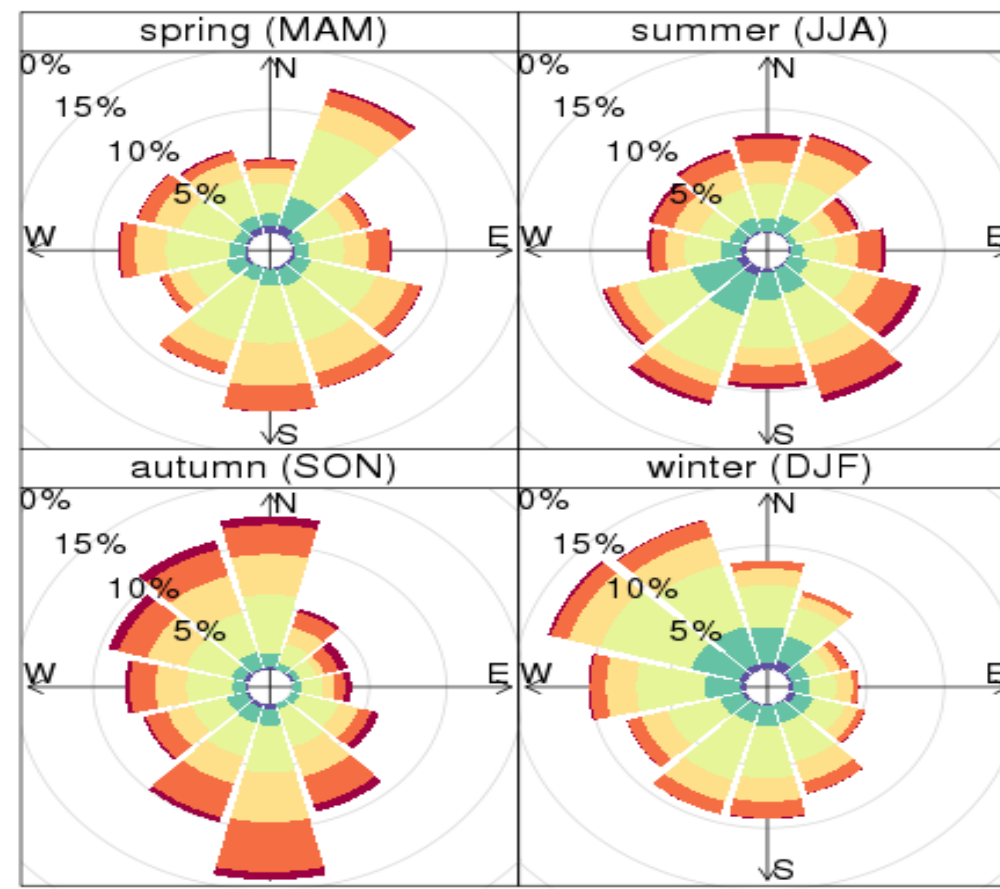

\section{2 to 0.5 \\ 0.17 to 0.2 \\ 0.15 to 0.17 \\ 0.12 to 0.15 \\ 0.1 to 0.12 \\ 0 to 0.1}

b

Figure S19 Pollution-rose diagram of PM1 (a) $\omega_{0}$ and (b) b at BND. The percentages at a given radius represent the percentage of hourly profiles for a given wind sector. 
(a)

\section{EGB}
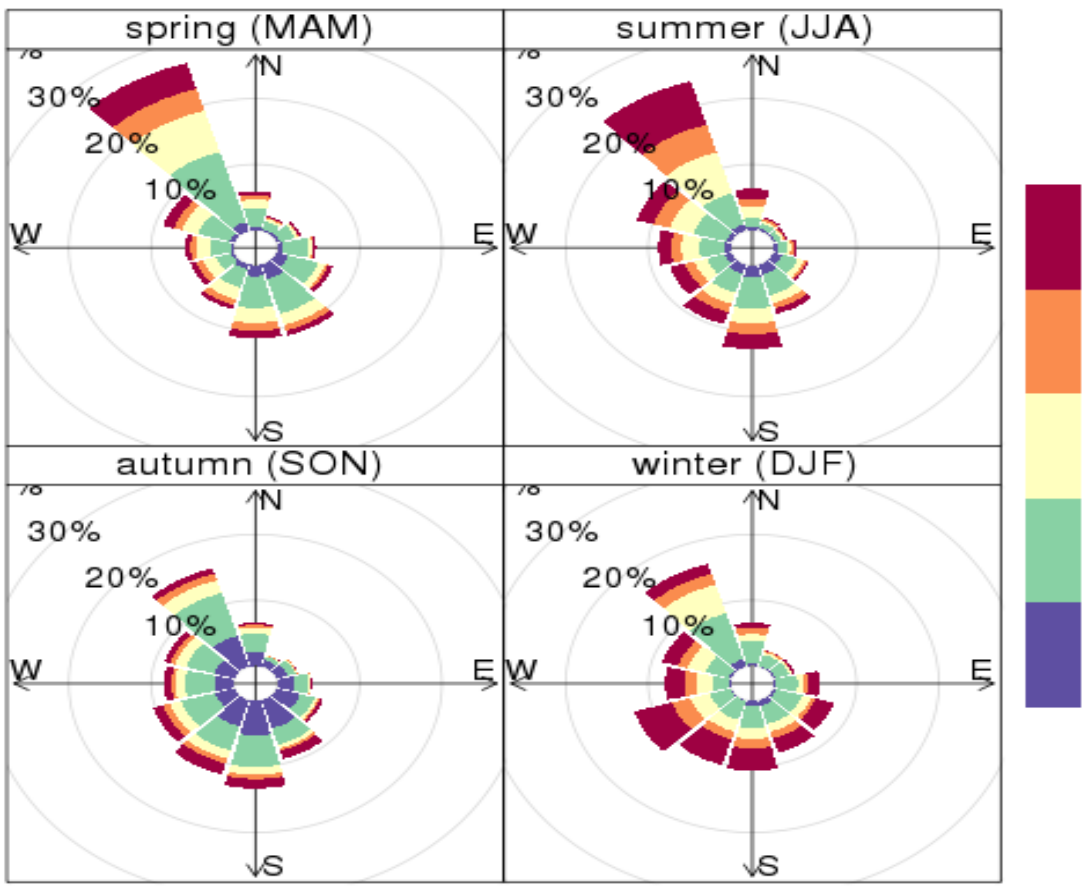

0.95 to 1

0.93 to 0.95

0.9 to 0.93

0.8 to 0.9

0.5 to 0.8

$\omega_{\circ}$

(b)

\section{EGB}

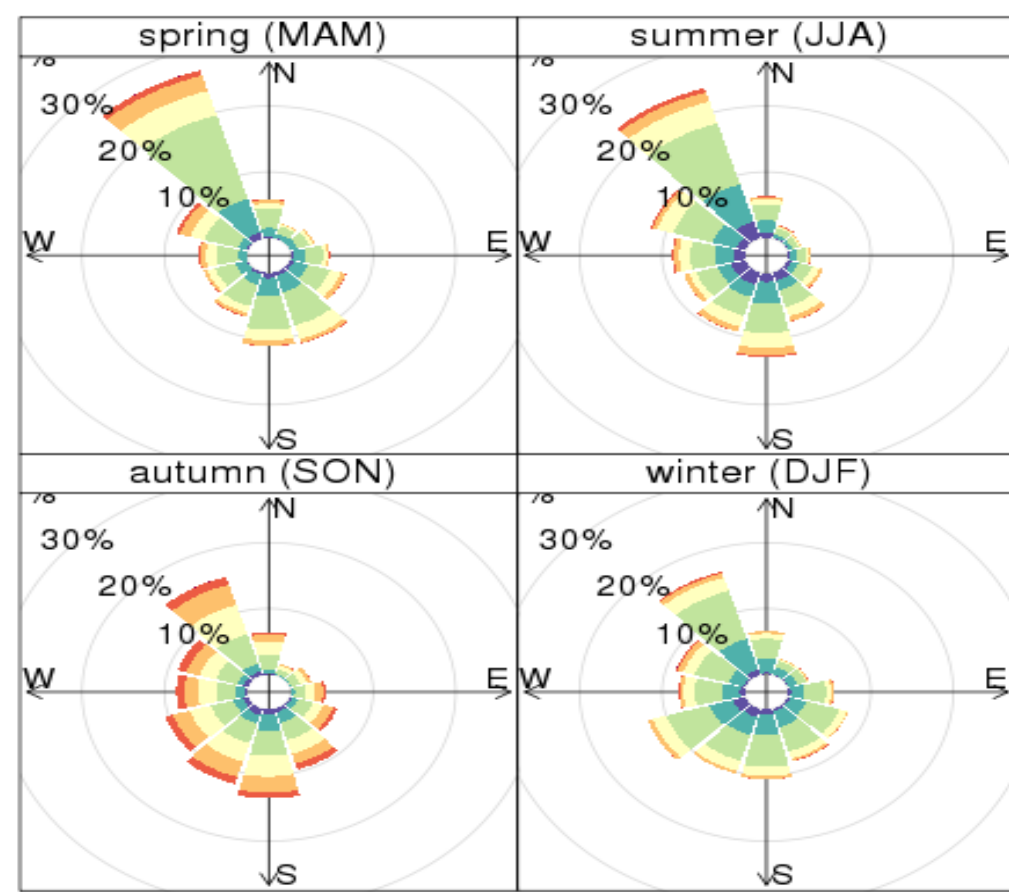

0.5 to 0.75

0.2 to 0.5

0.17 to 0.2

0.15 to 0.17

0.12 to 0.15

0.1 to 0.12

0.05 to 0.1

b

Figure S20. Pollution-rose diagram of PM1 (a) $\omega_{0}$ and (b) b at EGB. The percentages at a given radius represent the percentage of hourly profiles for a given wind sector. 


\section{SGP}

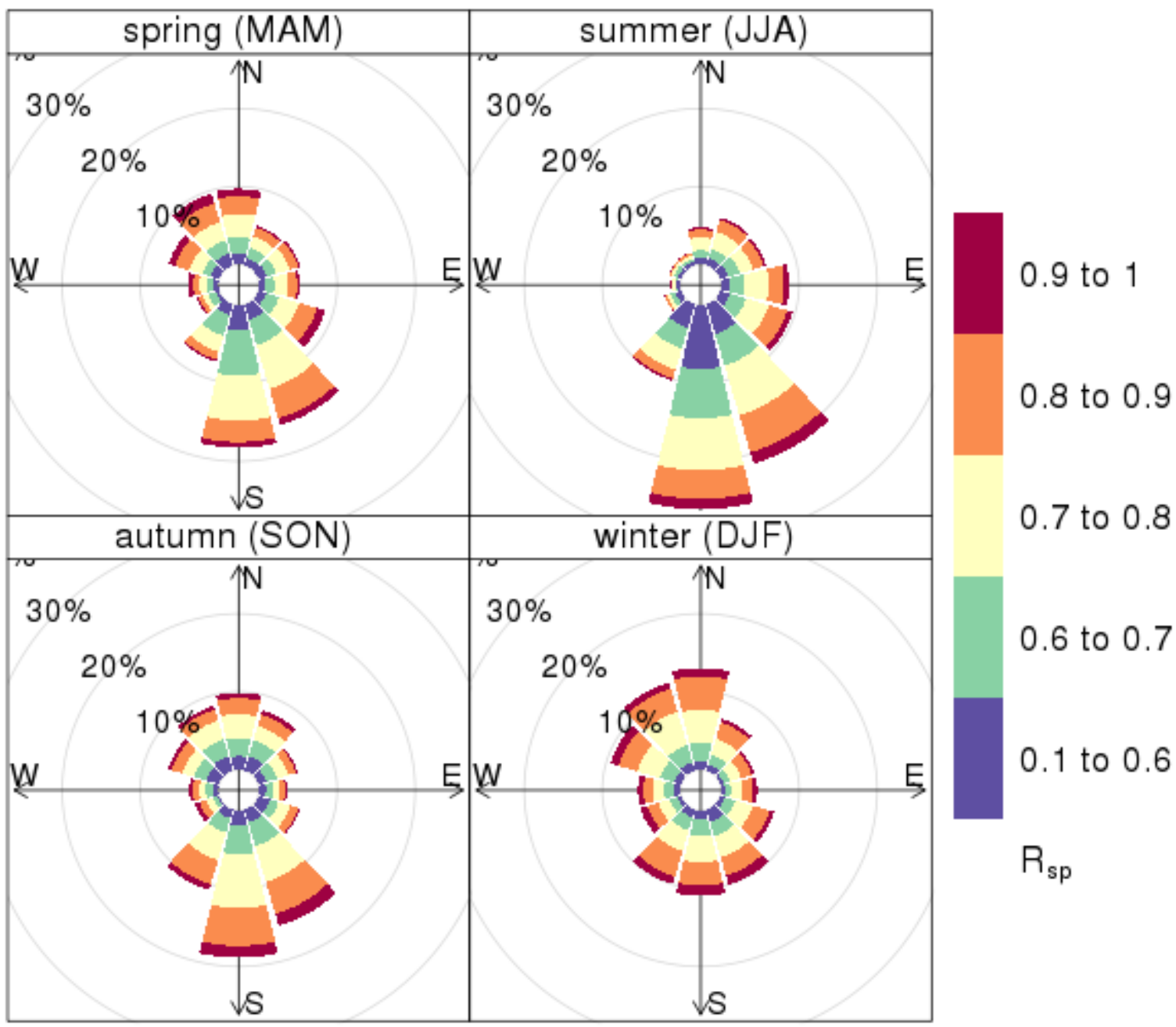

Figure S21 Pollution-rose diagram of $\mathrm{R}_{\mathrm{sp}}$ at SGP. The percentages at a given radius represent the percentage of hourly profiles for a given wind sector. 
(a)

\section{SGP}

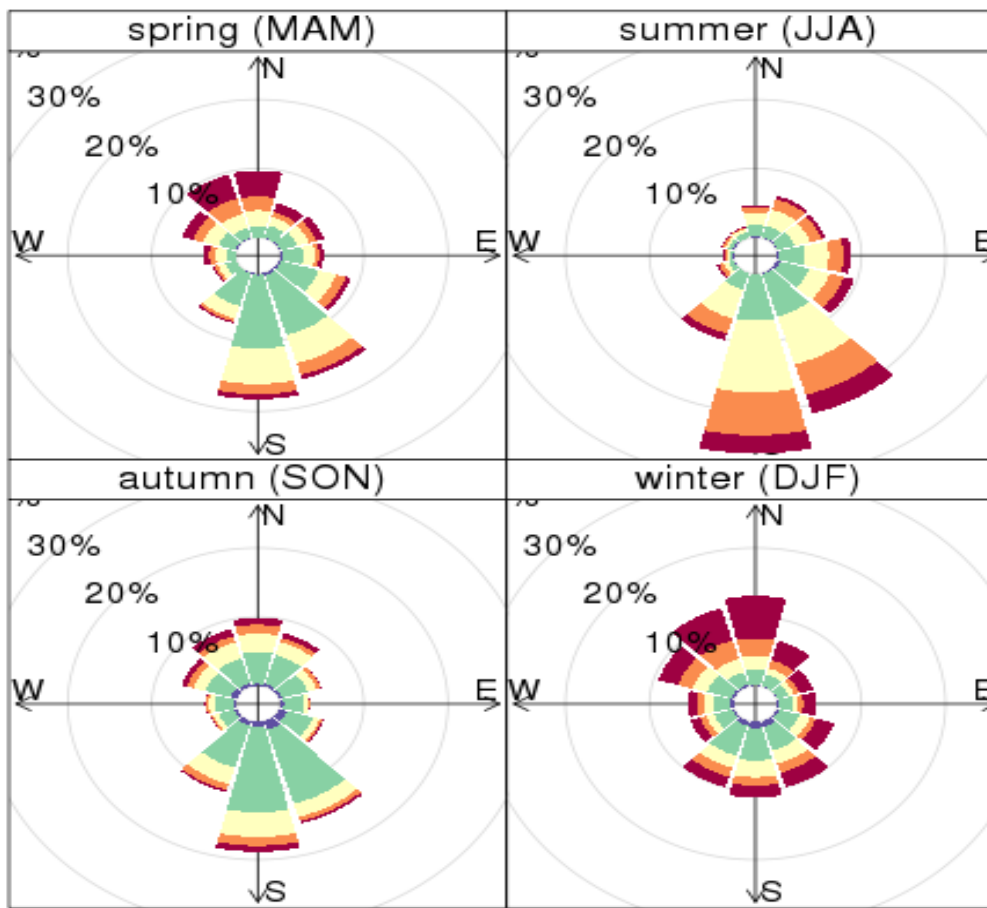

0.95 to 1

0.93 to 0.95

0.9 to 0.93

0.8 to 0.9

0.5 to 0.8

$\omega_{\circ}$

(b)

SGP

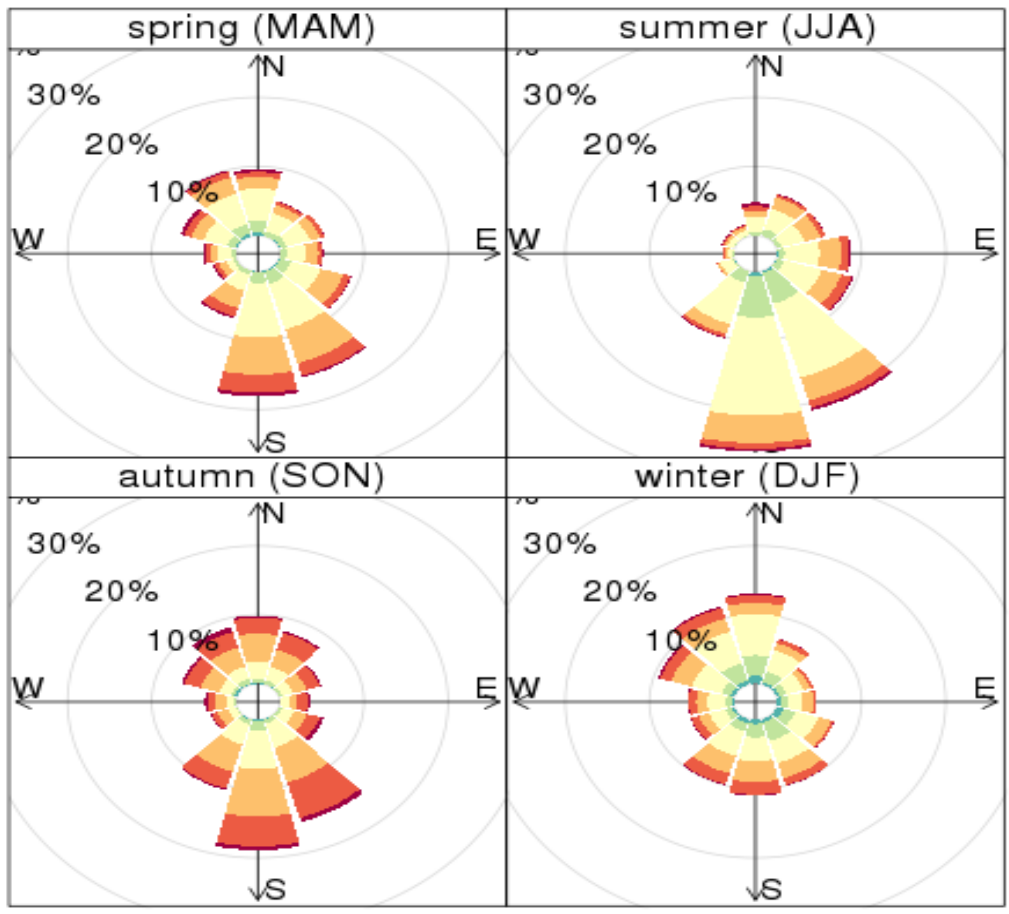

0.2 to 0.615

0.17 to 0.2

0.15 to 0.17

0.12 to 0.15

0.1 to 0.12

0.05 to 0.1

0 to 0.05

b

Figure S22 Pollution-rose diagram of PM1 (a) $\omega_{0}$ and (b) b at SGP. The percentages at a given radius represent the percentage of hourly profiles for a given wind sector. 
(a)

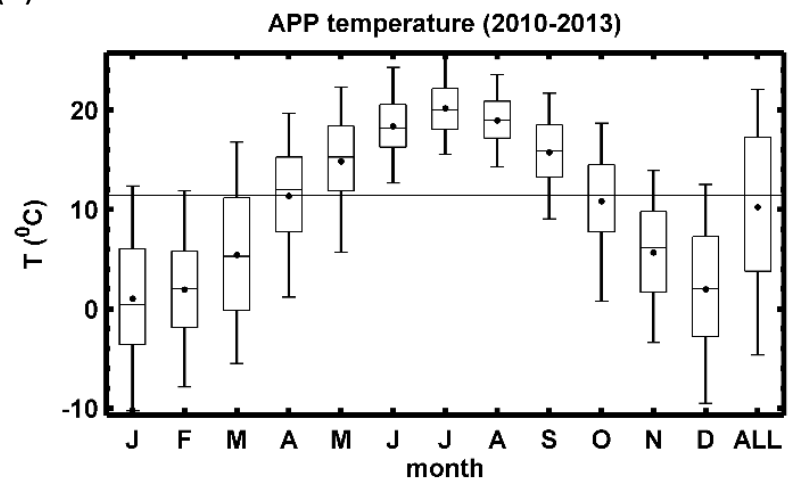

(c)

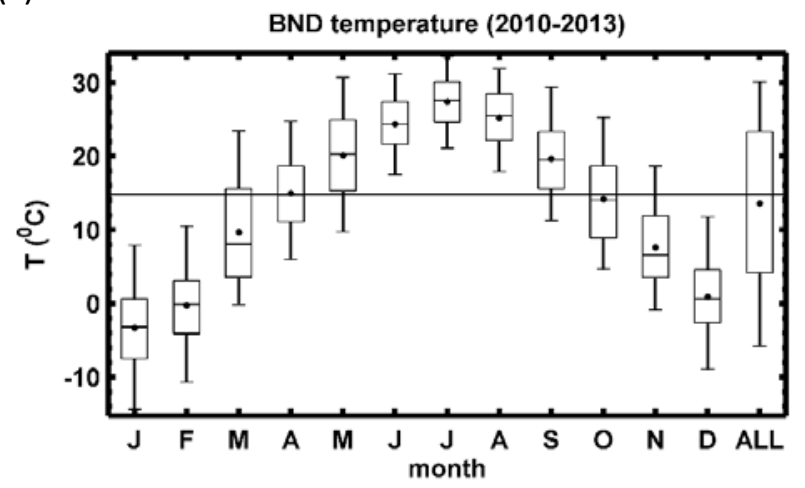

(e)

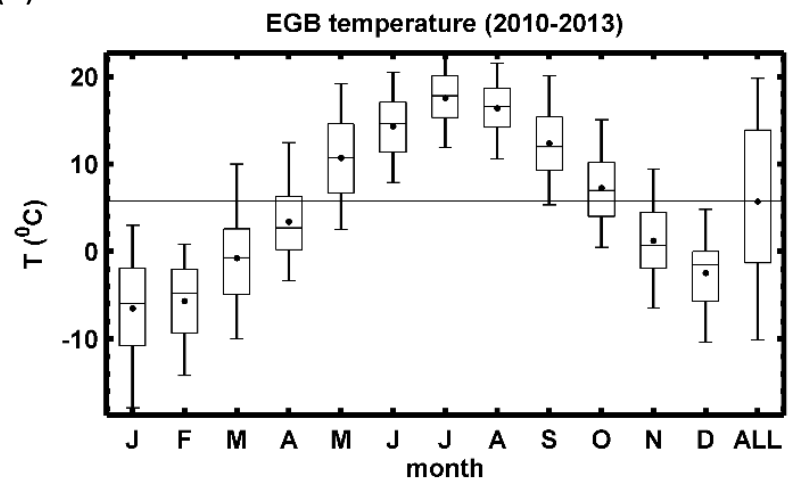

(g)

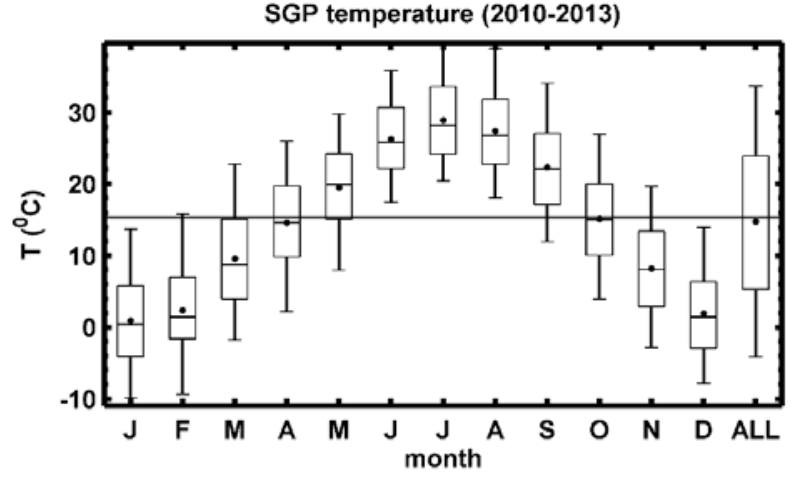

(b)

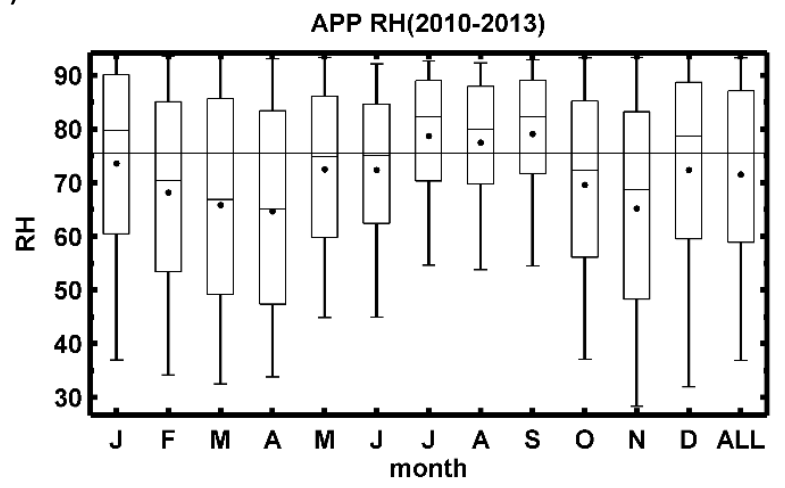

(d)

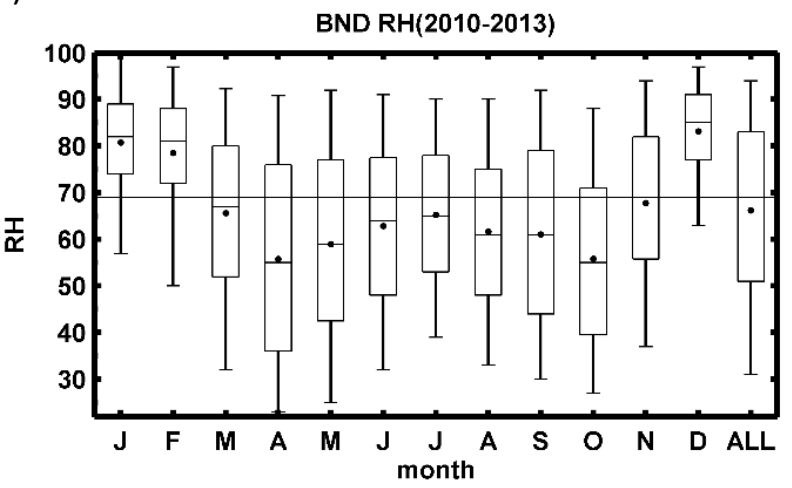

(f)

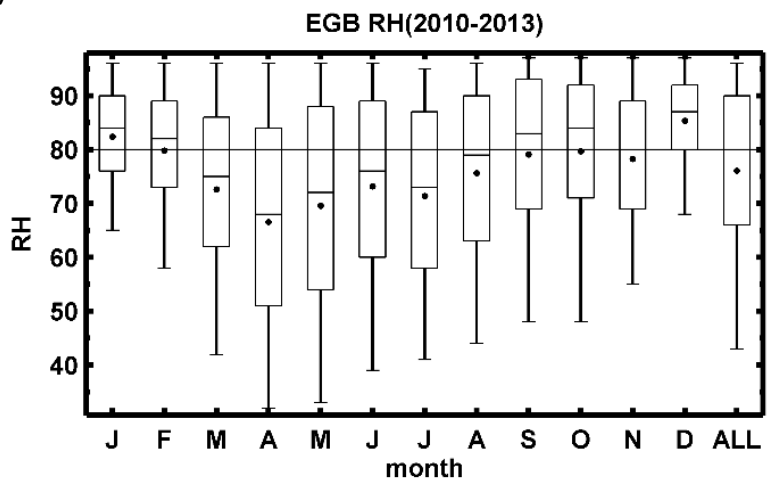

(h)

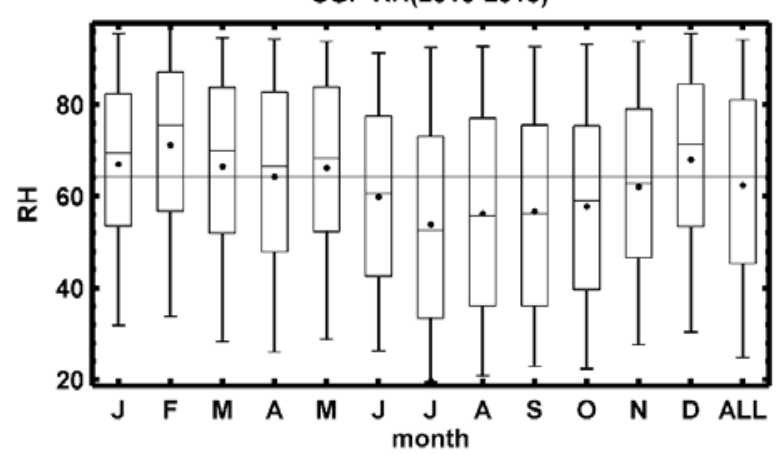

Figure S23. Boxplots of monthly-binned temperature and relative humidity over the entire 2010-2013 period. The 'ALL' box provides the statistics for all hours over the 2010-2013 years. The mean is denoted by the dot for while the horizontal bar represents the median. The top and bottom of the box represent $75^{\text {th }}$ and $25^{\text {th }}$ percentiles while the top and bottom whisker extend to the $95^{\text {th }}$ and $5^{\text {th }}$ percentiles, respectively. The horizontal line drawn through all boxes of each plot represents the median value over all hours for the given year(s). 

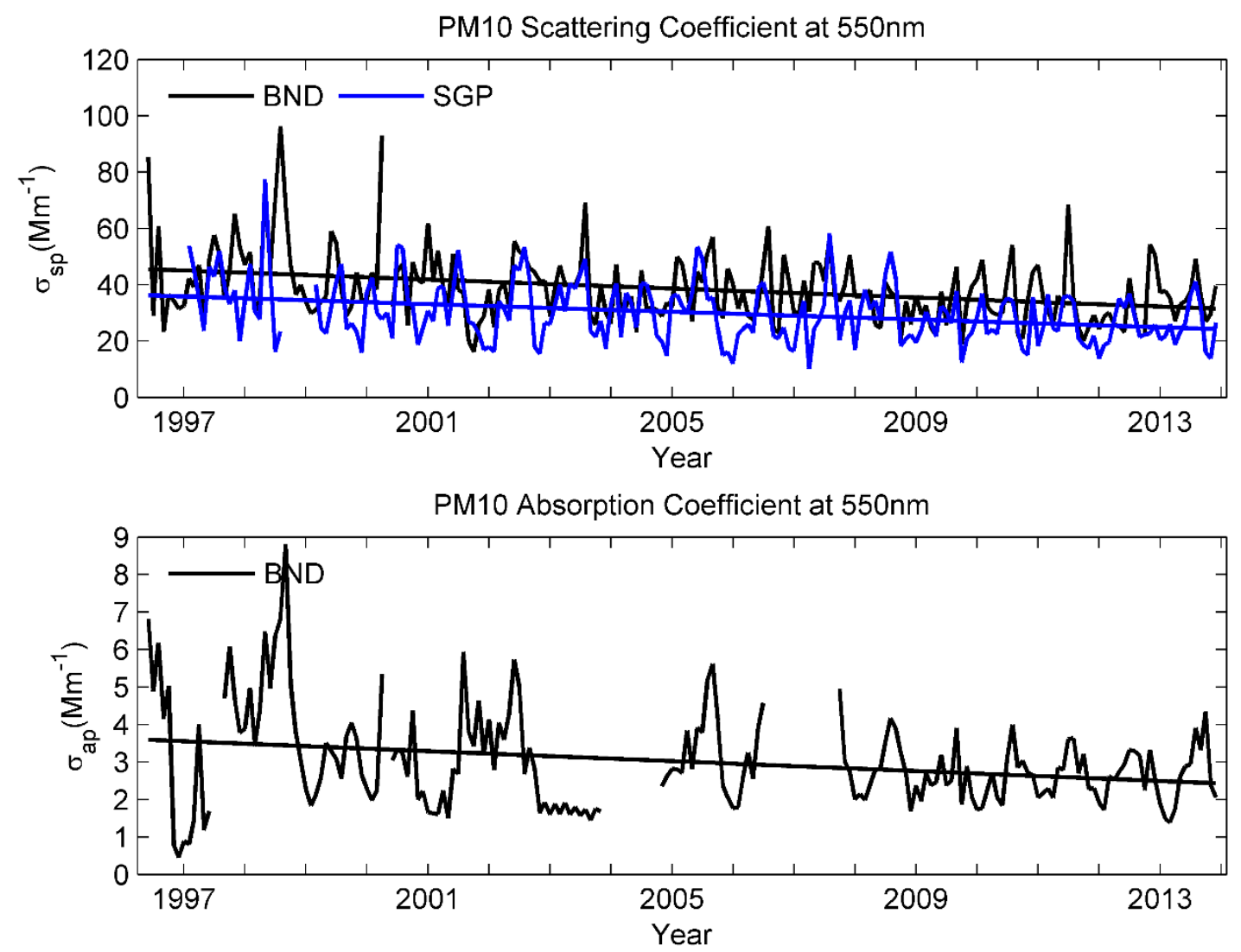

PM1 Absorption Coefficient at 550nm

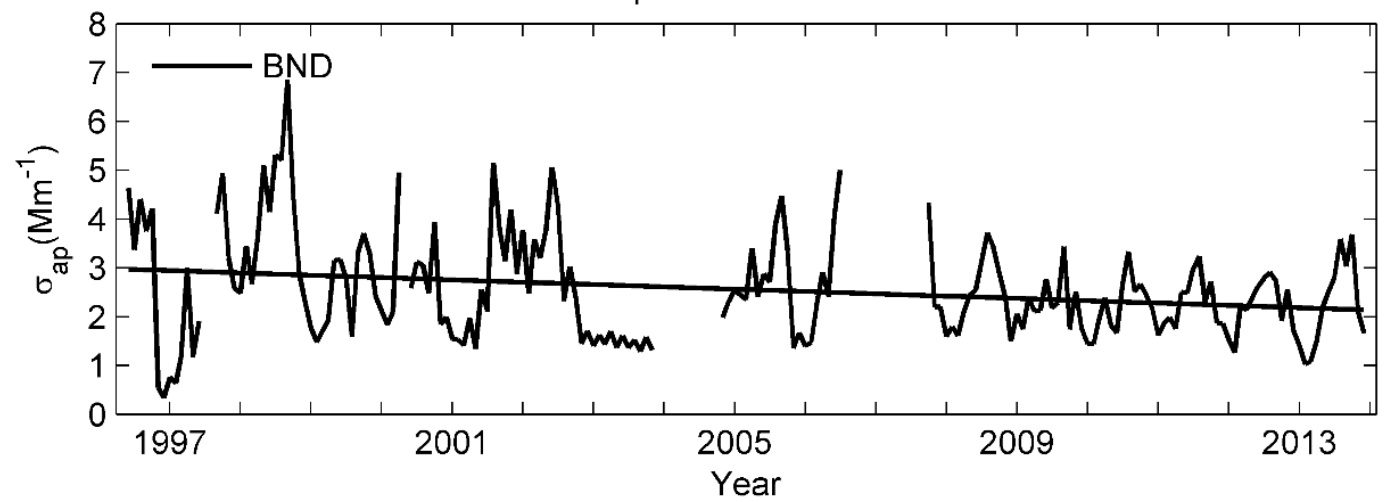

Figure S24. Time series of monthly-averaged PM10 $\sigma_{\mathrm{sp}}$ for BND (1996-2013) and SGP (1997-2013), along with PM10 and PM1 $\sigma_{\mathrm{ap}}$ for BND. Trend lines, representing least-squared fits of the data, are also shown. Broken lines on the curves represent data gaps. 


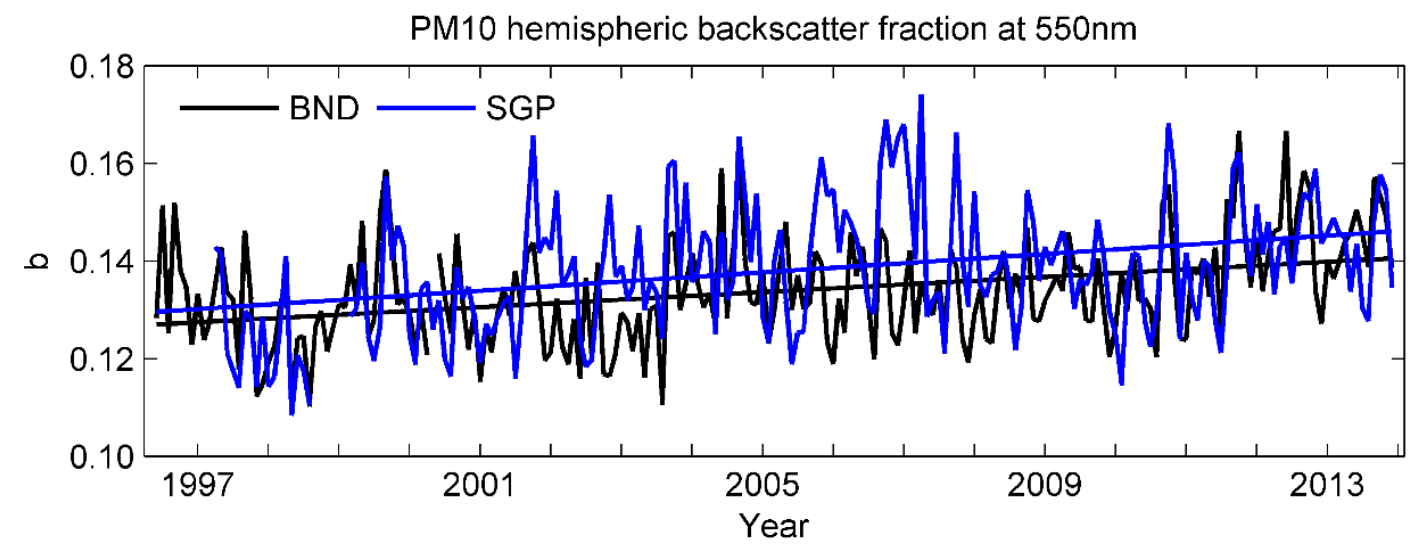

PM10 Scattering Angstrom exponent (450nm/700nm)

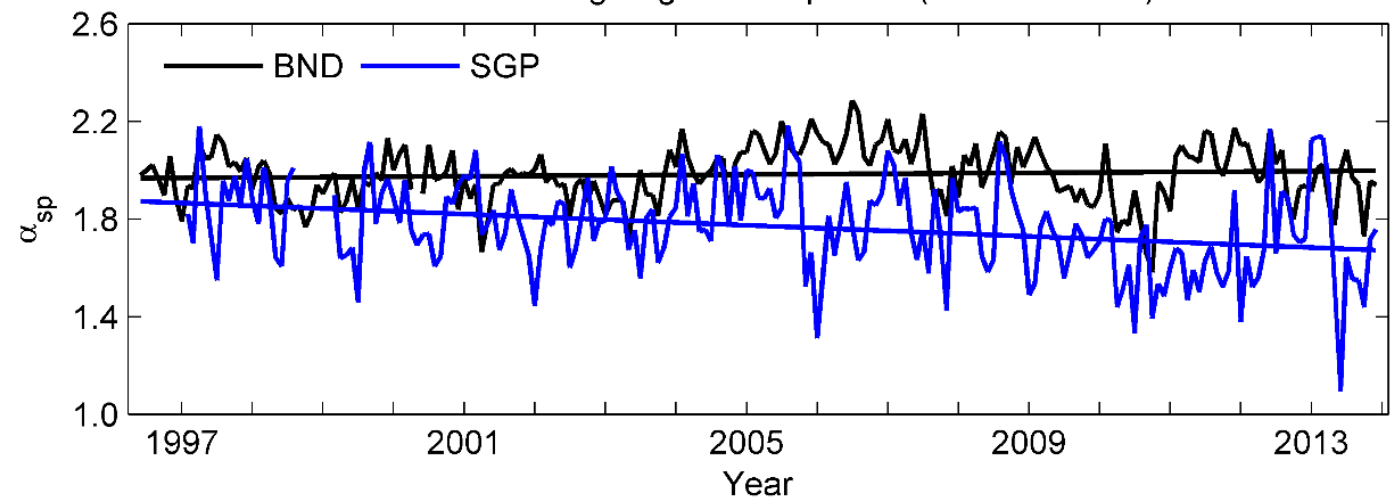

PM10 Single-scattering albedo at 550nm

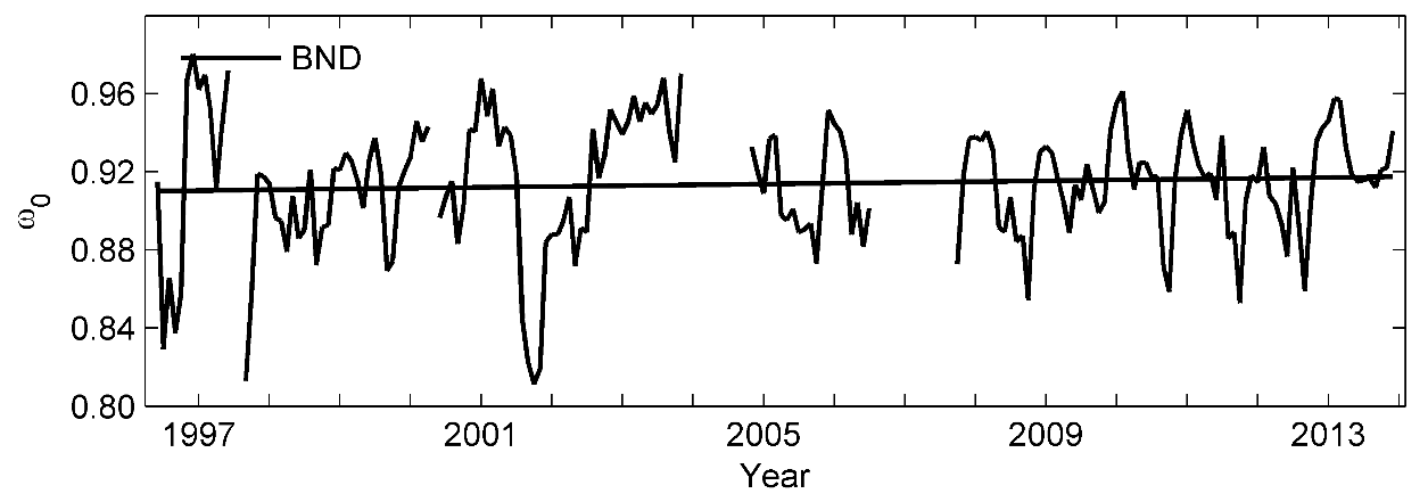

PM1 Single-scattering albedo at 550nm

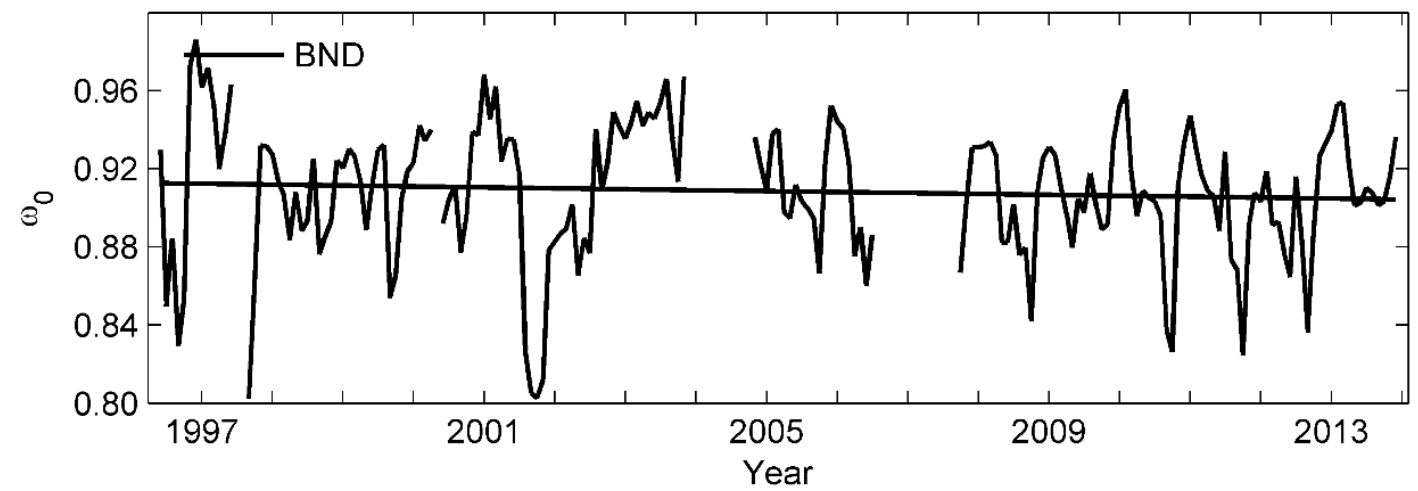

Figure S25. Time series of monthly-averaged PM10 b and PM10 $\alpha_{\mathrm{sp}}$ for BND (1996-2013) and SGP (1997-2013), along with PM10 and PM1 $\omega_{0}$ for BND. Trend lines, representing least-squared fits of the data, are also shown. Broken lines on the curves represent data gaps. 